YO CUENTO*: LATIN AMERICAN IMMIGRANT CHILDREN TELL THEIR STORIES

*Yo cuento is Spanish for I narrate/l matter

by

Mónica Carolina Valencia Vega, BA, University of Toronto, 2010

A Major Research Paper

Presented to Ryerson University

In partial fulfillment of the requirements for the degree of

\author{
Master of Arts \\ in the Program of \\ Immigration and Settlement Studies
}

Toronto, Ontario, Canada, 2011

(C) Mónica Carolina Valencia Vega 2011 


\section{Author's Declaration}

I hereby declare that I am the sole author of this major research paper.

I authorize Ryerson University to lend this paper to other institutions or individuals for the purpose of scholarly research.

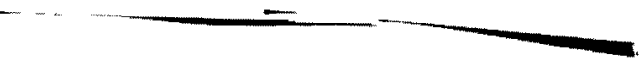

I further authorize Ryerson University to reproduce this paper by photocopying or by other means, in total or in part, at the request of other institutions or individuals for the purpose of scholarly research. 


\title{
YO CUENTO*: LATIN AMERICAN IMMIGRANT CHILDREN TELL THEIR STORIES
}

*Yo cuento is Spanish for I narrate/I matter

\author{
Mónica Carolina Valencia Vega \\ Master of Arts, 2011 \\ Immigration and Settlement Studies \\ Ryerson University
}

\begin{abstract}
Despite considerable interest in studying immigrant children in Canada, few studies include immigrant children as study participants. This study involved 10 children born in Latin American who have lived in Canada for five years or less. These children were between the ages of nine and 11- five boys and five girls. Five children were from Colombia, two from Venezuela, one from Mexico, one from Bolivia and one from Ecuador. I conducted individual research sessions where children and I drew, wrote and conversed. Children drew the most significant events in their migration process and wrote short narratives. The main findings from this study include the impact of grandmother/grandchild separation on immigrant children, children's multiple transitions across countries and within Canada, children's worries due to language barriers, and the value children place on peer cultural brokering. The paper concludes with recommendations and a reminder of the importance of conducting research with children.
\end{abstract}

\section{Key words:}

Immigrant children, Latin America, loss, residential mobility, cultural brokering 


\section{Acknowledgements}

I thank first and foremost the niños who participated in this study. The time they dedicated to me and the stories they shared made this research project a reality. Without their help this paper will lack significance because after all it is their experiences, emotions and thoughts that matter. I also thank the parents who warmly received me in their homes and gave me permission to talk to their children. I also thank my supervisor for believing in this project from the very beginning, and for providing me with her endless advice, support and guidance. I also thank my second reader for all the revisions and recommendations. I am thankful to my boyfriend for his encouragement, for editing the Spanish quotes and for taking me to the research locations. Lastly, I am thankful to my family for always being there for me, and helping me in any way needed so that I can achieve my goals. iMuchas Gracias! 


\section{Dedication}

This research paper is dedicated to my father, mother and sister because they helped me overcome all the obstacles I encountered as an immigrant child and taught me how to turn negative experiences into learning opportunities. When I immigrated to Miami my parents stayed up late at night, keeping me company until I finished my homework; they paid for tutors so that I would improve my English; they talked to my teachers when I was bullied, and they celebrated all my accomplishments. As a family, we also cried and laughed together over all the sour and sweet experiences of moving to a new place. After completing this study I have convinced myself, even more, of the quality time and support that immigrant children require from those around them.

This paper is also dedicated to Cheryl, Sebastian, Steve, James, Jessica, Isabela, Coni, Candice, Daniela and Anthony, because it also belongs to them. 
Table of Contents

Introduction

Rationale

3

Canadian Statistics

6

Literature Review

7

Theoretical Framework

37

Recruitment

41

Methodology

Research Session Location

55

Demographics

58

Children's Profiles

59

Findings

67

Discussion

92

Limitations

95

Recommendations

99

Conclusion

103

Bibliography

107 


\section{List of Illustrations}

Illustration 1

Illustration 2

Illustration 3

Illustration 4

Illustration 5

Illustration 6

Illustration 7

80

Illustration 8

80

Illustration 9

81

Illustration 10

Illustration 11

Illustration 12

Illustration 13

Illustration 14

\section{List of Appendices}

Appendix 1

Appendix 2 


\section{Introduction}

I used to sit on the green monkey bars staring at the worn track field. Sitting there, I could see the rest of the kids playing baseball, basketball and skipping rope. I felt safe up there, away from them-away from their scolds, insults and rudeness. On the monkey bars I did not have to worry about making out their language and learning game rules. I could escape from the rough blonde who used to mock me or the small boy who hit the other kids. One afternoon, as I sat on my usual spot, I tied a small dandelion to my shoelace and told myself that I would write about my experience and that I would call it 'el silencio de la soledad'. I gave it that name because I felt mute and lonely. I did not have anyone to talk to. They could not understand me nor could I understand them. Nobody was with me and I was with nobody.

The above paragraph is an excerpt from an autobiography I wrote in my last year of undergraduate studies. At the age of 11 l emigrated from Colombia and moved to Miami, where I encountered endless changes in my life. Ever since that afternoon I wanted to write my story as an immigrant child, but it took me ten years to finally narrate my experience. I would have really appreciated telling my story and making sense of it at the time, but I did not know how. As a result, I became committed to giving immigrant children the opportunity to voice their stories while they are still in the midst of their settlement experience. Children rarely get asked for their opinions and feelings about their present lives and it is even less common for immigrant children to be asked to share their thoughts and emotions about their lives as migrants.

I conducted a study that enabled ten immigrant children living in the Region of Peel and Region of Halton to narrate their own stories. The sample was drawn from the Latin American community because I wanted to employ my cultural and linguistic knowledge to better connect with the children and understand their experiences. The children originated in Ecuador, Venezuela, Mexico, Bolivia and Colombia. It is no surprise that half of the children came from Colombia as the demographics of recent immigrants to Canada shows that Colombia was one of the top immigrant source countries. The objective of the study was to give these ten children the opportunity to identify on their own their areas of concern. I wanted to find out what

\footnotetext{
${ }^{1}$ Solitude's Silence is the English translation for 'el silencio de la soledad'
} 
children themselves experience as immigrants, how they feel throughout those experiences and what interpretations they assign to those experiences. The experiences highlighted by the children involved in this study were related to the separation from grandparents, residential mobility, language barriers and peer cultural brokering. Having this information meant that teachers, schools, parents, settlement workers, researchers, counselors, and policy makers can improve their understanding of immigrant children. Therefore, the second research question was what are the implications for professional practice in order to better assist immigrant children. 


\section{Rationale}

Migrant children tend to be absent from research and policy-related projects. Their absence is not due to their low numbers nor is it due to their unimportance. After all, most adult migrants are accompanied by their children and mainstream society often views children as valuable human capital (Colbert 2010). The problem lies in the ongoing dominant view that frames children as productive for the future-valued only for who they will become (Albanese 2009). Orellana (2001) explains that adults are seen as contributors to society in the present because they pay taxes, while their children can be seen as a burden on the public purse. Another reason for excluding children from research and program evaluation stems from the "long-held belief that [immigrant] children adapt quickly" and that they do not get homesick (Fantino and Colak 2001). For instance, Boyd (2006) states that children acclimatise more easily than their parents. Nonetheless, the resiliency of immigrant children should not be overestimated and it should not be expected that they will "simply 'bounce back' following seemingly invisible emotional challenges or distress" (Albanese 2009, p. 148). Moreover, children's silent approach to immigration issues does not mean they are coping well with the new environment (Fantino and Colak 2001). Fantino and Colak note that perhaps their lack of expression is due to adults' unwillingness to listen. The book The Inner World of the Immigrant Child explores the importance of the silence of immigrant children (Igoa 1995). Igoa demonstrates that silence is a process in which the child is negotiating and filtering his/her surroundings. That means that although there is no external dialogue there are many conversations taking place internally.

Despite children's meaningful experiences, a large part of the literature has failed to tap into children's perspectives because researchers most often consult adults instead of children (Albanese 2009; Morrow and Richards 1996; Hill et al. 1996). Adults such as teachers, parents, and 'persons most knowledgeable' (PMKs-typically mothers) are treated as experts; however, there is no guarantee that their representations of children's views and understandings are accurate (Albanese 2009). Furthermore, researchers are often discouraged from carrying out studies with children due to the ethical complications and the disconnect that exists between a child participant and an adult researcher (Colbert 2010). Nevertheless, Article 12 of the United Nations Convention on the Rights of the Child states that a child who is 
capable of forming his or her own views should have "the right to express those views freely in all matters affecting the child" (United Nations 2007).

It is becoming more common for researchers to acknowledge that a child is capable of communicating his/her opinions and that children should be given the opportunity to inform research (Hill et al. 1996; Murray et al. 2003; Albanese 2009; Morrow and Richards 1996; Morgan et al. 2002; MacNaughton 2001; Fantino \& Colak 2001; Wagner 1999; Igoa 1995). Hill et al. (1996) say that children play an active role in "structuring and making sense of life as they experience it" (p. 130); thus their own perspectives should be explored. Albanese (2009) encourages researchers to "listen to children as they express what it is like to stand in their shoes and live in their worlds" (p. 35). Morrow and Richards (1996) concur, adding that children should be heard in procedures affecting them. They also explain that few adults attempt to understand children's lives in their own terms and few seek children's opinions and accounts of their life experiences. Murray et al. (2003) echo the previous comments as they state that children can express multiple ideas of and on their own. However, most studies focus on either youth or kindergarten children, and often, middle childhood is overlooked, as this is a "neglected life-stage" (Hill et al. 1996, 131).

Apart from recognizing children's ability to speak for themselves, researchers also acknowledge the value of children's input. Morrow and Richards (1996) argue that there are various aspects of children's lives that are unknown. Therefore, children's involvement in research would help reveal how they see themselves, how they see their circumstances, how they organize their lives and what is meaningful to them (Wagner 1999). For instance, a study on children with asthma found that children's insights into their own experiences differed from adults' concerns and priorities (Morgan et al. 2002). The major source of worry for children with asthma was bullying, an observation that had not been mentioned by adult informants. Moreover, social programs are more likely to be effective when they take into account people's life contexts and priorities (Hill et al. 1996). This means that children should be approached in order to find out what their needs are and how they can be addressed. Immigrant children's opinions can inform the policies and settlement programs that impact their daily lives. 
Researchers, teachers, counselors, and policy makers need to be informed about immigrant children so that this population is well served (Qin-Hilliard 2001).

Though the literature is increasingly acknowledging the significance of children as research informants, the literature review I conducted for this study revealed that the amount of research involving children as informants is minimal. The two types of investigations that do include immigrant children as key informants are clinical studies and evaluations of programs for bilingual literacy development (Esquivel et al. 2010; Bleiker et al. 2008; Cummins et al. 2006; Rousseau et al. 2005; Bagilishya et al. 1998, Dual-Language Book Club 2009; Taylor et al. 2008). 


\section{Canadian Statistics}

In 2009 alone 50, 292 children under the age of 15 entered Canada as permanent residents and refugees and in other immigrant categories (Citizenship and Immigration Canada (CIC) 2010a). Of the over 50,000 arriving that year, 5,100 originated from South and Central America (CIC 2010b) and most of them settled in Ontario (CIC 2010c). The largest proportion of foreign-born Ontario residents (68.3\%) lives in the Census Metropolitan Area (CMA) of Toronto (Statistics Canada 2008). Recent trends show that the Region of Peel's immigrant rate (23\%) is rising quickly, while still not close to Toronto's (52\%) (City of Toronto 2007; Region of Peel 2007a). The municipality of Mississauga, located in the Region of Peel, in 2006 had 13,365 people of Central and South American origins (Region of Peel 2011b). In the same year, the Region of Halton's recent immigrant population included $8 \%$ and $5 \%$ of South Americans and Central Americans, respectively (Region of Halton 2011). The second largest age category among recent arrivals in the Region of Halton is children under the age of 15 (Region of Halton 2011). The aforementioned statistics are relevant given that all of the children who participated in this study currently live in Mississauga (8) and the Region of Halton (2). The fact that Colombia, a South American country, ranked among Canada's top ten immigrant sending countries in 2006 (Statistics Canada 2008) is also relevant given that half of the participants in the current study were born in that country. 


\section{Literature Review}

Initially I had conducted a general literature review on immigrant children, which addressed issues of ethnic identity, cultural clashes, parent and child friction, poor school performance, denial of home language, brokering for parents and peer victimization. After completing the interviews I found that the areas of main concern for the child participants differed from the recurring themes found in the literature. Then, I conducted a second literature review in accordance to the children's responses emerging early in the interview process. The following review is divided into the four main areas relevant to these ten children: grandparents, transitions, school and language, and cultural brokering. The studies reviewed are from Canada, the U.S., Latin America and Europe. U.S. studies were used because a vast majority focuses on Latin American immigrant children.

\section{Grandparents - Loss, Immigration and Children}

The literature on grandparents and immigrant children tends to focus on two key themes: a) description of grandparents raising children in the receiving country (Fuller-Thomson and Minkler 2007a; Fuller-Thomson and Minkler 2007b; Milan and Hamm 2003; Goodman and Silverstein 2002) and b) grandparents raising children in their home countries when parents migrate without the children (Todorova et al. 2005, Falicov 2003, Falicov 2005, Orozco and Orozco 2001, Bernhard et al. 2008; León and Serrano 2010). This means that, for the most part, the research focuses on the living conditions of grandparents (i.e., health, economy) (FullerThomson and Minkler 2007a; Fuller-Thomson and Minkler 2007b; Goodman and Silverstein 2002) and on the role of grandparents who temporarily become the primary caregivers while parents work abroad (Orozco and Orozco 2001; Todorova et al. 2005; Falicov 2003). In terms of the latter, the effects on the children who are separated from their grandparents when reunited with their parents is also a recurring topic explored in the literature (ibid.). However, I did not find any research that addresses the effects on the child who is separated from his/her grandparents after emigrating in a nuclear family unit. Some texts superficlally mention that children miss their extended family relatives, but none explore this issue in detail (Orozco and Orozco 2001; Falicov 2005, Todorova et al. 2005). In contrast, it is common to find research that 
discusses the emotional hardships of children who are separated from their parents because parents migrate before them (Bernhard et al. 2008; Todorova et al. 2005; Falicov 2003; Falicov 2005; Orozco and Orozco 2001). This body of literature often talks about "ambiguous loss" (Todorova et al. 2005; Falicov 2003) and meaning construction by non-immigrating children who stay behind (Todorova et al. 2005). But, when "ambiguous loss" is discussed in terms of immigrants it only includes the experiences of adult immigrants (Orozco and Orozco 2001; Todorova et al. 2005; Falicov 2003; Falicov 2005).

\section{Loss - Adult Immigrants and Relatives}

Orozco and Orozco (2001) argue that migration has psychological and social implications for the individual and the family. For instance, they say that the separation from loved ones is stressful and traumatic, and triggers feelings of sadness, anxiety, loss and "perpetual mourning" (72). When (adult) immigrants experience separation they become disoriented and depressed while they mourn their lost attachments (Orozco and Orozco 2001; Todorova et al. 2005). The grief they feel is comparable to that experienced when someone dies (Falicov 2003). Hence, "the gains of immigration are tainted by loss" (Orozco and Orozco 2001, 69). The experience is painful and leads to a sense of longing (Todorova et al. 2005). For that reason, many adult migrants nurture the possibility of returning and reuniting with family (Falicov 2003). It can be damaging, however, for those who preserve the dream of returning because their grief prevents them from developing new attachments in the receiving society, keeping them in a state of limbo (Falicov 2003; Falicov 2005).

\section{Loss - Children Separated from their Parents}

The experience and perceptions of children left behind in their homeland during their parents' absence are key in children's adaptation to the new country once they become immigrants themselves (Orozco and Orozco 2001). If the separation from the parents is presented as temporary, necessary and beneficial, then it is more manageable for children (Todorova et al. 2005). Children left behind and adult immigrants experience ambiguous loss because the separation is incomplete, unclear and partial, given that the family members are physically 
absent but psychologically present (Falicov 2003; Todorova et al. 2005). Furthermore, the sense of grief, sadness and hopelessness can be prolonged and go unnoticed since there is no outlet to express those feelings (Todorova et al. 2005). Children left behind and immigrant parents cope with loss by making efforts to regain continuity, stability and a sense of coherence during the separation (Falicov 2003). Through meaning construction the individual is able to find value and new meaning in what remains after the separation (Todorova et. al. 2005). For example, migration narratives serve to provide coherence in the immigrant's life (ibid.).

\section{Loss - Immigrant Children}

Immigrant children can help their immigrant parents recover stability and continuity through their ability to blend languages and identities (Falicov 2003). In other words, Falicov frames immigrant children as possible catalysts for their parents' struggles with familial and cultural disconnects. This is consistent with other authors' assumptions of children experiencing pain only when they are separated from their parents and with the idea that only adult immigrants suffer when they are separated from the extended family (Orozco and Orozco 2001; Falicov 2005; Todorova et al. 2005). She even notes that "children of immigrants do not experience migration loss with the same poignancy as their parents "and if they experience loss, it is due to their exposure to their "parents' emotions and losses" (288). For example, in another chapter, Falicov $(2005,199)$ writes that children "may experience ambiguous loss themselves" due to their parents' sense of loss. The previous comments completely strip children of agency and sensibility, and limit children's experiences to whatever their parents feel.

\section{Extended Families}

The literature also acknowledges that in some cultures/countries extended families are integral to the functioning of the family system and it is usual for people to live in three- or fourgenerational houses (Orozco and Orozco 2001; Falicov 2003, 281; Todorova et al. 2005; Falicov 2005). In collectivist family models there are multiple caretakers, multiple affectionate attachments, and role models outside of the nuclear unit (Falicov 2003; Todorova et al. 2005). For that reason the western, nuclear definition of family cannot be applied to all immigrant 
families (Orozco and Orozco 2001; Falicov 2003; Telegdi 2006; Todorova et al. 2005). For instance, western models overlook the fact that disruptions in extended family relations can also lead to feelings of sadness and loss (Todorova et al. 2005, 182). Orozco and Orozco (2001) and Telegdi (2006) explain that the presence and support of social/family networks are key mediators of stress because relatives can provide guidance, acceptance and approval to migrants. The social support individuals have helps determine their ability to cope with stress and to achieve (Kilbride 2000). If (adult) immigrants have access to this type of support, then they can better adjust to the new country (Orozco and Orozco 2001; Falicov 2003; Telegdi 2006; Todorova et al. 2005; McLaren 2006). In the case of children, they can profit from the extended family network through their use of telecommunications and trips to the home country (Bagby 2007; Louie 2006; Chee et al. 2001, Falicov 2003). Moreover trips back home can help alleviate (adult) immigrant's pain due to separation from the extended family (Falicov 2003). Visiting home helps revive, renew and reinforce the connections that immigrants have with their extended family members (ibid.). It is also common for (adult) migrants to encourage relatives to migrate as a way to cure homesickness and reconnect with them. Ironically, the same literature that advocates for a broader definition of family fails to explore the immigrant child's separation from the non-nuclear family.

\section{Reunification and Children}

When children reunite with their parents they miss their grandparents (Orozco and Orozco 2001, Todorova et al. 2005, Bernhard et al. 2008) and also spend many hours unattended because their parents are busy working (Bacallao and Smokowski 2007; Doyle et al. 2011). During the separation children learn to regard their grandparents as the "sources of guidance" and givers of "meaningful practical advice" (Orozco and Orozco 2001, 76). Todorova et al. (2005) explain that children get attached to their grandparents "during the parent/child separation" (179). Some even have to be sent back to live with their grandparents because their parents seem like strangers to them (Bernhard et al. 2008). They add that the family network cushions the child's separation from his/her parents because children develop multiple significant relationships that satisfy their emotional needs (Todorova et al. 2005). 
Grandparents, for example, protect the grandchildren who stayed in the sending country and provide them with love, food and shelter (Bernhard et al. 2008; León and Serrano 2010).

\section{Latin American Families}

In Latin America, relatives play a significant role because they are interdependent, inclusive and tightly connected to each other (Falicov 2005; Thomson and Minkler 2007a; Goodman and Silverstein 2002; Thomson and Minkler 2007b). Childrearing responsibilities and crisis weathering can be shared among family members, especially with grandmothers (Falicov 2005; Goodman and Silverstein 2002). Hence it is usual for Latin American families to want to live together even after migrating (Falicov 2005; Thomson and Minkler 2007). Grandmothers in this culture are influential in terms of knowledge transfer, cultural exposure, nurturance and help (Falicov 2005; Thomson and Minkler 2007a; Thomson and Minkler 2007b; Goodman and Silverstein 2002). Sometimes, children can call two different women "mami/ mommy", but North American therapists "know very little about the meaning of this behaviour" (Falicov $2005,204)$. They do not know if it is an approach to ambiguous loss, a fluid definition of family, or a sign of multiple attachments, divided loyalties and confusion (Falicov 2005).

\section{Latin American Grandparents in the New Country}

Grandparents also help raise their grandchildren in the receiving country. Fuller-Thomson and Minkler (2007a; 2007b) found that the proportion of Mexican and Central American grandparents raising their grandchildren in the U.S. was four times higher than that of nonHispanic grandparents. In the U.S., $10.5 \%$ of Latin American children live with their grandparents compared to $5.4 \%$ of non-Hispanic children (Thomson and Minkler 2007a). Also they found that it is more common for women to raise their grandchildren (Thomson and Minkler 2007a). The importance of familialism and the emphasis on intergenerational ties common to the Latin American culture encourages grandparents to help with caregiving duties (Goodman and Silverstein 2002) so that their children can study and work (Thomson and Minkler 2007a; Thomson and Minkler 2007b). Consequently, grandparents not only view themselves as vital sources of support and caregiving, but are also culturally expected to 
collaborate in the upbringing of grandchildren (Thomson and Minkler 2007a; Goodman and Silverstein 2002).

Apart from the aforementioned, the literature focuses on the negative living conditions of grandparents who act as primary caregivers. These grandparents tend to be poor, depressed, unhealthy, and welfare recipients (Thomson and Minkler 2007a; Goodman and Silverstein 2002). Most of them become the primary caregivers because of their children's drug and substance abuse or incarceration (Thomson and Minkler 2007a; Thomson and Minkler 2007b; Goodman and Silverstein 2002).

\section{Immigrant Grandparents in Canada}

In Canada it is more common for immigrants than for the native born to live with grandparents $-7 \%$ of the foreign born live in multigenerational houses compared to $3 \%$ of those who are Canadian born (Milan and Hamm 2003). Two of the provinces with the highest number of immigrants have the highest occurrence of intergenerational houses- British Columbia (4.9\%) and Ontario (4.8\%) (Milan and Hamm 2003). The trend in Canada indicates a move from carerecipient grandparents to caregiver grandparents, given that they provide support to their children and grandchildren (Milan and Hamm 2003; Teledgi 2006). The Ontario Council of Agencies Serving Immigrants (OCASI) (2011a) and Todd (2011) state that the support provided by grandparents is very valuable because they provide unpaid childcare and domestic labour, enabling parents to work. A professor from the Université de Montréal explained that grandparents provide valuable emotional, practical and financial support for the family and that multigenerational families are the norm in countries such as China and Mexico (Thompson 2003). There are even programs offered to immigrant grandparents to help them improve their parenting skills (The Review 2007).

Despite the recognition of grandparents' contribution to immigrant families in Canada, the number of admissions to Canada has recently "declined substantially" as grandparents are excluded for lacking "market value" (McLaren 2006). Elliot (2011) of the Canadian Broadcasting Corporation (CBC) and Todd (2011) of the Vancouver Sun individually wrote two news articles, reporting that in $2011 \mathrm{CIC}$ was going to issue about 11,000 family reunification visas for 
grandparents, down from 16,000 issued in 2010. An interviewee in the CBC article stated that immigrants would not be able to see their parents alive and that grandchildren keep on waiting to be reunited with their grandparents (Elliot 2011). Another interviewee in the article by Todd (2011) expressed that grandparents will die before getting to Canada. Though $\mathrm{ClC}$ said the targets were not definite, the Immigration Minister said that "it's necessary to reduce family reunification visas so "priority" applicants... can be processed first" (Elliot 2011) and that the emphasis remains on immigrants who can contribute to the economy (Todd 2011; Elliot 2011).

McLaren (2006) states that more research is needed to investigate why grandparents are not considered as immediate family members in Canadian immigration policy. Moreover, this research must place sponsors and their parents at its centre (McLaren 2006). OCASI (2011a; 2011b) agrees with McLaren by saying that all Canadians have the right to extended family and that the definition of family needs to evolve. Teledgi (2006) says that Canada's understanding of family should "better reflect the extended family relationships that are common in many areas of the world". Moreover, family separation must be avoided because it poses negative effects in all aspects of immigrants' lives (Teledgi 2006).

\section{Literature from Latin America and Spain}

Since several authors underlined the need for a broader, non-nuclear definition of family, 1 reviewed the literature from Latin America. However, I found very little on the role grandmothers play in extended families. Most of the literature pertaining to this subject originates in Spain. I believe an explanation for this pattern lies on the fact that this phenomenon of grandmothers helping out with the grandchildren is novel in Spain (Osuma 2006; Villar et al. 2000; Tobío 2003; Planillo 2004) whereas in Latin America it is customary (Fuller-Thomson and Minkler 2007). The Spanish literature shows that grandmothers are becoming more emotionally involved with their grandchildren and doing more activities together (Osuma 2006) since grandmothers take care of children while their adult children work (Tobí 2003). Furthermore, grandchildren and grandparents report satisfaction at their mutual relationships (Villar et al. 2000). Grandchildren think that grandmothers are more in touch with the daily realities (Villar et al. 2000) and that they are more understanding, 
conversational, affectionate, trustworthy, cooperating and playful than other family members (Planillo 2004). In other words, the bond between grandparents and grandchildren is described as a "magia especial/ special magic" (Planillo 2004).

A study from Costa Rica explained that grandmothers help raise children by getting involved in children's education, leisure activities and health (Masis and Vargas 2007). The grandmother plays an important role because she supports the mother by instructing her and guiding her in childrearing matters (ibid.). They act as second mothers and might want to run the house and take full charge over their grandchildren's upbringing (ibid.). They can also spoil children because they are loving, sweet and caring to them (ibid.). They are highly affectionate and familiar with the child's personality and preferences (ibid.). As a result, children are able to enjoy their grandmothers' companionship through their fun, adventurous, tolerant, and generous exchange (ibid.).

Research from Costa Rica shows that grandmothers often accompany grandchildren to their extracurricular activities and medical appointments, take children to school and cook their favourite dishes while the parents work or study (Masis and Vargas 2007). Grandmothers also provide religious instruction, tutor children, monitor their exposure to media, and teach children values and habits (ibid.). They can also offer domestic and financial help. In Costa Rican society they are expected to "DAR a la familia/ GIVE to the family" and to form close bonds with their grandchildren (ibid.), and if they do not they are looked down upon. Furthermore, the grandmothers' role centers on the emotional and immediate needs of the child, contrasting with the grandfathers' responsibility for the child's education and for the handiwork around the house (ibid.).

In a study from Venezuela, grandmothers were found to have more authority than fathers in relation to the norms, values and rules taught at home (Fernández and Reyes 1999). Their words are taken very seriously, they act as guides for their daughters and the grandmother's house becomes a central place for the family (ibid.). Ultimately, the principal function of the grandmother is to pamper and show affection to their grandchildren (ibid.).

To conclude, the literature fails to address the separation between immigrant children and their grandparents and the hardships of living with that loss. Many scholars assume that 
the only separation that can be emotionally devastating for children is that from the parents who emigrate. Moreover, the literature on loss and migration presents loss only in relation to adult immigrants who miss their extended family members. Also, when grandchildren's relationship with their grandparents is discussed it covers only those grandparents who are currently living with immigrant children in the receiving country. Finally, despite researchers acknowledging that the definition of the North American nuclear family needs to be extended to include the composition of immigrant families, they do not conduct studies with that proposed framework.

\section{Transitions - International Migration and Residential Mobility}

Half of Toronto's population changed their address between 2001 and $2006-63 \%$ moved within the city and $37 \%(250,000)$ arrived from another country (City of Toronto 2007$)$. The settling patterns of immigrants are also changing as their numbers continue to increase in the Regions of Peel and York (ibid.). The literature on transitions considers the two types of moves residential mobility and international migration - separately. Though it is more common for immigrants to be residentially mobile (Bose et al. 2007; Igoa 2005; Hagan et al. 1996; Hanna 2003; Fong and Hou 2001; Yu and Myers 2007), the combined effects of migration and residential mobility are often not discussed together. For that reason, I reviewed, separately, the literature that focuses on migration as a transition (Díaz 2002; Orozco and Orozco 2001; Falicov 2003; García Coll and Magnuson 2005; Rotter and Hawley 1998; Bonovitz 2004) and the literature that focuses on residential mobility (Hanna 2003; Fong and Hou 2001; Yu and Myers 2007; Hagan et al. 1996; Tucker et al. 1998; Bose et al. 2007). Most of the research on residential mobility and children emphasizes the negative effects mobility poses on children's school performance and on their social capital (Bose et al. 2007; Tucker et al. 1998; Hanna 2003; Hagan et al. 1996). The impact that residential transitions have on children's emotional wellbeing is frequently acknowledged but not explored in detail (Falicov 2003; Hanna 2003; Tucker et al. 1998; Orozco and Orozco 2001; Bose et al. 2007; Rotter and Hawley 1998; Díaz 2002; Bonovitz 2004). Moreover, research findings do not specify if immigrant children approach transitions more effectively because they have more experience with moves or if they 
fare worse because of their constant instability (García Coll and Magnuson 2005; Bose et al. 2007). On the contrary, there is extensive discussion of the factors that prompt adults to switch residences such as better schools, employment opportunities and access to services (Díaz 2002; Hanna 2003; Tucker et al. 1998; Orozco and Orozco 2001; Fong and Hou 2004; Yu and Myers 2007).

Most of the studies in this subject area gather quantitative data rather than qualitative data, rendering limited accounts on the lived experiences of movers (Fong and Hou 2001; Tucker et al. 1998; Hagan et al. 1996). Furthermore, the effects of moves on children is measured solely in terms of their academic success and rates of high school completion (Tucker et al. 1998; Hanna 2003) rather than the psychological impact and emotional wellbeing of mobile children.

\section{Migration Transitions}

It is well documented that transitions are stressful (Orozco and Orozco 2001). The loss and disruption experienced by children after immigrating determines how much their emotional wellbeing is enriched or impoverished (Bonovitz 2004). For migrants, moves bring a mix of emotions such as excitement, anticipation, hope, anxiety, and depression (Orozco and Orozco 2001; Rotter and Hawley 1998). Migration is a "major life transition where the stakes are high" and it is also more stressful when people cannot rely on their usual resources and coping strategies (Orozco and Orozco 2001). On the eve of departure adult migrants face uncertainty for both gains and losses (Orozco and Orozco 2001). Often children have only vague understandings of why their families migrate and, as result might be reluctant to move because they see it as an imposition (Orozco and Orozco 2001; Bonovitz 2004). Immigrant children usually experience ambivalence about emigrating because they are ordered or coaxed into leaving, since for the most part, they have no say on their parents' decision to emigrate (Falicov 2003; Díaz 2002; Rotter and Hawley 1998). This may result in a difficult adaptation where they face immense changes that can lead to depression or anxiety (ibid.). The changes include new lifestyles, norms and customs, language and schools (Díaz 2002). 
For the most part, teachers, counselors and settlement workers tend to underestimate the psychological distress that results from the settlement process (Anisef and Kilbride 2003). But, research shows that for the most part eventually children prefer to stay in the receiving country than return to the home country- despite their missing it (Orozco and Orozco 2001; Díaz 2002). In the case of refugee children counseling might be required once they settle in the new country due to the trauma they experienced prior to migrating (Orozco and Orozco 2001).

Lastly, immigrants can move across several countries. Bernhard et al. (2008) found that many of the transnational mothers in their study had lived in the U.S. prior to coming to Canada. They left the U.S because they could not stabilize their immigration status, while in Canada they had the possibility to acquire it (ibid.). Refugees, too, can sometimes move to a third safe country (Orozco and Orozco 2001, 27). However, Orozco and Orozco (2001) do not acknowledge that other immigrant classes can also transition between more than two countries; they assume that migration only involves one move, from "here" to "there" (30).

\section{Psychological Impact}

Garcia Coll and Magnuson (2005) note that it has been assumed that immigrant children adapt more easily because they are younger, malleable and receive more exposure to the new culture. But for children migration is also a complex process with profound effects on their psychological state and interpersonal relations (Bonovitz 2004; Igoa 1995). Bonovitz $(2004,139)$ states: "the younger the child immigrant, the greater the vulnerability to adverse effects...during the pre-emigration and post immigration period; $[\ldots]$ children are more sensitive to the inevitable issues of separation and loss involved in the immigration process". For that reason, preparedness for the changes ahead and knowledge of the new society's functioning help decrease problems (Rotter and Hawley 1998). Nonetheless, little is known about the impact of migration on children, their subjective experiences, their inner conflicts and their abilities to cope and grow (García Coll and Magnuson 2005, 107; García 2002; Bonovitz 2004). There are also no comprehensive models and theories about the psychological and psychosocial processes of immigrant children (García Coll and Magnuson 2005, 105). Furthermore, research focuses on "measurable negative outcomes" and ignores children's 
emotions, overlooking "very valuable sources of information" (García Coll and Magnuson 2005, 108). Teachers, like researchers, can benefit from knowing this valuable information, in order to understand children's backgrounds and histories, to serve them better (Colbert 2010).

Although Hanna (2003) states that residential moves are psychologically and socially disruptive, he suggests moves within the country of destination are not as emotionally pressing for immigrants as it was to emigrate from their hometown. They are attached to their regions of origin in the sending country, but not to the neighbourhood where they arrive in the receiving country (Hanna 2003). However, whenever the relocation is involuntary it is traumatic for all family members (Hanna 2003; Hagan et al. 1996). In terms of children, Hanna adds that each time children move they confront a turbulent and unfamiliar environment because they have to relearn places, people, routines and simple information such as "'where's the toilet?" and "'who's my teacher?" (Hanna 2003). Nonetheless, Hanna's insight is limited to the effects on the child's schooling, disregarding the effects on their broader psychological wellbeing and social experiences outside of school. Tucker et al. (1998), in reference to teenagers, are concerned only with academic consequences and base their responses on tests scores or questionnaires with those they consider the most knowledgeable persons-usually adults in the children's lives.

The disruptive consequences of moving on children have been a long-standing concern (Tucker et al. 1998). Moving is psychologically disruptive, stressful and disorienting to children because they lose their peer, family and community networks that act as sources of support (Bose et al. 2007; Tucker et al. 1998; Bonovitz.2004; Rotter and Hawley 1998). Consequently, children develop a sense of instability, uncertainty, confusion and disorganization, plus face challenges fitting into new groups (Tucker et al. 1998; Bose et. al. 2007; Bonovitz 2004). For instance, mobile youth have fewer close friends, tend to be less popular, and are more likely to be depressive (Bose et al. 2007).

Igoa's (2005) book offers one of the most detailed accounts of immigrant children's struggles with migratory moves because she incorporates children's first-hand narratives. In her classroom, she witnessed the trials children experience when adjusting to a different school system, language and country (Igoa 2005, 1). For instance, Igoa presents the thoughts and 
feelings of an 11-year-old boy from China in the following quote: "This is totally different environment than I have been used to. The change is different; it upsets the kind of life I had. It was different back home. School was different, teachers were different. I feel depressed because I miss my friends in my country" (13). The absence of the systems that formerly gave meaning to their lives creates emotional and social problems for children (Igoa 1995, 1; Díaz 2002; Rotter and Hawley 1998).

There are, however, ways to support children throughout their multiple transitions. The literature teaches that when children live with both parents, residential mobility is not as difficult to confront as it is for children who live in a single-parent home (Tucker et al. 1998). If parents transmit to immigrant children the mechanisms to refuel emotionally and to protect themselves against losses, children develop a greater sense of security (Bonovitz 2004; Rotter and Hawley 1998; Hagan et al. 1996). The support provided by a mother's and father's involvement in the child's life eases the child's transitions (Hagan et al. 1996). But often parents are preoccupied with their own struggles and losses during settling in a new place, so they have less time to dedicate to their children and often cannot empathize with the child's pain (Tucker et al. 1998; Bonovitz 2004; Hagan et al. 1996). As a result children have to develop their own defenses and that may hamper their development (Bonovitz 2004; Hagan et al. 1996). If parents are not available, then the extended family can help immigrant children. Bonovitz (2004) noticed how grandmothers helped migrant mothers by guiding them and providing them caregiving assistance. The grandchildren's adaptation to new surroundings improved with the grandmother's support to the family (Bonovitz 2004). On the other hand, immigrant families without extended family members can make the nuclear unit tighter as a means of support, though the fact that they are no longer intergenerational houses is also a cause for stress (Rotter and Hawley 1998).

\section{Residential Mobility}

Immigrant families are more likely to make intra-urban moves than the native-born (Bose et al. 2007). They usually move from neighbourhood to neighbourhood in search of better housing, better jobs, better education and higher incomes (Orozco and Orozco 2001; Hanna 2003; 
Tucker et al. 1998; Díaz 2002; Fong and Hou 2004; Yu and Myers 2007). If a neighbourhood does not provide immigrants with the facilities and programs they look for and it is not welcoming to them, then immigrants do not set roots in that area and plan new moves (Hanna 2003; Fong and Hou 2004; Yu and Myers 2007). When services are not readily available to immigrants they have to drive or take public transportation, but some families cannot afford to commute (Hanna 2003). On the other hand, if social networks are strong and the school's quality is high then immigrants are more likely to stay in place (Yu and Myers 2007; Hanna 2003). Each time a family moves their social capital is disrupted (Hanna 2003; Hagan et al. 1996; Bose et al. 2007). When the parents' social capital is lost then children are affected (Kilbride 2000) because parents do not know the new neighbours and teachers (Hagan et al. 1996).

Language and the presence of their ethnic community also influence families' decisions to move (Fong and Hou 2004; Hanna 2003). For example, they move according to whether they want to be in a community that speaks a familiar language or a community where they can speed up their language acquisition (Hanna 2003; Yu and Myers 2007). Immigrant families' moves also depend on their economic success- if they have a higher income they can afford to move to a better neighbourhood (Fong and Hou 2004; Yu and Myers 2007). Lastly, Fong and Hou's (2001) study on Canada's top immigrant recipient cities concluded that descendants of immigrants achieve higher residential integration.

Igoa's (1995) experiences as a teacher of immigrant children present the cases of many students who frequently moved schools and cities in short spans of time. In most cases, she will never see her students again, or know where they went or why they left (Igoa 1995; Hanna 2003). Students would also start school late or leave before the school year ended (Igoa 1995, Hanna 2003). When children move to new schools they may disrupt the classroom while they catch up to the rest of the class, often contributing to teachers' stress (Hanna 2003). Hanna (2003) also found in his study of Latin American elementary school-aged children that students had many absences and that the dropout rate for high school students was about $50 \%$. He implied that mobility in this population could provide an explanation for Latin American students' poor academic performance despite their English proficiency. Consistent with Hanna's findings, many other studies have identified a correlation among transitions, high 
school drop-out rates, repeating grades, behavioral problems and self-esteem (Bose et al. 2007; Tucker et al. 1998; Hagan et al. 1996). Additionally, the number of moves shows a positive correlation with negative effects for the child (Bose et al. 2007; Rotter and Hawley 1998; Tucker et al. 1998; Hagan et al. 1996; Hanna 2003).

Latin Americans also appear to be more mobile than other groups. For instance, Latin American families that rent move more often than those who own a home, and in turn their high mobility hampers children's stability (Hanna 2003). These families also tend to face more obstacles when finding housing because households tend to be larger and prices too expensive (Yu and Myers 2007).

\section{Uprooting and Transplanting}

Some of the literature on migration talks about the process of uprooting and transplanting (Igoa 1995; Ankori 2003). When a child is uprooted from his familiar environment he or she might experience shock as when a plant is transplanted from one patch of soil to another; and like plants children need someone's care to nurture them (39). In that way they are able to survive the transplant/transition into the new society (ibid.). An artist from Palestine illustrated the previous analogy by uprooting trees from Palestine and 'regrounding' them in Geneva, representing ideas of home, displacement and belonging (Ankori 2003). In a clinical study on immigrant children in Montreal, children participants made explicit the theme of uprooting and transplanting (Rousseau and Heusch 2000). Third-grade students were asked to tell the story of a trip to another country that included a beginning, middle and end. A nine-year-old girl from EI Salvador drew plants in all her drawings because she said she had brought plant cuttings from El Salvador. The plant symbolized her home country and cultural roots (ibid.). By her last drawing the plant was still in a pot and had not been transplanted into Canadian soil, displaying her uncertainty. Her uncertainty was a product of her family having to wait for a response from the refugee board, which at the end denied them status and the family had to return (Rousseau and Heusch 2000). Hence, the girl literally could not transplant herself to Canada.

In sum, the literature teaches about the stress caused by immigration and about the negative repercussions that residential mobility has on children. Nonetheless, the two types of 
moves are not explored together. Additionally, quantitative methodology limits the depth of the results. That is to say, despite identifying the emotional effects, immigrant children's voice is absent, failing to inform how they specifically experience those feelings of confusion, anxiety, stress and disorientation; how they overcome the challenges caused by transitions; and what they think of them.

\section{School and Language - Academic Performance, Parent Dis/engagement and Barriers}

A recurring theme in the literature on immigrant children is school experiences, including peer relations (Phelan et al. 1991; Ontario Institute for Education Studies (OISE) 2010; Perren et al. 2010; MacNaughton 2001) and school performance (Freire \& Bernhard 1999; Schugurensky 2007; Castro 2009; Bernhard et al. 2007; O'Reiley \& Yau 2009; Angel 2009). A great deal of research is available on immigrant children and schools, given that most of children's day is spent at school. The prominent themes in relation to immigrant children's school experiences are prejudice and academic underachievement, especially among the Latin American student population.

In 2008, the Toronto District School Board (TDSB) published a study that indicated that in 2002 the dropout rate for Latin American students was 38\%, continuing to be one of the ethnic groups with the highest dropout rates (Schugurensky 2009). Although dropout rates concern high-school students, Latin American elementary-aged children do poorly in standardized tests, which can be linked to future high school desertion (ibid.). A study on elementary schools by the TDSB found that Latin American children are one of the three groups experiencing the most challenges writing the province-wide test of the Education Quality and Accountability Office (EQAO) (Yau \& O'Reilley 2009). In 2008, 37\% of Latin American students achieved level three or four in reading, the lowest result in comparison to other minority students (Yau \& O'Reilley 2009).

Paradoxically, in the same year, Latin American parents ranked the highest at $87 \%$ for satisfaction with their child's school (ibid.). This finding can be linked to the parents' expectations of their children. For instance, Latin American parents are more likely to expect their children to go to college than to university (ibid.). Other authors confirm the previous link 
as they explain that immigrant parents may have mediocre standards for their children's education (Bettencourt 2000), especially within the Spanish-speaking community (Castro 2009; $D^{\prime}$ Andrea 2009; Angel 2009; Betancourt 2009). Parents' disengagement with school is another factor that affects the academic outcomes of Latin American children (Bascuñán 2009a; Bascuñán 2009b; Bernhard 2009; Freire and Bernhard 1999; Spanish Speaking Education Network 2010). The 'lingo' used in report cards and a lack of English are barriers that keep parents away from schools and teachers, and prevent parents from assisting children with their schoolwork (Bernhard 2009). Therefore, parents receive little or no information on the child's learning process and on the current events within the school community (ibid.).

Hanna (2003) argues that it is easy to blame children and their families for the students' poor performance, but government and school practices also play a role. If immigrant children lack the right support, their cultural and linguistic strengths are underutilized, devalued and ignored (Hanna 2003; Díaz 2002). It can all start with an inappropriate assessment by counselors who place children in the wrong level (Hanna 2003). Respondents stated to Hanna (2003) that being placed in grades behind was "discouraging" and "demeaning" because they had to study the mathematics they had learned a long time ago. Díaz's (2002) respondents stated that as immigrant students they were assigned less homework, which was in sharp contrast to the amount of homework they received in Mexico. Immigrant youth can feel frustrated at having to review old material, repeat the same assignments and not learn anything new (Orozco and Orozco 2001). This lowers their self-esteem and makes them think they are incompetent (Anisef and Kilbride 2003). Some immigrant children come from highly competitive educational backgrounds where they developed fine literacy and study skills (Orozco and Orozco 2001). They can be eager students who take learning seriously since they view education as the path to success (Orozco and Orozco 2001). Additionally, parents believe their children should be challenged and encouraged to exploit their potential (Díaz 2002). They want their children to be able to take advantage of the educational opportunities in the new country, eventually making their sacrifices worthwhile (Orozco and Orozco 2001).

In summary, the success of children's transition to their new school is dependant on their previous educational experiences and the quality of school in the receiving country 
(Orozco and Orozco 2001). For that reason, it is imperative that teachers and school staff learn each child's history and ensure that policies are actually contributing to immigrant children's school experiences (Colbert 2010; Orozco and Orozco 2001; Igoa 1995). For example, school policies and procedures can keep children away from school for months (Orozco and Orozco 2001). Vaccination requirements, confirmations of immigration status and documentation from previous schools create hurdles that impede children from enrolling in their new school (Orozco and Orozco 2001). The effects of school policies on children are later made evident through emerging behaviours and attitudes (Orozco and Orozco 2001). Also, teachers' perceptions of students may affect children's mental and emotional health (Kilbride 1997).

\section{Prejudice and Language}

Research on immigrant children often discusses the prejudice they face in schools (OISE 2010; Ragby 2007; Perren et al. 2010; Entorf and Lauk 2006; Phelan et al. 1991; MacNaughton 2001; Albanese 2009; Wolf 1997; Bettencourt 2000). Racialization in schools creates "significant stumbling blocks" that isolate, alienate and lead students to internalize an image of inferiority (Albanese 2009). Moreover, exclusion, discrimination and hostility "interfere with [children's] emotional health and social adaptation" (Orozco and Orozco 2001, 86). Children who are shy are the most vulnerable to prejudice (Orozco and Orozco 2001). Evidence of racial prejudice appears as early as pre-school years (MacNaughton 2001; Albanese 2009; Perren et al. 2010). Therefore, it should not be assumed that racism is limited to the experiences of high school immigrant students. Children from an early age classify and exclude peers on the basis of race (MacNaughton 2001; Perren et al. 2010). They recognize the variety of physical traits and socialize with children who share the same characteristics as them (MacNaughton 2001; Perren et al. 2010).

Moreover, children perceive language differences and use this criterion to select their friends (Perren et al. 2010; Nowak -Fabrykowski \& Shkan- Drij 2004; Souto-Manning 2007; Ragby 2007). Many Spanish-speaking students, for example, experience discrimination by their English-speaking peers (Souto-Manning 2007). They are often labeled as the students who cannot speak English, which leads to the assumption that these students are less intelligent, 
lazy, untalented and unskilled (Díaz 2002). Participants in a study by the Ontario Institute for Studies in Education (OISE) shared that their teachers and classmates make remarks and pose questions such as: "I hate Latinos" and, "Are you going to become a gardener or a janitor?" (2010). Racism in schools can affect the student's performance (Schugurensky 2009; Gaztambide-Fernández and Guerrero 2009) and places an emotional strain on students (Wolf 2007). They are pressured to assimilate as a solution to "the racism that signals to them that they will never be accepted" (Wolf 2007). But stigmatization can also be seen by immigrant students as a motivation to learn English as soon as possible (Garcia Coll and Magnuson 2005). Once they acquire English their self-esteem increases, "underscoring the psychological importance of linguistic acculturation" (García Coll and Magnuson 2005, 119).

In Ontario, one-third of newcomers are under the age of 19, and three quarters are from non-English speaking countries (People for Education 2009). Although school boards receive English as a Second Language (ESL) funding, the ESL policy does not specify for how long a child should be enrolled in ESL, nor is it required for schools to spend all funding on this program and for teachers to acquire ESL training (ibid.). Bettencourt's report (2000) notes that often newcomer students are involved in school fights as a result of their peers mocking them for their inability to speak English. Furthermore, Spanish-speaking students also become disinterested in school when they cannot communicate (OISE 2010; Souto-Manning 2007). One student expressed that she participated a lot in class, but the teacher would make no effort to understand her, always replying with "I don't know what you're saying" (OISE 2010). This discouraged the girl from participating and, in turn, she decided to skip all her classes except for her ESL class.

The literature makes it clear that schools need to address ESL deficiencies and incompetence (Orozco and Orozco 2001) as well as promoting the importance of the mother tongue (García Coll and Magnuson 2005). There are several justifications for fostering native languages in schools. Researchers note that children either lose their first language (Albanese 2009) or their fluency deteriorates across time (Orozco and Orozco 2001). Therefore, children need to frequently use their native language so that they can exercise their first language skills (Orozco and Orozco 2001). Hence, schools need to highlight the value of heritage languages 
(Park \& Sarkar 2007, Cummins 2001), such as Spanish, so that children learn to appreciate their culture and to benefit from their bilingual skills (Bernhard 2009, Bascuñán 2009b). Apart from promoting native languages, children's heritage should be valued within the school community so children develop pride in their culture and learn to see their cultural knowledge as a useful resource (Kilbride 2000, Cummins 2001).

Furthermore, studies have found that bilingualism is an asset to immigrants because it helps their cognitive development and acquisition of the second language (Kohnert et al. 2005; Souto-Manning 2007; Park \& Sarkar 2007; Chee et al. 2001; Zeitvogel 2011). The inclusion and development of native languages serve to create welcoming environments, combat stereotypes about inferior languages and validate children's cultural identity (Bleiker et al. 2008; SoutoManning; Park \& Sarkar 2007; Colbert 2010). Inclusive linguistic environments also enable children who struggle with language to overcome loneliness, fragmentation, alienation and even depression (Nowak-Fabrykowski \& Shkan-Drij 2004; Igoa 1995). The responsibility of promoting home languages does not rest solely on schools. Parents' and children's efforts are key to the preservation of first languages as well (Orozco and Orozco 2001). Language retention also helps immigrant children preserve their cultural identity and facilitates communication within the family (Louie 2006; Park \& Sarkar 2007). Family closeness is a determining factor in children's retention of their mother tongue (ibid.). Louie (2006) found that families from the Dominican Republic were more affectionate than families from China, which resulted in higher proficiency in the mother tongue for Dominican children compared to Chinese. Moreover, preserving the first language enables immigrant children to engage in transnational practices and keep in touch with their families in the sending country (Menjivar 2002; Louie 2006; Ragby 2007).

Lastly, it cannot be assumed that second language acquisition is a smooth, fast and effortless process for young immigrants (Orozco and Orozço 2001). Not knowing the language proves to be stressful for children, too (Rotter and Hawley 1998; García Coll and Magnuson 2005). It can take six to seven years for a child to achieve full mastery of the second language (Orozco and Orozco 2001). 


\section{Identity}

If children sustain transnational ties they are also more likely to maintain their heritage (Menjivar 2002; Louie 2006). However, it positions them in an ambivalent state of identity. Children are placed in two different worlds, histories, cultures and contexts (Menjivar 2002; Louie 2006; Wolf 1997; Harzig and Hoerder 2006). The struggles and clashes that immigrant children encounter in their journey of identity formation is an aspect extensively explored in the field of migration (Louie 2006; Menjívar 2006; MacNaughton 2001; Ragby 2007; Wolf 2007; Phelan et al. 1991; Fantino \& Colak 2001; Souto-Manning 2007; Bleiker et al. 2008; OISE 2010; Qin-Hilliard 2001). Qin-Hilliard discusses three different ways through which immigrant children negotiate identity: "ethnic flight" (abandon the ethnic group and mimic the dominant group), "adversarial identities" (construct identity in opposition to mainstream culture) and "transcultural identities" (develop competence in both cultures). Phelan et al. (1991)'s research with Latin American and Filipino youth reveals that some students choose to disassociate from their ethnic communities in order to fit into mainstream groups, avoid delinquency, and meet high academic standards.

Younger children also seem to follow this pattern. MacNaughton's (2001) research found that four and five-year-old immigrant children in Australia saw themselves as Australians of European descent (MacNaughton 2001). On the other hand, some children prefer to socialize within their ethnic groups to achieve a sense of belonging and overcome linguistic and cultural barriers (Phelan et. al 1991; Ragby 2007). Bernhard et al. (1997) argue that transcultural identities or biculturalism frameworks are the most appropriate to analyze immigrant children's identities. Wolf (2007) goes even further to say that immigrant children do not follow one specific path towards their identity; rather, the path is a fluid and constant process of identity negotiation.

Overall, there is a large body of literature that explores the school experiences of immigrant students, including their language acquisition. It is common to find discussions on poor academic performance, stigmatization and identity conflict. The role of parents and peer influence are also frequently mentioned by studies on this subject. But many studies focus on high school or kindergarten students, excluding middle childhood. As well it is rare to encounter 
data that result from personal interviews with children. And, as Diaz (2002) points out, there are a lot of studies concerned with school experiences, but not with the day-to-day lives of immigrant children. The current study hopes to address this gap in the research.

\section{Cultural Brokers - Brokering and Language Mediation}

The body of literature on brokering largely focuses on immigrant and first-generation children and youth who translate and interpret for their parents (Weisskirch 2005; Love and Buriel 2007; Morales and Hanson 2005; Orellana 2001; Orellana 2009; Pulido et al. 2003; Chee et al. 2001). Researchers discuss all the processes involved in this phenomenon including the causes, responsibilities of brokers, contributions to the family and society, and effects on the child (Weisskirch 2005; Love and Buriel 2007; Morales and Hanson 2005; Orellana 2001; Orellana 2009; Pulido et al. 2003; Chee et al. 2001). But brokering for and by school peers receives little attention in the literature. Furthermore, discussions on the aforementioned topic address brokering in dual-language classrooms, rather than on monolingual classrooms (Olmedo 2003; Angelova et al. 2006; Rubinstein-Ávila 2003; Coyoca and Lee 2009). It is also worth noting that the terminology on brokering is different in school contexts (i.e., the term language mediation is used instead of cultural brokering).

The literature explains that immigrant children aid their parents' settlement process by translating and interpreting for their parents in a variety of settings (Weisskirch 2005; Love and Buriel 2007; Morales and Hanson 2005; Orellana 2009; Pulido et al. 2003). Consequently, children take on adult responsibilities such as writing letters, reading contracts and filling government forms (Chee et al. 2001; Weisskirch 2005; Orellana 2009; Morales and Hanson 2005; Pulido et al. 2003). They act as personal interpreters to ensure their parents are informed about the new society and are understood by natives (ibid.).

Though the literature is consistent on children's influential roles within their immigrant families, the subject of whether children benefit psychologically and academically from these roles is debatable (Weisskirch 2005; Morales and Hanson 2005; Love and Buriel 2007). Lastly, studies on the effects of brokering tend to use quantitative designs such as surveys and numerical scales; and studies on language mediation utilize ethnographic observation (Benner 
2011; Weisskirch 2005; Love and Buriel 2007; Olmedo 2003; Angelova et al. 2006; RubinsteinÁvila 2003; Coyoca and Lee 2009). Additionally, several studies are based on retrospective accounts of brokers reflecting on childhood memories (Morales and Hanson 2005). In other words, the inclusion of current, first-hand insights from brokers and mediators is very limited.

\section{The Contributions of Brokers}

Gentemann and Whitehead (1983) define cultural brokers as actors who link the mainstream culture and subcultures. Brokering is not merely translating from one language to another, it requires an expertise that enables the child to navigate different cultures and communicate cultural symbols and information from one end to another and vice versa (Gentemann and Whitehead 1983). It is common for children to become brokers given that they acquire the second language faster than their parents due to their school involvement (Orellana 2009). Moreover, since they attend school they have more contact with natives compared to adults, learning to decipher and manage cultural practices and information that are unfamiliar to their parents (Orellana 2001; Chee et al. 2001). Children start brokering within the first five years of arrival and can be as young as eight years old (Morales and Hanson 2005). Generally, girls are most likely to broker than boys (Weisskirch 2005; Morales and Hanson 2005; Love and Buriel 2007).

Children's assistance is highly valuable because they help immigrant families access different services as well as form networks that contribute to the survival of families (Pulido et al. 2003; Chee et al. 2001). For instance, children translate for their parents in many different settings including hospitals, malls, car dealers, police stations, government agencies, schools and real estate offices (Orellana 2009; Pulido et al. 2003; Morales and Hanson 2005). In a way, cultural brokers contribute to the functioning of institutions like schools and clinics as they provide translation and interpretation services to their clientele (Pulido et al. 2003; Orellana 2009; Morales and Hanson 2005). They also write letters and resumes, translate mail, fill out forms and make calls on behalf of their parents (Orellana 2009; Pulido et al. 2003). Apart from translating, they make sure their parents' messages get communicated effectively (Orellana 2009). They must also have patience with their parents to explain to them foreign terms and 
ideas (Orellana 2001). Nevertheless, Morales and Hanson (2005) say research is needed to find out if children's translations and interpretations are accurate and informative. They suggest that studies should be more sophisticated by developing measurement scales and by including parents' perspectives (Morales and Hanson 2005).

The aforementioned demonstrates that children are not passively dependant on their parents; instead, they are actively working along with their parents to obtain things that the whole family needs (Orellana 2009; Pulido et al. 2003; Chee et al. 2001). Pulido et al. (2003) state that cultural brokering demonstrates children are invested with great societal power and "are not merely 'peripheral participants'". Chee et al. (2001), for example, suggest that in the U.S. the work of Latin American immigrant children as cultural brokers should be considered in national policy debates. In Canada, cultural brokering is also common among immigrant children. Proudfoot's (2010 p. A4) article discusses the phenomenon of child interpreters who are given a great deal of responsibility as they assist their parents with a range of activities such as shopping, translating apartment leases and doctor's orders. Even though the cultural brokering work by immigrant children advances their families' settlement and contributes to the functioning of many institutions, their work goes unrecognized and unvalued by the host society and social policies (Chee et al. 2001; Pulido et al. 2003; Orellana 2001; Orellana 2009). For this reason, Chee et al. (2001); Pulido et al. (2003); Orellana (2001) and Orellana (2009) believe that it is important to acknowledge immigrant children's work and regard them as subjects with critical roles in the settlement process.

\section{Effects on Child}

Children's duties as cultural brokers help form their ethnic identity because they develop their bilingual and bicultural skills (Weisskirch 2005; Morales and Hanson 2005). As a result, they have more opportunities to achieve a sense of belonging to their home culture (Weisskirch 2005). Moreover, brokers are more mature and independent than non-brokers (Morales and Hanson 2005). Their self-esteem can also increase when they learn how valuable their work is (Love and Buriel 2007; Morales and Hanson 2005). Moreover, brokering enables children and youth to gain communication skills and become knowledgeable in many areas (Benner 2011; 
Morales and Hanson 2005). Therefore, their cognitive and linguistic abilities are developed (Coyoca and Lee 2009; Olmedo 2003), and in turn aid their school performance (Morales and Hanson 2005; Weisskirch 2005; Love and Buriel 2007). However, the tasks of a cultural broker can be overwhelming, demanding and stressful (Benner 2011; Love and Buriel 2007; Morales and Hanson 2005), as they might feel responsible for helping their families settle (Benner 2011; Weisskirch 2005). For instance, their school performance can deteriorate due to their commitment to being the family broker (Love and Buriel 2007; Morales and Hanson 2005). Furthermore, it can have negative effects on the child's social life because they are placed in stigmatizing situations and have less time to spend with friends, increasing their feelings of loneliness (Benner 2011).

Weisskirch (2005) and Love and Buriel (2007) found the younger the child is the less they enjoy brokering and the more uncomfortable and embarrassed they feel at their parents' not knowing English. Some researchers say children who dislike brokering do not benefit from partaking in it (Morales and Hanson 2005). In contrast, older children appear to be satisfied, feel pride at collaborating as brokers and are aware of the benefits of brokering on their academic performance (Weisskirch 2005; Love and Buriel 2007). Another factor that shapes children's and youth's attitude towards brokering is their connection with their parents. If children have strong bonds with their parents, it is more likely they will regard brokering as beneficial (Love and Buriel 2007). It has also been shown that brokering strengthens children's relations with parents because they become more knowledgeable of and empathetic with their parents' struggles (Love and Buriel 2007). In terms of gender difference, girls view brokering more positively than boys, show greater ethnic affiliation, but also report more depression (Weisskirch 2005).

In sum, research seems to concentrate on cultural brokering offered by children and youth to their parents. The significance of cultural brokers and their contributions to their immigrant families' settlement is well known. The advantages and disadvantages that brokering poses on children are explored as well, although many times the data result from quantitative research instruments. Lastly, there is no discussion on the role of cultural brokers in schools and on the impact peer cultural brokering has on immigrant children. 


\section{Language Mediators in Classrooms}

Most of the literature that explores cultural brokering among peers uses the terms 'language mediation' for cultural brokering, 'scaffolding' for brokering, 'mediators', 'tutors', 'experts' or 'givers' for brokers, and 'tutee', 'receiver' or 'novice' for the brokee (Olmedo 2003; Angelova et al. 2006; Rubinstein-Ávila 2003; Fassier 1998). Though the dynamics of language mediation differ from those in the context where children help their parents, "studies lack a detailed account of how language brokering gets constructed and negotiated among peers in classroom communities" (Coyoca and Lee 2009, 261).

The dual-language literature that is concerned with language mediation uses Lev Vygotsky's concept of children's development, which explains that social interactions with peers aid and advance children's learning processes (Angelova et al. 2006; Rubinstein-Ávila 2003). When children learn a second language, learning from peers plays a critical role (Olmedo 2003; Fassier 1998). Studies have revealed that children as young as kindergarten-age make judgments on the linguistic abilities of their peers (Perren et al. 2010; Olmedo 2003). Children can assess each other's language proficiency and provide scaffolds so that peers can communicate and be understood (Olmedo 2003). This is especially true for dual-language classrooms where a supportive environment encourages collaboration and scaffolding between native and non-native speakers (Angelova et al. 2006; Rubinstein-Ávila 2003). In this type of settings, children learn to rely on one another, not simply on the teacher (Olmedo 2003). Even those children who are not fully bilingual make an effort to help monolinguals (Olmedo 2003). This is made possible due to the nature of dual-language programs that combine native English speakers with speakers of other languages, promoting strong bilingual and biliteracy skills (Rubinstein-Ávila 2003; Angelova et al. 2006). All subjects in dual-language schools are taught in both languages (Angelova et al. 2006), in most cases in the U.S., English and Spanish (Rubinstein-Ávila 2003). Therefore, students in this curriculum learn to use native languages to acquire second languages (Rubinstein-Ávila 2003).

Unlike what occurs in the parent-child dyad, the mediator, the teacher or the child who needs help can initiate scaffolding (Coyoca and Lee 2009). Mediation can take three different forms: unidirectional (a person interprets for another), distributed (one person interprets for a 
group or vice versa) and reciprocal (one person interprets for another but in return receives help from the brokee in some other area) (Coyoca and Lee 2009). Reciprocal mediation allows for the role of the tutor and tutee to be fluid as the expert can master one subject whereas the novice can be the expert in another subject (Angelova et al. 2006; Coyoca and Lee 2009; Rubinstein-Ávila 2003). To mediate, the child must first comprehend the message that needs to be communicated and then identify if the other child needs assistance (Olmedo 2003). Once this is done, the child chooses the most appropriate strategy, which includes translation, codeswitching, paralinguistic cues, interpreting and paraphrasing (Olmedo 2003; Angelova et al. 2006). They can also quiz tutees about books they read, remind them of vocabulary, mimic actions and repeat words for them (Rubinstein-Ávila 2003). Using any of these strategies serves to clarify information, communicate requests, provide directions and explain concepts (Olmedo 2003; Angelova et al. 2006). The most widely used strategy among peers is translation (Olmedo 2003) and what concerns them the most is phonological and semantic accuracy (RubinsteinÁvila 2003). Children teach each other pronunciation and grammar, and congratulate tutees when they get it right (Rubinstein-Ávila 2003; Angelova et al. 2006). Tutees also repeat to themselves the phrases or words used by tutors when mediating, so that they can memorize them and avoid having to ask for translation and interpretation again (Angelova et al. 2006).

Even though helping one another in the classroom has advantages such as fomenting peer support, the disadvantages include exclusion, language hierarchy, imposed brokering, frustration, limited opportunities, stigma and dependency (Coyoca and Lee 2009). The disadvantages arise from the language hierarchy that promotes inequalities among languages (Olmedo 2003; Coyoca and Lee 2009). For instance, those children who speak English occupy a higher status than those who speak Spanish (Olmedo 2003; Coyoca and Lee 2009). As a result, children may choose to hide their linguistic identity by refusing to mediate, given that it reveals their ethnic identity (Coyoca and Lee 2009). Moreover, mediators can abuse their power to alienate children and decide who gets their assistance (Coyoca and Lee 2009). Hence, children may be excluded on the basis that they speak a language other than English, resulting in low self-esteem and stigmatization (Coyoca and Lee 2009). But in other cases, children can remind each other to be patient and understanding of each child's learning abilities and needs 
(Angelova et al. 2006). In some classrooms, there is no conflict or superiority and instead children are accommodating and volunteer to assist those who require scaffolding (Angelova et al. 2006).

Though Rotter and Hawley (1998) suggest adults prepare immigrant children for their new life by teaching them sociocultural differences, strategies to cope with teasing and study skills, language mediators are also appropriate for this endeavor. For instance, Díaz (2002) explains that students construct a caring school environment as they help each other understand coursework. She noticed that students work in groups and tell those who do not understand English what is required of them (Díaz 2002; Olmedo 2003). According to the students the caring environment was a product of peer support and not a consequence of their teachers' aid (Díaz 2002). Even after school they get together to translate for their peers (Díaz 2002). In school, however, it is harder for them to mediate because sometimes they are forbidden to use Spanish or are given a set amount of time to do so (Díaz 2002). Those restrictions hamper the non-English speaker because they do not get a complete translation/interpretation or when they do, it is not relevant anymore (Díaz 2002). It is also difficult to mediate when writing tests because either the tutee receives no translation or the tutor is rushed to finish his/her test quickly to help that other student (Díaz 2002).

Sometimes, the expectations on tutors are too pressing because tutees get frustrated when they do not understand and then expect tutors to translate and interpret at all times (Díaz 2002). Olmedo (2003) also observed that whenever children needed interpretation they would look around at peers to signal to them that they wanted help. Hence, bilingual children might get distracted from their own schoolwork (Diaz 2002). Regardless, the communal cooperation and counting on others prove to be useful (Olmedo 2003) since students believe they could not succeed in school if they lacked each other's help (Díaz 2002). Immigrant youth have identified their classmates as their most helpful asset during their settlement because peers teach them how to dress, what to do in school, what to do after school, what subjects to enroll in and much more (Anisef and Kilbride 2003). Some schools even have buddy programs where newcomers are paired with cultural brokers (ibid.). 


\section{Types of Classrooms}

Bilingual programs are usually stigmatized, whereas dual-immersion programs are exalted (Rubinstein-Ávila 2003). Bilingual programs make use of the mother tongue up until the child learns the second language and dual-immersion programs use both languages even after the child has acquired the second language. Bilingual education is viewed as "subtractive", for once immigrant children develop English proficiency the mother tongue is no longer exercised; and dual-language education is viewed as additive because positive race relations and bilingualism are developed simultaneously (Rubinstein-Ávila 2003). Regardless of the reputation of duallanguage education, Rubinstein-Ávila notes that these programs continue to perpetuate the gap between majority and minority students as majority students profit the most. Due to all these differences, Olmedo (2003) and Fassier (1998) recommend that researchers investigate if scaffolding dynamics in monolingual, English as a Second Language, and bilingual classrooms are the same as in dual-language classrooms.

In the case of ESL classrooms peers may act as resources for second language learners, too. Children strive to understand each other and encourage peers to clarify or correct their speech (Fassier 1998). Fassier (1998) observed that children imitate the rhythm and phrasing of proficient ESL students, use gestures to communicate with one another, offer quick tutorials, correct misuse of words and help expand each other's vocabulary. Additionally, among peers they get exposed to other forms of rhetoric such as arguing, persuading and negotiating (Fassier 1998). Children's mediating roles are also flexible since the receiver can at times be the giver and vice versa (Fassier 1998). Nevertheless, there are cases where ESL students exclude children based on their English proficiency by regarding their contributions as irrelevant and by abstaining from imitating their speech (Fassier 1998).

Fassier noticed that children who share home languages form cliques where they use the mother tongue to communicate. Though these cliques may delay English acquisition they provide social, emotional and academic support (Fassier 1998). The increasing number of ESL classrooms signifies children are increasingly relying on other ESL students to advance their English acquisition (Fassier 1998). Nonetheless, some researchers insist that peer learning among ESL students might hamper the development of the second language because children 
learn incorrect information (Fassier 1998). Studies, however, have shown that interacting with non-native speakers does not result in more linguistic errors; rather, ESL students do learn by correcting themselves and others (Fassier 1998). Moreover, Fassier (1998) notes that the level of support he witnessed in his ethnographic research had never been addressed by ESL literature. He concluded that children are sometimes more accommodating to second language learners than adults. And this is not limited to ESL students. Native children can also tailor their language through the use of sound effects, facial expressions and demonstrations to make their messages accessible and clear (Fassier 1998).

Overall the literature on language mediation in dual-language classrooms paints a picturesque image of mutual contributions (with the exception of Coyoca and Lee 2009). Children scaffold for each other and invest in their peers' second language acquisition. But little is known about classrooms where one language dominates. Are children in this type of setting as giving and patient? Do children in monolingual classrooms have assurance that they will receive scaffolding when they require it? What do children think are the contributions of language mediation? How do they feel when it is denied or granted? All these questions remain unanswered. Moreover, the studies above employed samples from kindergarten, first, second and third grade students. But how about older children? Lastly, measuring scales and observations are the main sources of data, excluding the views of those in the midst of it all. So, what can and do children themselves tell us about their experiences with brokering and mediation? 


\section{Theoretical Framework}

Historically, definitions of childhood and children have formed part of numerous theories across a number of disciplines (Castañeda 2002; Albanese 2009). Children are referred to as mental states that one must adopt; as subjects in the making; as figures void of experience, attachments and responsibilities; as adults' memories of their childhoods; as vulnerable, exploitable and dependant people; and as fields of study that explore how adults are formed (Castañeda 2002). Castañeda states that what these forms of theorizing accomplish is to "erase the existence and experience of "actual' children"' (168). Commonly theories do not consider children as entities on their own nor do they take into account that children's experiences differ from what adults recall about their own childhoods (Castañeda 2002). Moreover, the aim of including children in theories is often to explain developmental processes and socialization patterns (Albanese 2009). For a long time, sociological approaches have framed children as people "being acted upon" or "becoming"' (Albanese 2009, 19). Therefore, for the most part, they are excluded from theory and methodology in sociology (Albanese 2009). For that reason, the new sociology of childhood is the most appropriate and relevant approach to guide the research design of this study and the analysis of its data. This theoretical understanding focuses on children in the present and not on what they will become (Corsaro 2005). It positions them as competent social agents who have the capacity for autonomy and decision-making (James et al. 1998), as agents and doers who actively participate in their social environment (Corsaro 2005). Children do not simply adapt or learn from their surroundings; instead, they are able to reproduce meaning and interpret the situations they face (King 2007; Corsaro 2005).

Sarah Matthews (2007) provides an overview of the development of the new sociology of childhood theory, which originated in the mid-1980s when researchers realized that the study of children was not given sufficient attention. The idea of children as persons who are "incomplete" or "in process" was revolutionized to become an understanding of children as "full members of the group" with the ability to affect "social structures and relationships" (Matthews 2007, p. 323). Matthews adds that this line of thought recognizes that children do make sense of what occurs in their social and physical worlds. Apart from interpreting, children also construct their worlds and contribute to cultural production. The new sociology of 
childhood, Matthews explains, takes into account that children are not a homogeneous group. Many developmental and psychological approaches have propagated the view that children are the same everywhere, ignoring the personhood of each child. But the differences among contexts and settings give rise to a variance of experiences in children's lives. For example, societies, locations and time periods all shape the circumstances children grow up with. Lastly, what is important about this new framework is that children are not regarded as being unable to speak for themselves and as not being worth talking to. Instead, children's views are prioritized as researchers are encouraged to directly speak with children and to consider them as the main informants on their own experiences. That is not to say, however, that children's relations with adults and peers are overlooked, for sociologists in this branch are aware of the dependency of children on other humans (Matthews 2007).

In sum, the new sociology of childhood fits well with the rationale and design of this study because immigrant children need to be given the opportunity to express their thoughts and feelings as they experience migration and settlement in the present. As well, the input from the child participants is presented in this research paper as valuable information for those people and institutions that have for so long spoken on their behalf.

The other theory employed in the current study is acculturative stress- a theory that is common among studies of immigrant children (García Coll and Magnuson 2005). Acculturative stress refers to the stressors present in the migration and acculturation experience of immigrants, their psychological impact, and to a larger extent the ways in which they are dealt with (Smart and Smart 1995; García Coll and Magnuson 2005; Caplan 2007; Suarez-Morales and Lopez 2009). Acculturation describes the process of adapting to the rules, ideas, routines, social roles and behaviors of the new society (Caplan 2007; Smart and Smart 1995). Formerly, many believed that immigrants ended up assimilating to the receiving society; however, the term acculturation has evolved to include many possible outcomes such as biculturalism, multiculturalism and adaptation (Caplan 2007). According to Rotter and Hawley (1998) acculturative stress is experienced throughout a series of stages that include contact (child's culture meets the dominant society's culture), conflict (child is aware of the differences between cultures) and adaptation (child learns to cope with the cultural clashes). 
Children like adults face a range of stressors during their migration and adaptation process (García Coll and Magnuson 2005). Two examples of stressors in the cases of immigrant children are loss caused by the separation from beloved relatives and a familiar environment (Garcia Coll and Magnuson 2005; Caplan 2007). Stress is also exacerbated by the involuntary nature of the emigration most children experience (Caplan 2007). In preadolescent Latin American children, language issues and leaving the homeland translate to more worries (Suarez-Morales and Lopez 2009). The loss of social networks and family support are particularly acute among Latin Americans because of their appreciation for collectiveness and familialism (Caplan 2007). It is customary for them to practice mutual support, nurture strong connections and partake in group activities, contrasting with the more individualistic norms common among many North Americans (Caplan 2007). In addition, social support, living with the family, and frequent contact have been shown to act as buffers for acculturative stress in Latin American immigrants (Caplan 2007). Other buffers include the accomplishments, success, and growth that result from the immigration experience (Caplan 2007).

Children's stressors such as learning a new language (Suarez-Morales and Lopez 2009) and discrimination- mostly based on physical appearance-create anxiety in children (Caplan 2007; Suarez-Morales and Lopez 2009). Anxiety symptoms include lack of concentration and an increase in worrisome thoughts (Suarez-Morales and Lopez 2009). Children worry a lot while they adjust and learn English; after all, "worry is the most common symptom of anxiety in children" (Suarez-Morales and Lopez 2009, 344). Suarez-Morales and Lopez (2009) note that only one study has reported on the correlation between anxiety and immigrant youth's English proficiency. If a child is unable to turn the stressor into an opportunity for growth, the learning of a new language becomes a threatening experience that leads to anxiety (Suarez-Morales and Lopez 2009). If children fail to cope with anxiety it may lead to behavioural and psychological problems (Caplan 2007). Discrimination leads to anxiety as well, which in turn affects the academic performance of children (Suarez-Morales and Lopez 2009). Though U.S. literature concentrates on discrimination as a major stressor for immigrant children, I deliberately centered the discussion on family loss and language as these topics are more applicable to the current study. 
Although some studies consider the same set of stressors for both adults and children (Caplan 2007; Suarez-Morales and Lopez 2009), it should be noted that there are discrepancies between adults' acculturative stress and children's. For instance, adults' stressors tend to be related to their socio-economic context, housing conditions and healthcare (Smart and Smart 1995). Hence, it is important to consider the age differences when studying acculturative stress because the nature and intensity of stress varies across the age groups (Smart and Smart 1995).

A flaw of acculturative stress theory is its tendency to focus on the maladjustment of young immigrants, which is usually measured by scales and indicators (García Coll and Magnuson 2005). If studies are too concerned with measurable negative outcomes, then children's actual experiences and processes with migration and settlement can be and often are left out (García Coll and Magnuson 2005). Moreover, positive consequences such as children's personal growth and coping strategies may not be taken into account (Garcia Coll and Magnuson 2005).On the other hand, the combination of acculturative stress theory with the new sociology of childhood inevitably leads a researcher to deviate from inventories that seek to measure negative effects. Instead, I anticipate that the conjunction of both theories will encourage thorough descriptions of the lived and particular experiences of children as they encounter a variety of stressors during their immigration and settlement process. I believe these theories could allow me to delve into the world of Latin American immigrant children in Canada in order to explore and expose their worries, their emotions, their views, their achievements, their aspirations, and ultimately their unique stories.

Furthermore, I have chosen not to concentrate on cultural clashes and adaptation as presented in acculturative theory; rather I would like to address the changes in Latin American immigrant children's lives after emigrating as they saw them and the manner in which they perceived those changes shaping their settlement experience in Canada. Through the initiative of giving voice to each of the participants, I set on a journey that revealed the changes relevant to this context and the feelings and opinions those changes evoked in ten wonderful children. 


\section{Recruitment $^{2}$}

The criteria for potential participants required them to be between the ages of nine and 11 , born in a Latin American country and residing in Canada for five years or less. Before the recruitment process started I was told that parents would be reluctant to participate and that they would most likely not participate at all. People thought that parents would be uneasy about letting their children be interviewed and that I would probably not be able to recruit as many children as I hoped to recruit. The actual recruiting, however, was exactly the opposite of what was believed. I was able to recruit more than ten children, but only conducted ten interviews due to time constraints (see Demographics section). I prepared a short, clear flyer with a colour image to provide the parents with further details and contact information (see Appendix 1). I posted it on e-mail serve lists of a church with a Spanish community, a theatre group for children of Spanish-speaking parents and a settlement centre that serves immigrant of Latin American origin. I also attended events by the church and theater group to introduce myself and network with the parents. The parents' response was very encouraging. They seemed very interested in the study and told me that there is indeed a need to conduct research with children to be able to find out about their experiences. They gave me permission to interview their children without any hesitation. Some others wanted me to interview their children but I could not because they did not meet the requirements, such as country of origin. The biggest obstacle in recruiting was that most children of Latin American parents had been born in the U.S. so they could not be included in the study.

Some parents asked me if they could help me with recruitment. They said this research was very important and that they will be happy to tell their friends about it. With their help I was introduced to their family members, neighbours, and friends either through e-mail or by phone. I then set up appointments with all the parents and arranged meetings in libraries or their homes. Most parents preferred their homes because it was convenient for them in terms of time and transportation. Once I conducted the interviews many parents again told me how

\footnotetext{
${ }^{2}$ Please note that the sections to follow might be longer than customary. The study's exploratory and descriptive nature led to several innovative findings, which require detailed descriptions and comprehensive discussions.
} 
important and interesting this topic was and that they will tell their friends about the study. As a result, their friends and neighbours contacted me and said they would like their children to participate. Children also helped me with recruiting. Since children participants were also interested in my project they asked me how many more children I needed and if they could tell their friends about me.

During recruitment there were some interesting comments made by the parents. One mother said that she had never thought about how her children felt and had never wondered about their experience as immigrants. She added, "I'll go home tonight and ask them how they felt, how was it like for them". Another mother said that she would like her child to speak to me so that it will be "like a therapy" and he could "express all that he felt". Though I explained to her that this was not therapy, her comment showed that children do need to be given the opportunity to express and make sense of their emotions and experiences. These comments also demonstrate that immigrant parents might forget to ask how their children feel, or simply assume that their children will 'get over it'. In sum, it can be said that the primary stages of this study (recruiting) helped to make parents realize that there is a need to pay closer attention to the emotional processes and lived experiences that immigrant children go through. In other words, even before the report was written parents understood that this subject area is of great value to their children.

I am writing this section of the paper in order to provide evidence that serves to contradict the common assumptions that one should avoid research with children, that parents are not willing to participate, and that it will be nearly impossible to recruit children for studies. This section also reveals that parents of Latin American origin are very open, approachable, enthusiastic and accommodating to research (being Latin American myself may have helped). Instead of bombarding me with questions about the study and methodology, of restricting me for time and study location, and demanding confidentiality for their children, these parents consented to participate without hesitation or hassles. Nonetheless, I made sure to follow the ethics code at every step of the process by providing them with detailed information and informing them about their rights and my obligation to respect their children's confidentiality. They regard their children's participation as an accomplishment to be proud of. Hence, they 
wanted their children's names to be used. However, I refused and said that I was committed to protecting their children's identity. A parent even told me that her child would be so happy when he finds out that he will appear in a report. Perhaps researchers avoid conducting research with children because they do not think parents will consent, but as I share my recruitment experiences I hope to demonstrate that in some cultures/countries and under some circumstances parents are willing and happy to consent to their children's participation. Lastly, the recruiting stage serves to highlight the interest of parents, children and the media ${ }^{3}$ on hearing children's migration stories.

\footnotetext{
${ }^{3}$ Several media outlets contacted me in order to become informed about my research project. Producers for two Spanish TV shows wanted to interview me, editors from two Spanish papers wanted to publish my findings and a radio host wanted to promote my study. Although I was glad to find that the Latin American community was interested in the topic and that they wanted to learn more about it, 1 told them that I could not divulge anything related to my findings until the MRP is complete because I must observe the ethical code.
} 


\section{Methodology}

The methodology for this study took a great deal of careful planning. On the most basic level, this study involved in-depth unstructured qualitative interviews (which included drawing, writing and storytelling-more on this below) with ten immigrant children from Latin American countries, who were between the ages of nine and 11 and had resided in Canada for less than five years.

Unstructured interviews seemed to be a perfect fit for this study's objective because the method focuses on revealing participants' perspective and experiences. This type of interview is designed to "bring out how the interviewees themselves interpret and make sense of issues and events" (Bryman et al. 2009). Nondirective, in-depth interviews enable participants to share their insights, feelings and subjective meanings (Neuman 2011 p. 449). The interview is an informal, friendly conversation with pauses and brief silences, which encourages participants to express themselves as they normally speak and think (ibid. p. 450). It also involves expressions of interest and of ignorance by the researcher and questions by the participant (ibid. p. 451). The researcher also shares his/her experiences and background to build trust and enable the participant to open up (ibid. p. 450). The researcher's involvement plays an integral role through his/her use of digressions, listening, interruptions, probes and responses (ibid.). Moreover, I chose individual interviews in order to invest my undivided attention to one child at a time, take detailed field notes, observe children's body language, be responsive to their cues and help them understand the activities.

Typically in an interview, questionnaire, or survey, child participants are guided into addressing certain topics of discussion by the researcher (Murray et al. 2003; Morgan et al. 2002). Such interview instruments often lead children to refuse to talk, open up and collaborate during research sessions (Murray et al. 2003; Morgan et al. 2002; Morrow and Richards 1996). They feel intimidated, confused or overwhelmed and object to doing what they are instructed to do or to answering what they are asked (ibid.). Consequently, a combination of drawing and writing proved to be a better approach. Esquivel et al. $(2010$, p. 31) explain that "drawings in combination with narratives provide insights to inner experiences of children related to traumatic experiences such as displacement...or planned relocations". Rousseau and Heusch 
(2000) agree as they state that that analyzing stories and drawings helps improve the understanding of the processes immigrant children go through.

Though the literature mentions that story writing and drawing are the most utilized methods when conducting research with children (Morgan et al. 2002; Murray et al. 2003; Morrow and Richards 1996), the studies that provided me with detailed accounts of this methodology in relation to immigrant children were intended either for cultural interventions or first language literacy development (Esquivel et al. 2010; Bleiker et al. 2008; Cummins et al. 2006; Rousseau et al. 2005; Bagilishya et al. 1998, Dual-Language Book Club 2009; Taylor et al. 2008).

Esquivel et al. (2010) explain that drawing helps children get an idea of what they want to write about. Drawings, for instance, can increase the amount of information being reported, facilitate retrieval of memories, help the child organize a narrative and provide distance between the child and his or her artistic creation (ibid.). Their own illustrations enable them to have a visual representation of an event, place, or story, making it easier for them to describe it in a written or oral form (Rousseau and Heusch 2000; Esquivel et al. 2010). Drawing also allows children to communicate non-verbally. Therefore, they are capable of transmitting their feelings and thoughts, overcoming limitations imposed by words (Esquivel et al. 2010; Hill et al. 1996; MacNaughton 2001). The shapes, materials and colours they employ for their illustrations make the data rich as all of these aspects can be analyzed (Rousseau et al. 2005; Bagilishya et al. 1998; Rousseau and Heusch 2000). In this type of methodology, it is also customary for children to explain their drawings. After they have completed their illustrations, children narrate the story depicted by their drawings or they explain the meaning of what appears in the picture (Rousseau and Heusch 2000; Igoa 1995).

Story writing allows the child to both "impose structure on the temporal flow of experiences and interpret [them]" (Esquivel et al. 2010 p. 22). Most importantly, stories are more concerned with meaning than facts (ibid.). The body of literature argues that story writing is a medium through which immigrant children construct meaning by organizing, connecting, conceptualizing and making sense of their experiences (Taylor et al. 2008; Lacroix et al. 2005; Rousseau et al. 2005; Esquivel et al. 2010). In most cases, immigrant children write about their 
families, their traditions and homeland (Taylor et al. 2008; Bleiker et al. 2008). In their stories children discuss their struggles and issues in the receiving country. They write about the difficulties of learning a new language, adapting to a new society and making friends (Igoa 1995). Immigrant children's texts also reveal their hopes, goals and desires (Lacroix et al. 2005; Dual-Language Book Club 2009). They also write in their native languages, creating duallanguage stories (Blaiker et al. 2008; Dual-Language Book Club 2009). Lastly, story writing also helps children distance themselves from the information they share with the researcher (Esquivel et al. 2010).

The bond and commonality between researcher and child participant are key to the success of research with children (Morgan et al. 2002; Murray et al. 2003; Morrow and Richards 1996). Additionally, children should not regard the researcher as if he or she were a teacher or an authority figure (Albanese 2009; Morgan et al. 2002). This has great potential to limit the contributions by child participants (ibid.). Consequently, researchers are advised to participate along with children (MacNaughton 2001; Hill et al. 1996, Albanese 2009). Researchers can sit at the same level as the child, play with them, permit them to set rules and operate the tape recorder (Murray et al. 2003; Morgan et al. 2002; Coyoca and Lee 2009). Depending on the methodology, researchers role-play, play with dolls, sit on the floor and draw with child participants (MacNaughton 2001; Morgan et al. 2002; Hill et al. 1996).

Beyond taking into account the recommendations by the literature, a great deal of thought was given to a range of seemingly mundane things, from the clothes I wore to the size of the paper used and other materials employed in research sessions. For example, I chose to include 46 markers-fine and standard- 64 crayons, about ten pens and pencils-mechanical and standard-, 8 gel pens, 4 erasers, sharpener, lead, white out, cardboard, 4 notebooks, three set of stickers. I purposely bought colourful materials to make the research session less dull for the children. Even the pencil cases were bright green with blue and pink. Two notebooks were small and two were big with covers either in solid colours or patterned. I bought the solidcoloured notebooks anticipating that the boys were more likely to be drawn to these, and the patterned notebooks I chose with the girls in mind. However, when they were given the choice to select one, most of them picked the small red notebook. The notebook for my field notes 
had a picture of a Mexican painting of a small girl. I decided to provide children with notebooks rather than loose pages because it gave them a sense of privacy and ownership. I ripped out the pages on which the last child had written, so for every session the child was given his/her own "new" notebook. Also, they could close it, covering what they wrote.

The pieces of Bristol board were longer horizontally than vertically, to facilitate the drawing of the child's sequence of events. Children were given the choice either to use the whole piece of Bristol board, to use the back and front, to cut it, to split it or fold it. The stickers included airplanes, cars, compasses, suitcases, hot air balloons and other objects associated with traveling. The stickers were 3D and could be reused. A map about the same length as the Bristol board was used to give them a visual aid for the storytelling portion of the session.

I also bought each child a gift comprised of chips, soda, chocolate and candy. The gift bags were colourful and contained a personalized thank-you card. I decorated the envelope with stickers and wrote the name of the child on it. Inside the card I thanked them for participating and told them that I enjoyed drawing and writing with them and that what we did may help children like them. Before signing the card I wished them a fun summer. The main message was written in Spanish, but the sign-off phrase was written in English. I decided to use both languages because I did not know what their level of English was and also because I supposed that it was natural for them to use both languages. I was, for the most part, correct.

Before meeting with each child I carefully selected my wardrobe. I wore a coloured shirt-aqua blue, green, pink or baby blue- with a flower-patterned tank top over it. I also wore jeans and purple running shoes. The sweater was purple with green, and I made sure things matched as well. For example, I wore earrings according to the colour of the shirt. Children did notice my clothing. Some said they liked my earrings and others said they liked the flowered tank tops. I was not trying to look childish or clown-like but I decided to wear something that would be attractive to children, make me seem more approachable, and make them more comfortable. The outfit was not a costume either because it is something I would wear to go anywhere but work. Moreover, I wanted to be comfortable in case we had to move around during the interview. Finally, I wore a watch so that I could discreetly check the time without 
having to use my cell phone because I did not want children to feel rushed or feel like I was not paying attention.

When I met with the parents I explained to them their rights and my obligations as outlined in the consent form. After asking them if they had any questions they signed the form. Then, I introduced myself to the child and explained why I was there. I asked them if they wanted to speak in English or Spanish and whether they liked the assent form in Spanish or English. After we agreed on the language to be used I gave them the assent form. Most of them selected the consent form in English, but in terms of spoken language they were comfortable in both languages. They read it and then I explained it to them using simple language. I asked them if they had any questions before writing their names on it. All parents and children authorized me to record the session and to show the child's drawing in the final written project. However, Sebastian hesitated when he read the clause on allowing me to show his drawing without his name. I noticed his hesitation so I clarified to him what that phrase meant. To my surprise, he scratched the NO and replaced it with $\mathrm{Si}$, which meant he did want his name to appear (see Appendix 2). He said he wanted to be known because he likes to perform and be interviewed. In the future he hopes to be a journalist and work for TV or radio. His decision displays a degree of agency and autonomy of children. They are capable of making many decisions when they are given the opportunities. Sebastian showed me that he did not want to conform to my way and he insisted on making the change to the form, himself.

Each research session lasted from one and a half hours to two hours, depending on how fast the child completed the activities. The sessions consisted of unstructured interviews involving interactive drawing and writing exercises. A list of topics and a script were prepared to help guide the interview. The topics provided me with an overview of the areas and issues that were highlighted in the initial literature review. The topics included the following: (see appendix 3). The script provided me with the order of the activities and a written introduction for each of them. Apart from knowing the order and the introductions, the course of the interview and the areas to be explored depended completely on what the child wished to share with me.

I began each session by showing the child the materials we were going to use and the digital recorder. I asked them if they had seen a recorder before and for those who saw it for 
the first time I let them record themselves to get familiar with it. Then, I let them press record so that I could start telling them my story. I used the map and a sticker- an airplane or suitcaseto show them my journey from Colombia to the U.S. to Canada. I told them about the hardships I faced for not knowing English and for the lack of support by peers. But I also told them about my achievements and the happiness I felt when I saw snow for the first time. I started the session with my story because it gave them the opportunity to get to know me, to feel comfortable and to get an idea of how to tell their stories. In order to discourage children from copying my story I gave them a short, general narrative with little detail. In the end I realized my discreteness did work because the issues identified by them did not correlate with the events in my story.

When they had their turn they picked a sticker and moved it over the map depending on the countries they have lived in. Most picked airplanes, but Candice and Isabel chose the Eiffel Tower and hot air balloon, respectively. Candice said she liked France because its language and fashion were beautiful and Isabel said she liked the rainbow colours on the hot air balloon. The map was useful because several children used it to help them draw their home countries. It also served as a conversation starter. Isabel, for example, pointed at Germany while I set up the materials on the table. Then we started talking about a school project she was doing on Germany and I made the connection between the report I would have to write for my research with the report she would have to write for her assignment on Germany.

In the first two sessions I did not ask children anything when they told me their stories using the map. For the rest of the sessions I started to ask follow up questions throughout the research session. At the beginning I was unsure about the right timing of questions. But as I got comfortable l learned when I should pose questions. Once the primary stage- tracing their journey on a map- was completed we proceeded to the second stage-drawing. I introduced the activity by asking them whether they preferred crayons or markers. Then, I presented them with all the materials and explained to them that they could use the paper in any way they wished. I gave them examples of what other children had done with their boards. I told them that I would draw as well and at the end we would talk about our drawings. I told them that we were going to draw about something that they remembered, liked, missed or was important to 
them about moving from one country to another. Most children started drawing right away but there were a few that did not know what to draw. So, I asked them if they would rather write and provided them with the writing materials. This entails observation and flexibility. I observed that they stared at the paper and then I was flexible in terms of the session structure to give them the option of writing instead. This proved to be productive because it accommodated the needs and interests of the child and not of the researcher or project. In this way, the child could do the 'easiest' (most comfortable) activity first and better express him/herself. Furthermore, I noticed that quiet children were more committed to their drawings while talkative children were less detailed at drawing.

While we drew I asked them questions about what they had told me so far. I also wrote notes on my notebook while they were busy drawing or writing. If they were talking and said something interesting or something that needed a follow up question I made short handwritten note of it in my book. Some children were able to converse with me while drawing but others preferred to focus on simply drawing. If they were talkative, I continued with the conversation, if not I stopped. We talked about a range of things such as my career, their goals, favourite colours, grandmothers, school and weather. Some children took longer than others because they were very detailed. I took as long as they took drawing so that they would get all the time they needed. I also told them to let me know when they were finished so that we would both end at the same time without having to wait on the other. For those who took longer, I did not stop them because perhaps they needed time to process their memories or they needed time to illustrate exactly what they wanted to convey. A lot of the children would ask me to check their work to make sure they were on the right track. This attitude is consistent with children's habit of being supervised and receiving feedback from adults on how to do their assignments. However, I reminded them that they were free to decide what they wanted to draw, how they wanted to do it and what they wanted to use as materials.

Once we had completed our drawings I would ask them to decide if they wanted to present first or last. Most children told me to go first. During my explanation, I flipped my drawing so that it would face them and be lifted up from the table so that they would see it. I told them what my drawing meant and let them know that if they had any questions they could 
just ask. They asked about colours, my feelings, objects I drew and school settings. Then, I would invite them to tell me about their drawing. If they were quiet children I held my questions for the end, but if they were outgoing I asked them questions during their presentation. Talkative children could answer a question and then continue with the explanation, but shy children tended to just answer the question and stop talking. In order to not interrupt children I waited for them to finish what they were saying or just wait until the end to ask the rest of the questions. During their expositions I expressed interest by moving my eyes across the drawing as they explained it and by uttering affirmative sounds that gave them the message that I wanted to know more. Also, I did not look at them as much as I looked at the drawing because if they were to feel on the spot or nervous their explanations tended to be shorter and less detailed.

After the presentations, we would take a break. We would eat snacks or drink something provided by their mothers and they would go to the washroom if needed. After a 1015 minute break, I introduced the writing activity. I gave them four notebooks and a lot of pens and pencils and told them to choose whatever they liked. I explained to them that we were going to write about either our drawings or about something that was important, that they remembered or something new that had not been shared before. I also selected a notebook and a pen and told them that they could give their stories a title as well. Most children asked me what language they should use and I told them to use the language they felt most comfortable with. While we wrote together I also discretely took notes on my other notebook meant for recording observations. I noticed that some children would compare how much they had written with how much I had written. Hence, I told them not to worry about length as long as they were satisfied with their narratives. Some asked me how to spell words and I helped them while few others wrote in a combination of the two languages. I also told them to let me know when they were finished. When they were done I asked them if they wanted to present first or last and that they could either read the story or explain it. A lot of children also asked me if I wanted to hear the story in English or Spanish and I told them that it was their choice. When I presented I let them know that if they had any questions they were free to ask. Some asked me what happened next or about the reasoning for a certain event described in my story. 
When I explained my story I highlighted any commonality that existed between their experiences and mine. I also asked questions at the end of their presentations to obtain further information and clarification or to encourage them to provide me more details about something they had not expanded on.

After completing the writing activity, I asked them what they had enjoyed the most. Then, I told them I had to interview more children and I wanted to hear their input in terms of what they wish I had done differently. I asked them if they would make any changes to the activities or the questions and if they would like me to add or change something. After receiving their feedback I told them to pick the name they wanted me to use in the written report so that their identities can be protected. Though some selected anglicized names, most children simply suggested the names they find appealing in general. Then, I gave them a gift bag and thanked them for talking with me. Children took their gifts somewhere else and opened them while I spoke with their parents. However, a lot of kids returned and looked at me to wait for a chance to speak with me again. Therefore, l looked at them and smiled, giving them the cue that 1 could talk to them too, not just the parents. At that moment, some children said to me: "que te vaya muy bien en tu proyecto/ hope that your project goes really well" or "mucha suerte/ lots of luck" or "gracias por dejarme participar/ thank you for letting me participate". As a response I said again to those children: "thank you for your help". Then the children and I kept talking about mundane topics such as drawing, pets, sore throats, and future goals.

The research design for this study required two key qualities-observation and adaptability. Observation was needed because I had to be well aware of the child's personality, preferences, body language, verbal responses, comfort level, and surroundings. From the start of every research session I paid close attention to the way the child acted in order to find out how to make them comfortable and how to make myself approachable. Once I became familiar with the child's personality I remained observant for any cues that would signal their boredom, tiredness or excitement. If I noticed that they were getting uncomfortable or anxious-looking away, fiddling with objects, moving too much-I changed the activities, introduced a new topic or stopped the session. Moreover, knowing what the child enjoyed and disliked shaped the way I conducted the interview because I would allot more time to a certain activity or provide a 
particular child with more detailed instructions or emphasize a specific personal experience that they would relate to. In other words, I personalized the interview in order to meet and suit the needs and styles of each child. Personalizing the interview is crucial or else the child will lose interest in the interview and choose to share less about themselves. Being attentive only functioned as long as I was flexible enough to adapt the interview to make the aforementioned changes. I had to adapt the interview to each child but also I had to adapt myself to better connect with the child. Connecting with the children meant that with some I joked and with others I was more serious, with some I talked strictly about the interview topics and with others I talked about other subjects, with some I included more questions and with others I shared more about my own experiences.

Also my undivided attention was required because I learned about the areas the child wanted to share and I could detect how they were feeling in case they felt sad and did not express it verbally as an adult participant might ${ }^{4}$. However, I discovered that children could also verbally let the researcher know how they feel. When I interviewed Sebastian he said that when he thinks of Ecuador his "mente esta muy triste como ahorita/ mind is too sad like now". As soon as I heard "like now" I started talking about snow in Canada and how he liked it. Then, he told me a funny story about the first time he saw snow. In other instances children told me about the difficulties they experienced due to not knowing English or moving from city to city. At those points I tried to highlight a positive aspect such as becoming bilingual and being able to make friends in different places.

I found that speaking both languages, sharing the same cultural background and having the same migratory histories enabled me to quickly establish rapport with each child. As a result, they were able to trust me and find interest in the research they participated in. Lastly, it is of paramount importance to be genuinely interested in children and in hearing their voices. I realized that children perceived my enthusiasm and motivation in meeting with them to tell our

\footnotetext{
${ }^{4}$ I realized that I felt exhausted after completing the research sessions. I attributed my fatigue to the degree of alertness and quick reflexes that were demanded of me. I could not overlook important information, cues, and details and I had to take care of the children, write notes, observe their actions, direct the discussion, respond to their questions while drawing and writing with them. Fortunately, 1 became tired after finishing the research session, so it did not interfere with the interview.
} 
stories. The methodology described above was found to be suitable for this study's research questions, which include what children themselves experience as immigrants, how they feel throughout those experiences, what interpretations they assign to those experiences and what the implications on professional practice are. 


\section{Research Session Location}

Most of the interviews I conducted took place in the participants' homes. Parents found it convenient for me to go to their homes because they did not have to drive or to wait in the library. In the library parents were a little impatient because they had nothing do while they waited. But at home parents could continue with their daily tasks and that way the session was not rushed. It is also easier for them because most parents had younger children and it would be difficult to transport all the children to the library. I also noticed that children felt more comfortable and were more expressive when they were at home. It could be possible that children relate the library to a school environment where they are supposed to behave and obey. They also may have seen me as more of a 'total stranger' because I was not allowed to come into their home. By visiting their homes, I may have been perceived as more of a trusted family friend. Where the library proved to be better was in the fact that it was silent, private and void of distractions.

In their homes, younger siblings or younger cousins were more likely to interrupt the session when they got curious about the interview. Siblings wanted to know what we were doing and wanted to draw and write with us. For that reason, I realized that I needed to bring extra materials to entertain the younger children, preferably at a distance. This is something that researchers should be aware of and anticipate when conducting interviews in children's homes. Parents can also be a distraction for children by either listening to the children's responses or by intruding with their comments. When parents asked me to come to their homes, I made it clear that I needed privacy and silence. Most of them tried to meet those requirements by going into a separate part of the home with the rest of the children until the session was completed. However, this was not possible in every case because many families lived in small apartments and it would be impossible to stay in one room and not go to the kitchen or the bathroom. Therefore, from time to time during the research session parents or younger children would walk by.

If I saw that children were distracted I carefully redirected their attention to whatever we were doing. I would talk for a bit with the younger children and tell them that I would draw and write with them later. Then, they would go away and I continued the session. I also realized 
that it was important to be patient with younger siblings to avoid making participants feel embarrassed by their siblings' actions. Also, it needs to be taken into consideration that many Latin American families share individual experiences as a group. Hence, though I was interviewing one child, I was not just dealing with that child, I was also expected to interact with the whole family unit.

The home environment allowed the child to be more confident and talkative, and also promoted bond building between the child and me. For example, children showed me a variety of objects that helped me to further understand their stories. Steven showed me his drawing collection and the cage of the bird he used to have but which died. James showed me his aunt's car because he wanted me to know what was his favourite colour. However, this also demonstrated the close relationships that exist between these children and their extended families. Sometimes, the objects they showed me also helped me to start conversations and prompted questions. Coni did not talk a lot during the research session but he let me read a story he wrote for a book published by his school. The book was a compilation of students' writings and drawings on their places of origin. After reading Coni's story I was able to formulate new questions that resulted in more detailed answers about his immigration experiences. Daniela showed me a painting she created with her dad using caulking of different colours. By seeing this painting I not only learnt that Daniela's dad works in construction, but that he plays with her every day after work. They do a lot of activities together and invent their own word games and exercise routines such as racing up and down the stairs. In a library 1 would not have had the chance to see children's creations or the belongings they value. At their homes I was also able to observe family relations. For example, I noticed that Daniela had a close relationship with her dad. He kissed her forehead when he arrived from work and played the word game with her. I also paid attention to the type of comments parents made to children and the way siblings interacted. Moreover, in their homes parents conversed with me and told me about their views on their migration experiences, which in some cases explained the child's attitude towards his/her own experiences. I benefitted from witnessing how each child lives, which expanded my understanding of his/her life. For example, I noticed that there was a correlation between James' extended family presence and his emotional state. In 
comparison to the other children James did not identify issues of nostalgia or grief. Hence, I concluded that the regular visits by his extended family contributed to his wellbeing. In-home interviews also gave the child and me time to talk after the interview. Even after thanking them and telling them that we were done, some children would stay where we conducted the interview to chat with me about new subjects or about my project. Their interest in talking with me helped me to realize that we had built a kind of rapport or that at least they enjoyed sharing their stories.

Lastly, it is important to highlight that in those cases where children were asked about their preference for study location, they all chose to stay at home. Though in-home interviews present more distractions, they also present more opportunities for rapport-building and for gaining information about a child. In a short amount of time I gathered at lot of data and a better comprehension of the child's story. 


\section{Demographics}

The children who participated in the study included five girls and five boys-five were from Colombia, two from Venezuela, one from Ecuador, one from Bolivia and one from Mexico. Two children were nine years old, five were ten years old and three were 11 years old. The minimum amount of time the children had resided in Canada was one year and the maximum was five years. Four children had lived in the U.S. for a period of time ranging from days to years, and the rest arrived in Canada directly from their country of origin. They all came to Canada with their families under a variety of immigrant classes- economic, family and refugee. Only one child had come with her/his mother because she was divorced. All children who participated in this study have been given pseudonyms to protect their identity and respect their privacy.

The sample size, as Bryman et al (2009) explain, was affected by factors of time and cost. Nonetheless, ten children were recruited instead of a smaller sample because it "increases the precision of the estimates derived from it" (Bryman et al p.194). Snowball sampling was utilized in this study where the researcher makes initial contact with a few people who meet the criteria for participation and through them the researcher establishes contact with others (Bryman et al. 2009 p. 198). Therefore, a non-probability sample was formed because some units in the population were more likely to be selected than others (ibid. p. 187)- namely those within the social networks of the first group that was contacted. 


\section{Children's Profiles}

This study sought to provide children with the medium to voice their individual stories in the making. Ten recent immigrant children from Latin American countries between the ages of nine and eleven talked to me about their families left behind, their school fears, their uncertainty, their career aspirations, their difficulties in learning English, their goals, their transitions and their achievements. Another purpose of this study was to learn about the needs, challenges, and emotions of immigrant children so that researchers, policy makers, school personnel and parents can offer children aid and support. In this manner, changes or improvements can be made to properly meet the gaps and needs identified by immigrant children themselves.

The following profiles present a synopsis of each child's story. I decided to dedicate a whole paragraph explaining the situation of each child because I do not want to present children as merely data sources, but as agents with unique life stories. It should be acknowledged, however, that a research session of one-and-half or two hours is not enough to wholly grasp the experience of each child. Profiles are organized in the order in which the interviews were conducted. The phrases in quotation marks signify the children's verbal comments and the phrases in italics and without quotation marks represent their written comments. Their written texts may contain spelling mistakes because I have preserved the child's original writing. Here are their historias:

\section{Casa desastre (disaster house)}

Cheryl is a ten-year-old girl from Venezuela who has lived in Canada for almost three years. She used the phrase "casa desastre" to describe the last night before leaving Venezuela. She also drew her family-cousins, uncles, aunts, siblings, mother-packing their luggage at her grandmother's house. Cheryl explains that the house was a disaster because it was a mess while they packed. Getting everything ready made Cheryl and her younger sister really tired. On the drawing depicting a waiting room at the airport, Cheryl draws her sister with "zzz" on top of her head and she writes "yawn" beside her own face. On the drawing of the Air Canada airplane, a speech bubble comes out of a window, which reads yeay. This yeay, according to Cheryl, signifies that she can finally rest and fall asleep. In her story she writes, nosotros 
tuvimos que esperar mucho para el avion que mi hermana se quedo dormida/ we had to wait so long for the airplane that my sister fell asleep. Hence, children like adults, also feel the stress and anxiety of moving from one country to another. The experience of packing, of saying goodbye and of traveling proved to be exhausting for Cheryl. Nonetheless, she was happy to be reunited with her father who was already in Canada. He picked them up at the airport and took them out for breakfast. She writes that when they were done eating mi papá nos llevo a conocer [Oakville] a mi me gusto mucho conocer Oakville/my dad took us to get to know [Oakville]; I liked it a lot, getting to know Oakville.

Siempre preguntas en mi cabeza (always questions in my head)

Sebastian is a nine-year-old boy from Ecuador who has been living in Canada for five years. It seems as if Sebastian has been thinking a lot about his migration experience. When given the piece of Bristol board, Sebastian was the only child to use both sides of the board. During the interview he responded quickly, knowing exactly what he wanted to say. Though he knows his story very well, his narration is filled with uncertainty and doubt. He says: "no sé qué voy a hacer en el futuro. Siempre hay preguntas en mi cabeza, siempre/I don't know what I'm going to do in the future. There are always questions in my head, always". He adds that when he grows up, "creo que voy a regresar al Ecuador/I think l'm going to return to Ecuador". He is constantly wondering about whether he will go back to Ecuador. In his drawing, even on his way to Canada, he looked out the airplane window counting how many kilometres he was away from Ecuador. When Sebastian deals with these questions he feels sad, and according to him, moving to Canada was not a good decision by his parents. However, he explains that he would be happy if his family could live with him in Canada. He seems to be having a hard time adjusting to living away from his extended family and wishes to go back in order to be with them. Sebastian's narrative and drawing both end with a sense of hopelessness and disorientation. He concludes his story with resignation, so now here I am living life, and finishes his drawing with a boy sitting on the floor, raising his eyebrows, shrugging his shoulders and with a thought bubble containing an airplane. 
Cosas graciosas en Canada (funny things in Canada)

Steven is a ten-year-old-boy from Colombia who came to Canada two years ago. He used the word "graciosas/funny" numerous times during the interview. Steven's parents warned me before the session that adjusting to Canada had been difficult for Steven and that he had seen a counselor and a psychologist. Ironically, Steven described his migration story as a funny experience where he had witnessed many cosas graciosas. He indicated that the leaf on the Canadian flag is identical to the leaves on trees and that in Canada, dogs get married and horses wear jackets. On the map he drew of the Americas, he added a happy face beside the city where he currently lives. Steven also talked a lot about animals. His favourite memory of Canada is going to the zoo, but he does not like how expensive dogs are in this country. In Colombia, he had two sharks but was not able to buy a dog. Sometimes, he misses his family and his bird. He says his grandmothers "eran las que más me querian/ were the ones that loved me the most". Also, he recounts how he used to ask his bird: "¿Usted me quiere? Y el movia la cabeza que si/ do you love me? And he would move his head as if saying yes". At first sight, it seems as if Steven was only focused on funny or lighthearted topics; however, he was well aware of a child's struggles with migration. He suggested to me that I should ask children how they feel in Canada in order to know "si ellos están felices, tristes/ if they're happy, sad". He told me that it is "importante/important" to know their feelings in order to understand "la historia de cómo vinieron aquil/ the story of how they came here".

\section{Will They Be Litterbugs}

James is a ten-year-old boy from Bolivia who came to Canada four and a half years ago. In his narrative and the interview James shares his justification for coming to Canada and his preconceptions of this new place. He writes that when his parents told him they were moving to Canada, he was so worried about the citizens. He wondered if they would be nice and if they care about the envirement, will they be litterbugs. James had many stories about his country's insecurity. His family was involved in a car accident, a house robbery and a kidnapping attempt. James states "the point we moved from Bolivia to Canada is because of the robberies and all the dangers". In his drawing, he painted his dad sleeping on the plane and having a dream. 
Inside his dad's dream bubble there is a man running free in a field. James says his dad is "running in flowers and jumping for joy and having fun. In Bolivia there were a lot of stealing and stuff like that". In his drawing of the plane, James also has a thought bubble over his head which reads: "are the citizens nice". However, Canadians were not the only thing James was curious about. In Bolivia he also imagined what the weather would be like in Canada. He thought that maybe there is snow and summer in Canada. And, he was "curious cuz I wanted to know if [snow] was cold or freezing, hard or soft". James also likes when his grandmother visits him in Canada. He said, "I tell her some jokes, she will play with me sometimes. It gives me company".

Me sentía triste (I used to feel sad)

Isabel is an 11-year-old girl from Colombia who has been living in Canada for one year. At the beginning she felt "triste/ sad" and "mal/ bad" and wanted to go back to Colombia. She felt sad because a girl mocked her, she missed her grandmother, she did not understand English and she was not assigned any math homework. Isabel wanted to be able to do "lo que todo el mundo estaba haciendo/ what everyone was doing". She wanted to do math exercises but she was only given easy homework because she could not speak the language. She also felt "triste porque en la office había una señora que no me dejaba entrar a la escuela. No sé por qué nos ponian muchas trabas/ sad because in the office there was this lady who did not let me register in school. I don't know why we were given so much trouble". Isabel explains that she cried when the other kids were mean to her and one day, she cried in school "porque extrañaba a Colombia, por mi abuelita, por mi familia/ because I missed Colombia, my grandmother, my family". Nonetheless, Isabel received help from another Spanish-speaking girl and in exchange she helped the girl with math. She started to feel happy when she received math homework and when her sister was born. She says "me sentía feliz por mi hermanita porque venía y podia jugar con ella/ I felt happy because of my sister because I would come and I could play with her". 


\section{I was Ready and Could Speak English!}

Jessica is a ten-year-old girl born in Colombia who arrived in Canada four and a half years ago. Jessica, like many of the other children I interviewed, lived in several cities and attended multiple schools. Each time she started in a new school Jessica worried about making new friends- "I felt nervous because you never know what's going to happen". She says she felt "triste porque yo estaba un poquito aburrida asi de estar sola entonces yo quería amiguitas/ sad because I was a little bored like that being alone so I wanted to make friends". She was preoccupied because she did not know what to say and she was scared that if she said something wrong the other girls would laugh at her. At the beginning her cousin introduced her to some friends but when she moved to another school she had to find her own friends. Although she wanted to make friends, she could not approach them because she could not communicate with them. Hence, Jessica wanted to learn to speak and write English so that she could understand her peers. In her story she wrote: after 9 months in school I was ready and could speak English! Jessica was finally ready to communicate with other children and she was very excited about it. Her use of several exclamation marks in her story and drawing reveal her desire to speak up. Jessica finishes her drawing with a close-up of her face and those of two other girls to whom she is talking. In the picture, Jessica seems happy to be able to utter the words: "Hello, my name is Jessica!"

Yo desidy jugar futboll con mis amigos (I decided to play soccer with my friends) Coni is an 11-year-old boy from Colombia who has been in Canada for one year. Coni shared with me his memories of all the games he used to play with his friends. He also talked about the games he plays in Canada with his new friends. Though Coni did not volunteer any answers, when it came to games he would give a long description about the games he invented and how he played them. Fortunately, on his first day of school in Canada, other children approached him, greeted him and invited him to play with them. On his drawing he drew himself with a smile on his face while playing soccer with another smiling boy. In other words, it seems as if the transition for Coni was comforting since he could do what he used to do in his home country. He felt welcomed in school because he was allowed to play his favourite sport with the 
other children. Moreover, his friends taught him how to "comportarse/behave" in the classroom and advised him on what to take to school for lunch. He explains, "aqui comen más sándwich, en Colombia comen más cosas diferentes/ here they eat more sandwich, in Colombia they eat more different things". He also remembers the trips in Colombia when he used to go with the whole family to the beach and country house and all the things they used to do such as playing soccer with his uncle and swimming in a pool at night with his cousins. Coni wishes his grandparents would come to Canada so that he could play in the snow with them. He misses them a lot because "casi toda la vida vivimos con ellos/ almost all my life we lived with them".

\section{They said yes, and YESS!!!!}

Daniela is an 11-year-old girl who was born in Colombia and has been in Canada for three years. Before coming to Canada she lived in Miami for three years. Her migration story can be summarized in one word: YES. These three letters are full of meaning for Daniela because they refer to the refugee board's acceptance of her family's case. When Daniela heard the good news she "hugged the person [judge]" and said "thank you!". She says she woke up at 6:00 a.m. the morning before the hearing and she was "crying and stuff, I was praying and stuff". In her story she writes we came to Canada and the goverment sayd yes!!! And I was so so happy sater to cry!!! :) When she explained her written narrative to me she added that she was crying "of happiness because I was young and I'm like I, I understood". Her annotation deserves to be highlighted because it clearly depicts that a child is capable and does understand the importance and the magnitude of decisions made by immigration officials. Another decisive point in Daniela's life was the day her family was rejected by US immigration. She even calls it "a bad day". She writes, there was a bad day because they sayd NO the goverment. From an early age, Daniela was well aware of the great impact immigration laws have on her life. Interestingly, Daniela values the "yes" and explains that the "yes" was important for her because she "understood that I could finally go to my family". When she recently migrated she thought she "was never gonna see them again and I was like 'oh my God' and I started crying every night". The family member she misses the most is her grandmother. During the interview Daniela spent a lot of time talking about her grandmother and was very keen on showing me 
pictures of her. She says her grandmother "loves me more than everybody" and she wants to reunite with her because "grandmas like they're experienced so whatever they make, you love $i t^{\prime \prime}$.

\section{I wonder where my new home will be}

Anthony is a ten-year old boy from Venezuela who arrived in Canada five years ago. The theme of his drawing and his narrative is "moving". His story is titled Moving to Canada, and he uses the word "moved" twice in the story. During the interview he talked about "mudarse/ moving" to new schools and apartments. He not only moved from one country to another but changed schools, houses and cities several times within the last five years. His drawing is divided in three sections, representing the three different moves he has made in Canada. In the second section he writes inside a speech bubble, I wonder where my new home will be, and in the third section he writes in another speech bubble, so is this my $3^{\text {rd }}$ school?? It is evident that Anthony has many questions and feels unstable because he is uncertain about whether he will have to move again. The multiple transitions in his life keep him wondering about where his next house and school will be. Anthony says the most important aspect of his drawing is "mudándome a nueva casa y a otras casas/ moving to a new house and to other houses". The phrase "I moved again" in his written narrative illustrates the repetition and exhaustion of "mudarse". It is stressful for him because he has to make new friends and he is shy. In the first section of his drawing, a boy standing in front of a school thinks to himself I'm shy. His shyness makes him nervous every time he starts a new school and when he did not speak English, the only friends he had were those in Venezuela. He concludes that he dislikes moving because "algunos amigos no los veo más/ some friends I don't see anymore", but likes it because "hago nuevos amigos/I make new friends".

Después me fue mejor que antes (after I did better than before)

Candice is a nine-year-old girl from Mexico who has lived in Canada for two and a half years. She used the word "mejor/ better" multiple times during the interview in her story and drawing. She frames her story in terms of betterment. In her drawing she clearly illustrates how 
she progressed from a rough start to a bright present. She organized her drawing by year. In the 2008 scene, she writes primero me senti mal y triste/ first I felt bad and sad because she did not know how to play basketball and the other kids did know. In her 2010 scene she writes después me fue mejor que antes/after / did better than before. She did better because she could speak English and was able to make friends. This scene shows that Candice has learnt to do what the other kids do- speak English. Candice says she likes her second school better because her language classes are more advanced so she can learn more. However, she is also worried because "ya que sé el inglés, no puedo escribir bien el español/ now that I know English, I can't write well in Spanish". Candice has decided to practice her Spanish writing skills by sending emails to her "primas y primos en español/ cousins in Spanish". She adds that it is important not to forget Spanish because she wants to "comunicarme bien con mis papás y mis hermanos/ communicate well with my parents and my brothers". Candice, like the rest of the children, also misses her "tita/grandma" because she used to tell her stories, eat with her and go out. Nonetheless, Candice states in her written narrative that she has a better life than in Mexico and that she likes Canada much much much much much BETTER because she has more opportunities and a better education. 


\section{Findings}

I identified four main themes and two sub-themes. The main themes include absence of grandparents in children's lives after emigration, family mobility (across countries and within countries), children's preoccupations with school and language, and cultural brokering among peers.

The most recurring and pronounced theme in the research sessions was the place and role of grandparents in the children's lives, with particular emphasis on grandmothers. The ten children discussed their extended families and grandparents, but eight of them delved in great detail about their relationships with their grandparents. It was unexpected to hear child after child talk about how much they miss their grandmothers and how much their grandmothers cared for them. Another recurring theme was moves and transitions across borders and within cities. All the children talked about their move from another country, but many also experienced a number of moves and transitions once in Canada, moving between cities, moving from house to house within cities, and frequently changing schools. Those who were highly mobile expressed their anxiety and instability about moving from place to place. School and language were also very important topics for these children because they had many worries regarding their reception by peers and language barriers. Lastly, children shared their cultural brokering experiences and the way they benefitted from them. When they started school it was common for them to receive translation and interpretation assistance from their classmates and eventually they ended up doing the same for other immigrant children who came after them.

The last two findings are based on two aspects that I think should be highlighted. Though the children were immigrants, they did not only talk about immigration-related subjects, they also expressed their aspirations and career goals. This is important because it acknowledges that these children are complex and that they should not be framed only in terms of their struggles as immigrants. The other observation relates to children's feelings. They repeatedly discussed their sadness, anxiety, fear, boredom, happiness and hope. It is paramount to pay attention to their emotions because I realized that that is how they measure and describe their settlement success. The phrases in quotation marks signify the children's 
verbal comments and the phrases in italics and without quotation marks represent their written comments. Their written texts may contain spelling mistakes because I have preserved the child's original writing.

\section{Grandparents- Porque los perdi (because I lost them)}

Coni's simple and striking phrase-- "porque los perdi" (because I lost them)-summarizes the experience of children who lose their grandparents. In three words he was able to convey a poignant message. Perder (to lose) implies that he can no longer have what he once did. Eight out of ten children expressed that they greatly miss their grandparents, especially their grandmothers. They also wish their grandparents could come to Canada to visit or live with them. Many used to live in intergenerational homes before coming to Canada so they are accustomed to growing up with their grandmothers. Their grandmothers played a crucial role in their lives: they cooked for them, they played with them, they told them stories, they spoiled them, they took care of them, but most importantly they loved them immensely.

The following paragraphs contain a collage of the descriptions given by the children on the relationships they had with their grandmothers and on the activities they used to do together. Isabel explained that her grandmother "me cuidaba, me consentía, me daba lo que yo queria, me sacaba a pasear. Me hacia mi desayuno preferido/ took care of me, pampered me, gave me all I wanted, took me out on trips. She made me my favourite breakfast". Coni said that his grandparents lived with him almost all of his life and they "siempre me cuidaban mucho/ always took so much care of me". Even when they did not live in the same city, Coni would visit and "siempre me quedaba con mis abuelitos y a veces ibamos a la finca/ always stayed over at my grandparents' and sometimes we went to the country house". Candice said her grandmother "siempre vivía con nosotros...saliamos. Me contaba historias, comíamos. Ella a veces nos daba de comer/ always lived with me...we would go out. She told me stories, we ate together. She sometimes gave me things to eat". Candice still remembers how her brothers and she used to shout: "ia comer, tita!/ come eat, grandma!".

James says he enjoys his grandmother's visits to Canada because she "is really fun. I tell her some jokes, she will play with me sometimes. It gives me company". Moreover, he watches 
movies with her and she would "always give me something to drink when I was thirsty. I would ask her and she would give it to me. The same with my other grandma". Cheryl remembers staying at her grandmother's house where her aunts, uncles and cousins helped her pack the night before the flight. Steven said that his grandmothers "eran las que más me querian. Me mimaban. Me hacian comida. Ellas me querian mucho/ were the ones who loved me the most. They pampered me. They cooked for me. They loved me a lot". Daniela also used to have a close relationship with her grandmother. She described her grandmother as a vibrant lady, full of energy and "a funny grandma which I love". Daniela added that grandmothers are "experienced so whatever they make, you love it...somehow they have the magic touch". In Miami it was easier for her grandmother to visit her. She said that she "couldn't wait for summer because I will see my grandma and summer, summer, summer and it comes grandma!!! The whole summer I was so happy". According to Daniela, she is her grandmother's favourite because she is "far away from her" and her grandmother "loves me more than everybody".

The time children shared with their grandmothers leaves a huge gap in their lives. The separation causes children to feel sad and to miss their grandparents. In the same way that Coni's words communicate children's ioss, Sebastian's drawing illustrates the painful experience of leaving family behind. He drew a boy extending a hand to reach his family, looking back at them while his mother dragged him away (see Illustration 1). When he presented the drawing he said his mother was "tratando de cogerme, tratando de llevame porque yo estaba muy triste y no queria ir/ trying to grab me, trying to take me because I was very sad and did not want to leave". Once in the airplane he looked out the window "viendo cuántos kilómetros [estaba] del Ecuador/ to see how many kilometres I was from Ecuador". He added that he is confused because he is "pensando en el futuro. Creo que voy a irme al Ecuador otra vez/ thinking of the future. I believe I'm going to go to Ecuador again" since that is where his family lives. He says that if his "familia en Ecuador estaba en Canadá prefiero Canadá/ family in Ecuador were in Canada, I would prefer Canada". 


\section{Illustration 1}

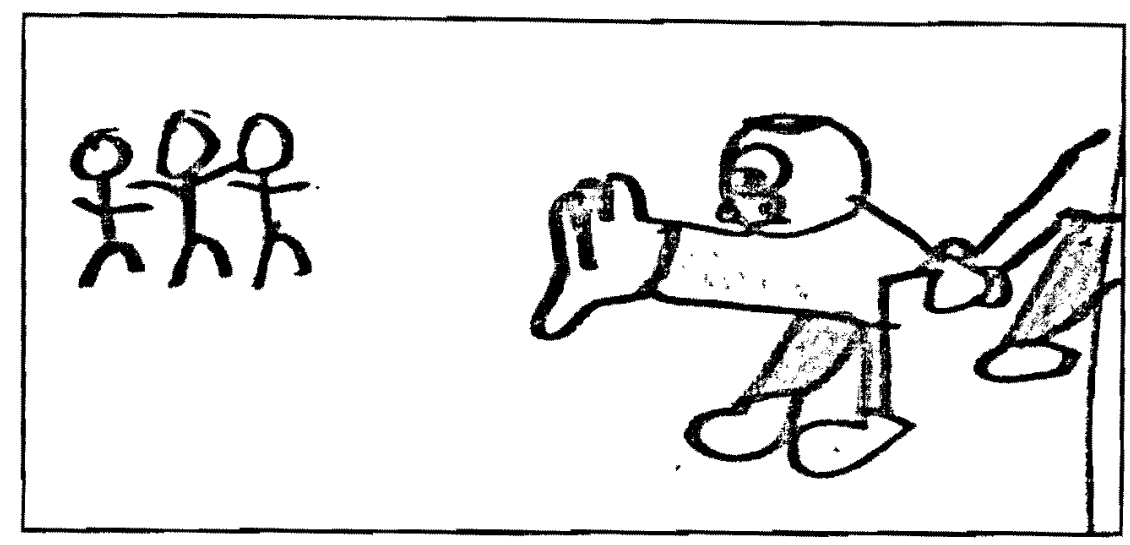

Coni and Steve both stated that who they miss the most are grandparents and grandmothers, respectively. Steve explained that at first he felt happy in Canada, but when he talked with his grandmother "Ia extrañé y entonces me senti triste/ I missed her and then I felt sad". Steve recommended that I ask children how they feel in order to know "si extrañan la familia, a alguien/ if they miss the family, somebody". He said he misses them a lot and that in Canada "a veces me siento aburrido/ sometimes I feel bored". Isabel said in Canada she used to feel "triste/ sad" and she wanted to return to Colombia because "extrañaba a mi abuelita/ I missed my grandmother". She narrated that one day in her school "me puse a llorar porque extrañaba...a mi abuelita, a mi familia/ I cried because I missed my grandmother, my family". Daniela dislikes hearing her friends talk about their grandmothers because she cannot spend time with her grandmother, like they do- "all my friends talk about how, like, having their grandma is cool and I, like, get sad". Also, she feels upset because she is not able to ask her grandmother, "Can you make me something?" Though her grandmother visited her in Miami, when Daniela asked her to visit her in Canada her grandmother told her: "I'm too tired to get the visa, I'm too old to get the visa, it's too cold there". When her grandmother gave her those excuses, Daniela lightheartedly expressed her disappointment by telling her: "I thought you were my grandma," nonetheless she sympathizes with her grandmother as she knows that "grandmas get cold easily".

The separation can also cause stress for children if and when their grandmothers' health deteriorates. For instance, Daniela explained that when her grandmother became sick she was very worried. When she was hospitalized, Daniela "was really scared because I was all the way 


\section{Illustration 1}
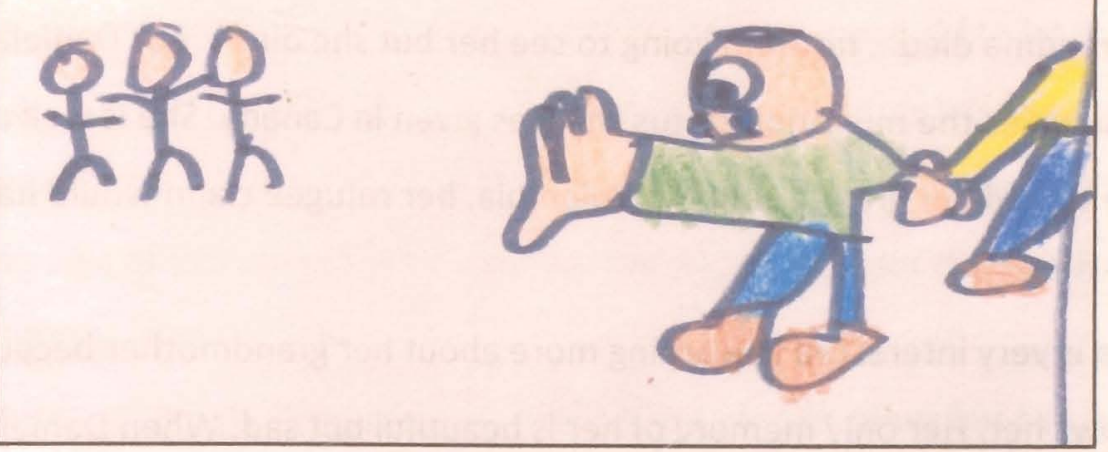

Coni and Steve both stated that who they miss the most are grandparents and grandmothers, respectively. Steve explained that at first he felt happy in Canada, but when he talked with his grandmother "la extrañé y entonces me sentí triste/ I missed her and then I felt sad". Steve recommended that I ask children how they feel in order to know "si extrañan la familia, a alguien/ if they miss the family, somebody". He said he misses them a lot and that in Canada " $a$ veces me siento aburrido/ sometimes I feel bored". Isabel said in Canada she used to feel "triste/ sad" and she wanted to return to Colombia because "extrañaba a mi abuelita/ I missed my grandmother". She narrated that one day in her school "me puse a llorar porque extrañaba...a mi abuelita, a mi familia/ I cried because I missed my grandmother, my family". Daniela dislikes hearing her friends talk about their grandmothers because she cannot spend time with her grandmother, like they do- "all my friends talk about how, like, having their grandma is cool and I, like, get sad". Also, she feels upset because she is not able to ask her grandmother, "Can you make me something?" Though her grandmother visited her in Miami, when Daniela asked her to visit her in Canada her grandmother told her: "I' $m$ too tired to get the visa, I'm too old to get the visa, it's too cold there". When her grandmother gave her those excuses, Daniela lightheartedly expressed her disappointment by telling her: "I thought you were my grandma," nonetheless she sympathizes with her grandmother as she knows that "grandmas get cold easily".

The separation can also cause stress for children if and when their grandmothers' health deteriorates. For instance, Daniela explained that when her grandmother became sick she was very worried. When she was hospitalized, Daniela "was really scared because I was all the way 
here in Canada and I can't do anything about it or I can't go because I will lose everything I gained here". And, even if she had gotten the opportunity to see her she would have said "'oh my God' my grandma died... now I'm going to see her but she dies". For Daniela "everything I gained here" signifies the migration status she was given in Canada. She is well aware of the fact that if she visited her grandmother in Colombia, her refugee claim would have been denied.

Daniela is very interested in learning more about her grandmother because she thinks she barely knows her. Her only memory of her is beautiful but sad. When Daniela was about to get into the taxi en route to the airport, her grandmother came out of the house and gave her a rosary and told her these words: "'está bendecida. It's for you to keep until we come back/you're blessed. It's for you to keep until we come back". She added that she remembers "her by [the rosary] everyday. Like everyday I wake up and it reminds me". Also, when Daniela was younger every night before she went to sleep she used to cry because "of all my family and cousins" and she "was freaking out" because she thought she was never going to see them again. When her family's refugee claim was accepted she was content to be able to return in order to "meet my family and hug them". In her drawing of Colombia, Daniela included a red heart to signify that that is where her family is (see lllustration 2).

\section{Illustration 2}

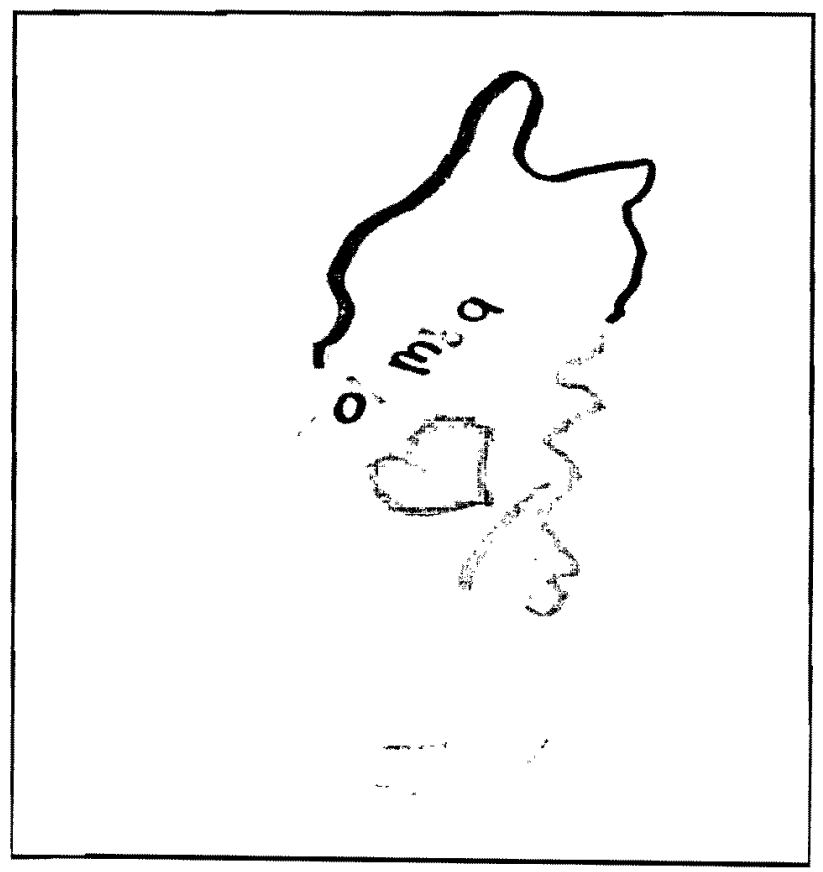


here in Canada and I can't do anything about it or I can't go because I will lose everything I gained here". And, even if she had gotten the opportunity to see her she would have said "oh my God' my grandma died... now I'm going to see her but she dies". For Daniela "everything I gained here" signifies the migration status she was given in Canada. She is well aware of the fact that if she visited her grandmother in Colombia, her refugee claim would have been denied.

Daniela is very interested in learning more about her grandmother because she thinks she barely knows her. Her only memory of her is beautiful but sad. When Daniela was about to get into the taxi en route to the airport, her grandmother came out of the house and gave her a rosary and told her these words: "'está bendecida. It's for you to keep until we come back/you're blessed. It's for you to keep until we come back". She added that she remembers "her by [the rosary] everyday. Like everyday I wake up and it reminds me". Also, when Daniela was younger every night before she went to sleep she used to cry because "of all my family and cousins" and she "was freaking out" because she thought she was never going to see them again. When her family's refugee claim was accepted she was content to be able to return in order to "meet my family and hug them". In her drawing of Colombia, Daniela included a red heart to signify that that is where her family is (see Illustration 2).

\section{Illustration 2}

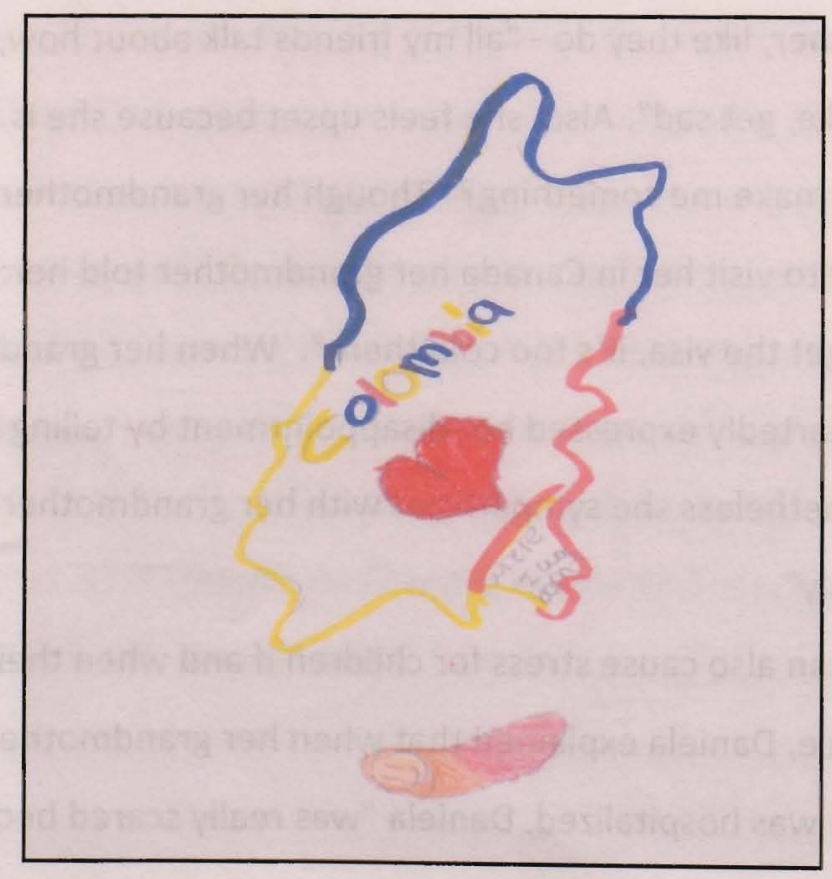


For those who are fortunate to see their grandmothers in Canada, there are also obstacles that must be overcome. James talked about instances when his grandparents were not allowed in Canada despite his uncle's effort to "do whatever he could to let them come in". The last time his grandmother came "she was really nervous" and after her interview was done she was "really worried because the woman [immigration officer] was really mad" but when "they called her to one of the immigration windows and then they said she was free to come here she was so happy" and so was James.

It is evident that the bond between grandchild and grandmother has the potential to affect the immigrant child to a great extent, both positively and negatively. In positive terms, children gain happiness when they have the opportunity to reunite with their grandmothers and even value their immigration status on the basis of being able to visit their families. In other words, the emotional impact caused by the children's separation from their grandmothers indirectly reveals how much they know and understand Canadian immigration policies. The aforementioned should be highlighted to inform adults that children do understand the immigration process thanks to their first-hand experiences. Moreover, children's treasured memories of their grandparents bring happiness to their daily lives. In negative terms, children can become sad, uncertain and bored when their grandparents and other relatives are absent. They can get so melancholic that they cry, feel powerless and desire to return home. They can also be consumed by longing and by a constant grief that reminds them of their loss and of the lost time they could have had with their grandparents.

Lastly, several of the children expressed that they communicate with their grandmothers over the phone, Skype and MSN. They also keep pictures of them on Facebook. They practice their Spanish every time they speak with them and also when they write e-mails to their cousins. Though sometimes they cannot communicate'verbally with their Spanishspeaking relatives, with grandmothers it is never a problem. Therefore, I would conclude that a constant exchange between these immigrant children and their grandmothers is a practice that also serves to preserve their mother tongue.

In sum, extended family and grandparents- especially grandmothers- are very important and dear to these children. In Daniela's case she even said that she could live without 
her mom and dad as long as she has "toda mi familia/ my whole family". La familia for these children is not just the mother and the father, but cousins, uncles, aunts and grandparents. The breaking of this extended unit, the absence of the support network, and losing various relationships are challenging obstacles for these children. Furthermore, they must adapt to the changes of their family composition- a process that proves to be emotionally charged for some.

Transitions- Me mudé de casa y me mudé a Canadá (I moved houses and I moved to Canada) This section's title- "Me mudé de casa y me mudé a Canadá" (I moved houses and I moved to Canada) -originated from Anthony's interview. In this short sentence, Anthony highlights the two topics to be covered in this section. There are two types of transitions or major moves that immigrant children experience-international and local. Children experienced international migrations and transitions in their move from one country to another, and local transitions when moving from one city or neighbourhood to another, once in Canada. It is common for research to assume that an immigrant child leaves the sending country to arrive in the receiving country, reinforcing a dichotomy of here and there. But beyond that, the ongoing mobility of immigrant children is generally overlooked. In their new country, children can move several times in a short span of time, complicating their adjustment.

In this study I found that four out of ten children lived in the U.S. for long or short periods of time before coming to Canada. Therefore, their migration stories are not simply about the dichotomy of "there" and "here". Some of their stories are about "there", "there" and "here". These multiple migrations add layers to children's stories and shape their perceptions of Canada based on their experiences in the U.S. For example, Isabel and Daniela were afraid to start school in Canada because in the U.S. they had experienced bullying. Isabel said her classmates in Houston were "mean" and for that reason she was worried about her first day of school in Mississauga. She was "preocupada por lo de los niños como, ¿qué tal que no me gusten?/ worried about the children because, what if I didn't like them?". Nonetheless, she was not made fun of, and that is why she likes Canada better. In Daniela's case the "popular" girl in her school in Miami ignored her so the rest of the classmates ignored her as well. The same girl also gossiped about her and made her feel uncomfortable. In the section of 
her drawing depicting the U.S., she drew a girl sitting in front of a school desk with a speech bubble that states: I'm not feeling to good (see lllustration 3).

Illustration 3

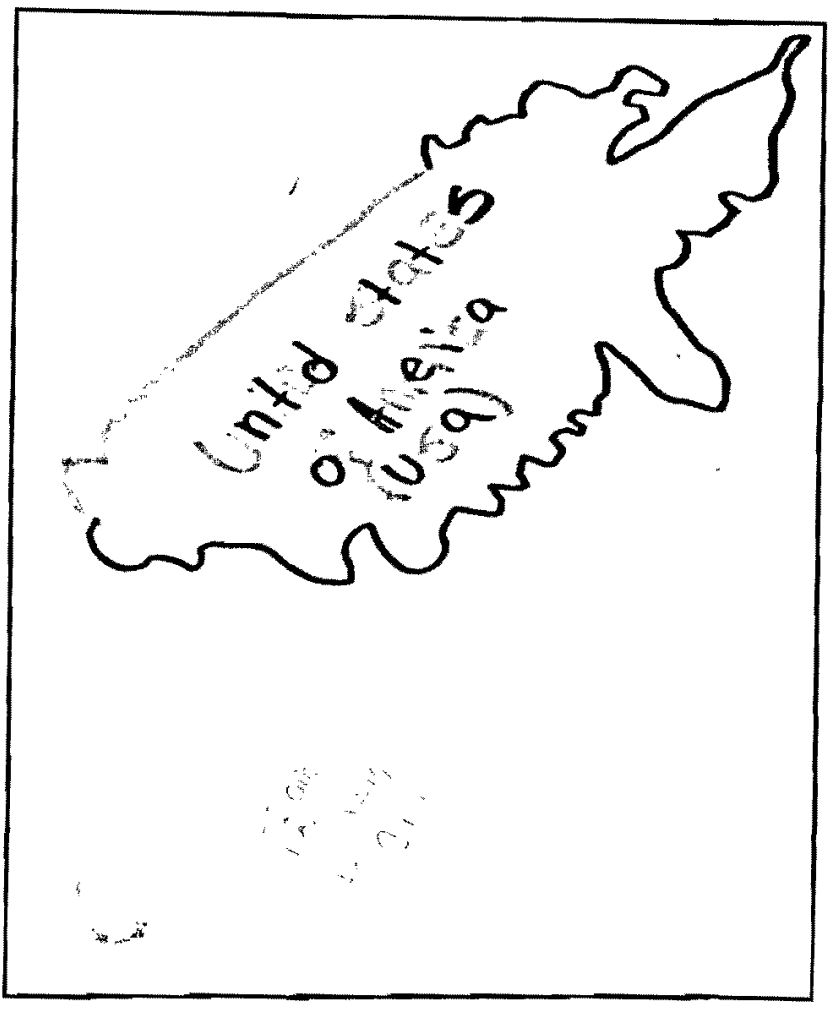

When children have lived in several countries their points of reference to make comparisons increase. For instance, Daniela compares Canada and the U.S., instead of comparing Canada and Colombia. She likes Canada better because "here's where they gave me everything. Like they gave me a yes, because in the U.S. they told me no, you can't get the visa". The journey from the U.S. to Canada also involves staying in different cities. The children usually stayed in Buffalo while Canada processed their refugee claims. Steve's travel map provides a version of a multi-layered trip (see Illustration 4). It is important to note that all the children who lived in the U.S. prior to moving to Canada were both born in Colombia and came to Canada as refugees. It is evident, then, that migration for these children was more complex than for those children who moved from point $A$ to point $B$, as they faced many changes by moving from one place to another. The issue of multiple migrations should be further researched to investigate how it affects children, how they cope with transitions, and how they differ from immigrant children who make direct trips. 
her drawing depicting the U.S., she drew a girl sitting in front of a school desk with a speech bubble that states: I'm not feeling to good (see Illustration 3).

\section{Illustration 3}

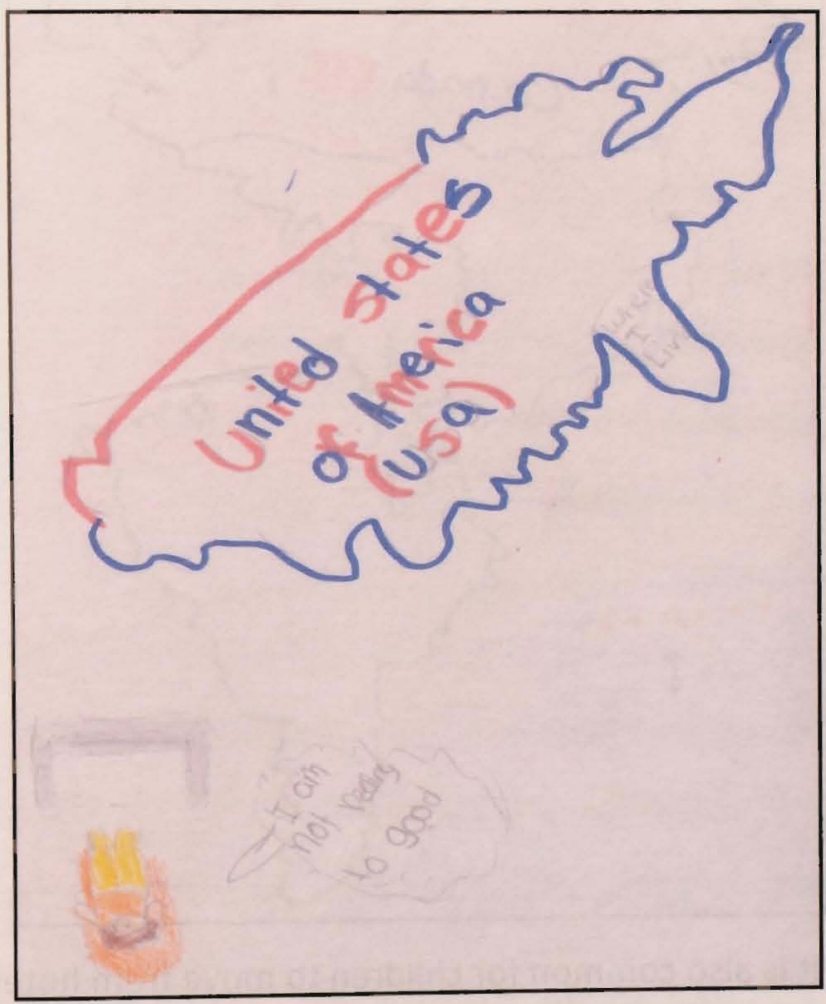

When children have lived in several countries their points of reference to make comparisons increase. For instance, Daniela compares Canada and the U.S., instead of comparing Canada and Colombia. She likes Canada better because "here's where they gave me everything. Like they gave me a yes, because in the U.S. they told me no, you can't get the visa". The journey from the U.S. to Canada also involves staying in different cities. The children usually stayed in Buffalo while Canada processed their refugee claims. Steve's travel map provides a version of a multi-layered trip (see Illustration 4). It is important to note that all the children who lived in the U.S. prior to moving to Canada were both born in Colombia and came to Canada as refugees. It is evident, then, that migration for these children was more complex than for those children who moved from point $A$ to point $B$, as they faced many changes by moving from one place to another. The issue of multiple migrations should be further researched to investigate how it affects children, how they cope with transitions, and how they differ from immigrant children who make direct trips. 


\section{Illustration 4}

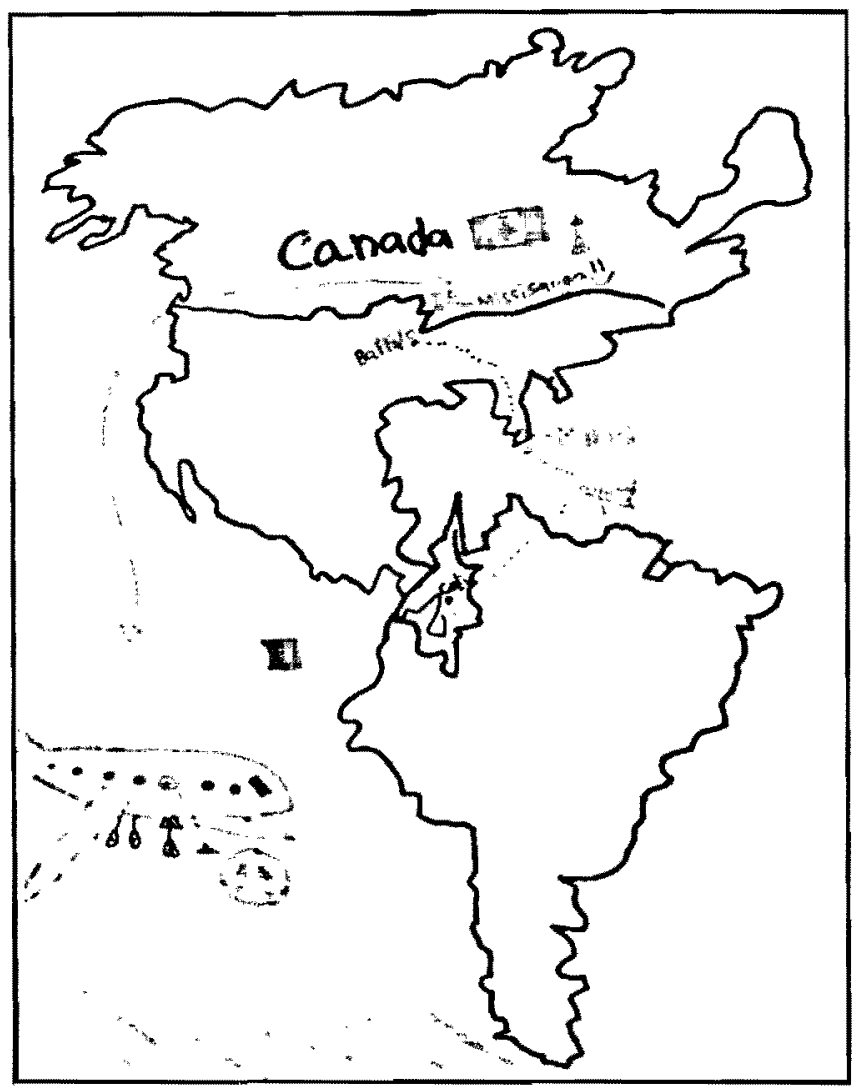

Once in Canada, it is also common for children to move from hotels to apartments to houses and from one school to another. Jessica moved from Colombia to Miami and then arrived in Canada, where she moved from Mississauga to St. Catharines to Milton. Every time she moves she worries about making friends because she does not want to be lonely. She said she was a little bored of being "sola entonces yo quería amiguitas pero no sabía qué decir/ lonely so I wanted friends but I didn't know what to say". Going to a new school is challenging for any child, however, the difficulty is amplified when the child is new to the country and does not speak the language. Jessica also felt nervous about moving to Canada because "no sabia muchas personas, no sabía si podía aprender inglés y comunicarse con las niñas/ I didn't know many people, I didn't know if I could learn English and communicate with the girls". When she changes cities she feels "kind of sad leaving the friends that I left behind, but I feel happy because I always make new friends in each school. But every first day of school I feel nervous because you never know what's going to happen". 


\section{Illustration 4}

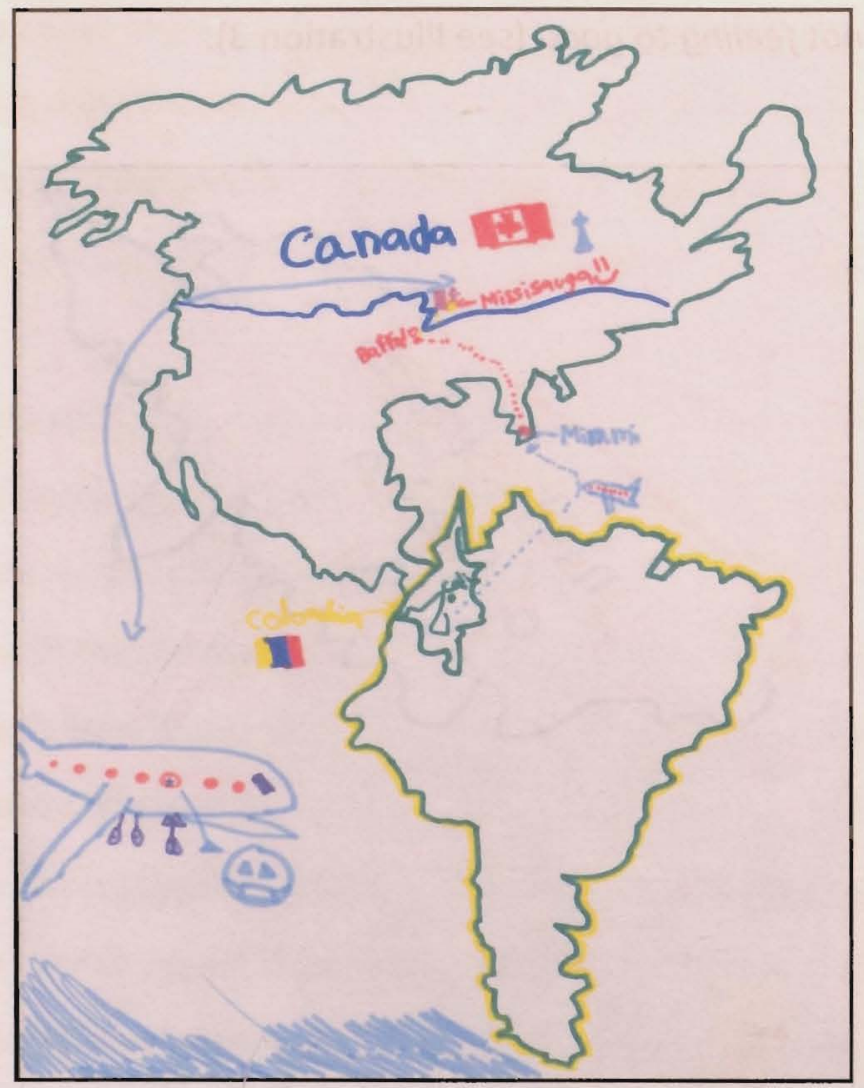

Once in Canada, it is also common for children to move from hotels to apartments to houses and from one school to another. Jessica moved from Colombia to Miami and then arrived in Canada, where she moved from Mississauga to St. Catharines to Milton. Every time she moves she worries about making friends because she does not want to be lonely. She said she was a little bored of being "sola entonces yo quería amiguitas pero no sabía qué decir/ lonely so I wanted friends but I didn't know what to say". Going to a new school is challenging for any child, however, the difficulty is amplified when the child is new to the country and does not speak the language. Jessica also felt nervous about moving to Canada because "no sabía muchas personas, no sabia si podía aprender inglés y comunicarse con las niñas/I didn't know many people, I didn't know if I could learn English and communicate with the girls". When she changes cities she feels "kind of sad leaving the friends that I left behind, but I feel happy because I always make new friends in each school. But every first day of school I feel nervous because you never know what's going to happen". 
Anthony like Jessica switched schools three times. He has lived in Toronto and Mississauga. In his narrative, he uses the word again several times to indicate that he regularly changed schools and homes. For instance, he writes / moved again and / also went to a new school again. It seems as if he is tired of the uncertainty of not knowing whether he will be able to settle down. He concludes his story with I am still in the same school, indicating a type of permanence through the use of the word still and signaling a type of triumph to be able to remain long enough in the same place. He also wrote that when he started new schools he felt nervous and shy, which means that moving requires Anthony to confront the challenge of starting all over again despite his shyness and anxiety. The instability has made Anthony uncertain because whenever he moves he expects to move again. In his drawing he shows his family moving into an apartment and he writes inside a speech bubble I wonder where my new home will be (see Illustration 5). Even though his new home is in front of him, he wonders where that home is. His comment demonstrates that he both does not know if he will stay in that new apartment and that he is having difficulty defining 'home'. Similarly, in the last section of his drawing he writes inside a speech bubble so is this my $3^{\text {rd }}$ school?? Clearly, Anthony is questioning and doubting whether that will be his last school or whether he would have to leave again. It also shows his exhaustion by highlighting that he has already moved three times.

\section{Illustration 5}

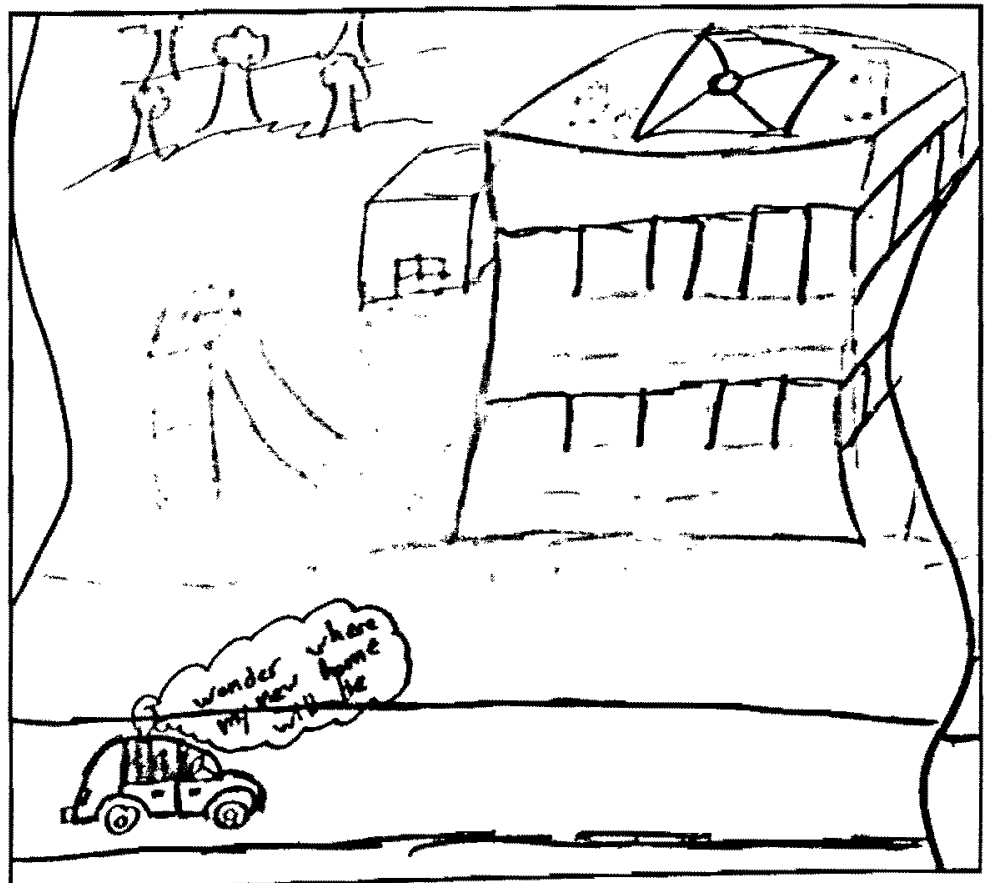


Anthony like Jessica switched schools three times. He has lived in Toronto and Mississauga. In his narrative, he uses the word again several times to indicate that he regularly changed schools and homes. For instance, he writes I moved again and I also went to a new school again. It seems as if he is tired of the uncertainty of not knowing whether he will be able to settle down. He concludes his story with I am still in the same school, indicating a type of permanence through the use of the word still and signaling a type of triumph to be able to remain long enough in the same place. He also wrote that when he started new schools he felt nervous and shy, which means that moving requires Anthony to confront the challenge of starting all over again despite his shyness and anxiety. The instability has made Anthony uncertain because whenever he moves he expects to move again. In his drawing he shows his family moving into an apartment and he writes inside a speech bubble / wonder where my new home will be (see Illustration 5). Even though his new home is in front of him, he wonders where that home is. His comment demonstrates that he both does not know if he will stay in that new apartment and that he is having difficulty defining 'home'. Similarly, in the last section of his drawing he writes inside a speech bubble so is this my $3^{\text {rd }}$ school?? Clearly, Anthony is questioning and doubting whether that will be his last school or whether he would have to leave again. It also shows his exhaustion by highlighting that he has already moved three times.

\section{Illustration 5}

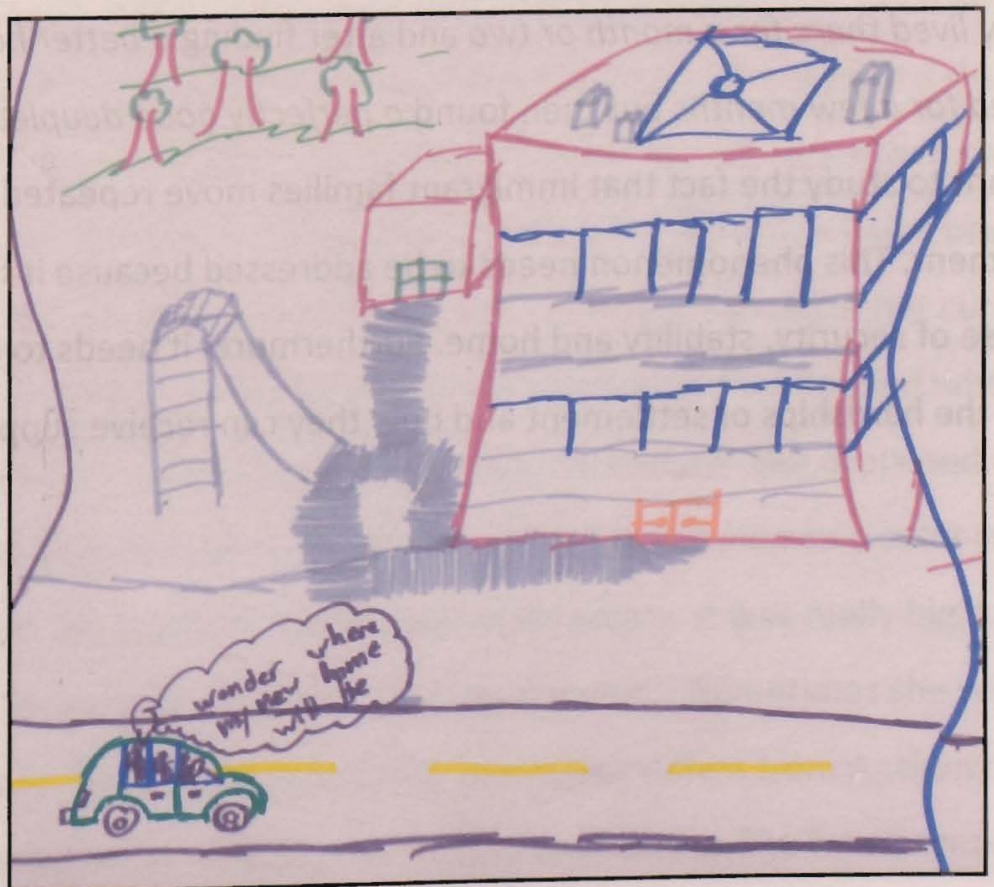


It is important to add that Anthony told me he wanted a Canadian name as a pseudonym. Though this might be interpreted as the pressure to assimilate, I think his choice has practical reasons. His original name is unusual for non-Spanish speakers, so I can imagine Anthony having to explain his name and his origins every time he moves to a new school in his new country. Lastly, even if immigrant children might not explicitly voice their preoccupation with transitions they do experience the effects of their families' unstable situation.

Sebastian moved four times, each time to upgrade his family's living space. He wrote in his story that the last house his mother found is a perfectly good deupleuxe. Nonetheless, he prefers the first apartment building he lived in because it is "más cerca de mi amigo/ it's closer to my friend". Despite the multipie moves, Sebastian is considering moving back to Ecuador. He said "creo que voy a irme al Ecuador/I believe I'm going back to Ecuador". Irme means to take himself, which demonstrates that he is not waiting on his parents to either make that decision or take the trip. Nonetheless, he is not sure about where to go as he explains that "no sé qué voy a hacer en el futuro. Siempre hay preguntas en mi cabeza/ I don't know what I will do in the future. There're always questions in my head" (see Illustration 6). It is highly possible that Sebastian's confusion and uncertainty are a product of his family's constant moving. By simply reading his story, one is overwhelmed with so many moves. He starts with I imagrated from Equador and lived with another family for a few months, but his family found another apartment and they lived there for $a$ month or two and after finding $a$ better house... they moved in and stayed for a few months but then found a perfectly good deupleuxe.

It is important to study the fact that immigrant families move repeatedly during their first years of settlement. This phenomenon needs to be addressed because it fails to provide children with a sense of security, stability and home. Furthermore, it needs to be known how moving aggravates the hardships of settlement and how they can receive support during their transitions. 


\section{Illustration 6}

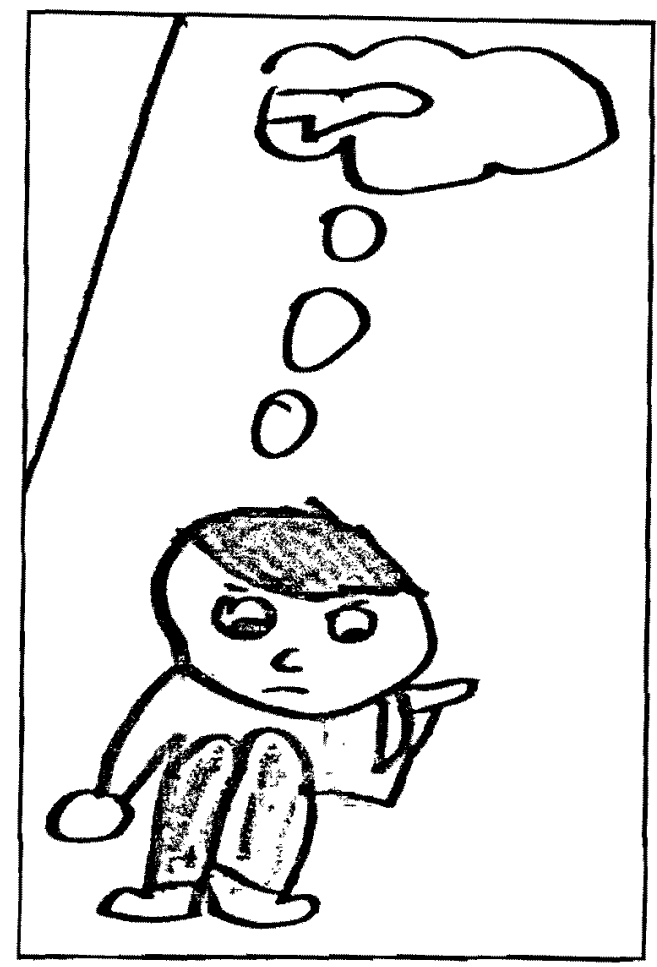

Candice's story is titled My Journeys. She uses the plural because she is referring to the various times she has switched residences and cities. When Candice arrived to Canada her family stayed in hotels in Toronto. She said "después fuimos a hoteles, a hoteles hasta que Ilegamos a Mississauga/ after we went to hotels, to hotels until we got to Mississauga". She did not like the smell of the hotels because it smelled like cigarettes and because she was not allowed to do what she can do in her home. After the hotels she lived in a shelter that she liked a lot because it was "muy divertido. Tenia cancha de basketball, nos daban comida también...nos llevaron a nadar, nos llevaron a bowling/ really fun. It had a basketball court, they gave us food too...they took us swimming, took us bowling". She likes her current apartment because it has big windows, unlike her basement apartment that flooded when the snow melted. But the house she likes the most is the one in Mexico. She explained that "Ia casa de México estaba muy bonita. Estaba grandísima. No sabía que íbamos a estar en algo más chico, en un apartamento/ the house in Mexico was really pretty. It was really big. I did not know that I was going to live in something smaller, in an apartment". Sometimes she wishes she had a house in Canada, too. Candice's approach to transitions differs from Anthony's and Sebastian's because she concentrates on the beneficial aspect of moving. She frames movement in terms 


\section{Illustration 6}

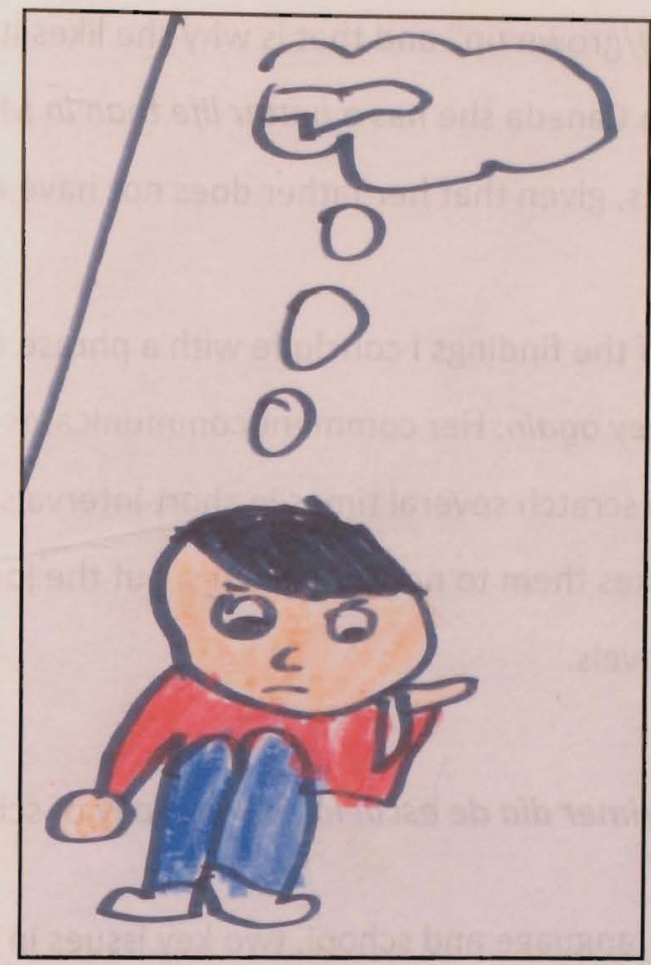

Candice's story is titled My Journeys. She uses the plural because she is referring to the various times she has switched residences and cities. When Candice arrived to Canada her family stayed in hotels in Toronto. She said "después fuimos a hoteles, a hoteles hasta que llegamos a Mississauga/ after we went to hotels, to hotels until we got to Mississauga". She did not like the smell of the hotels because it smelled like cigarettes and because she was not allowed to do what she can do in her home. After the hotels she lived in a shelter that she liked a lot because it was "muy divertido. Tenia cancha de basketball, nos daban comida también...nos llevaron a nadar, nos llevaron a bowling/ really fun. It had a basketball court, they gave us food too...they took us swimming, took us bowling". She likes her current apartment because it has big windows, unlike her basement apartment that flooded when the snow melted. But the house she likes the most is the one in Mexico. She explained that "la casa de México estaba muy bonita. Estaba grandísima. No sabía que íbamos a estar en algo más chico, en un apartamento/ the house in Mexico was really pretty. It was really big. I did not know that I was going to live in something smaller, in an apartment". Sometimes she wishes she had a house in Canada, too. Candice's approach to transitions differs from Anthony's and Sebastian's because she concentrates on the beneficial aspect of moving. She frames movement in terms 
of opportunity. In Canada she has "más oportunidades/more opportunities" even if she's "chiquita/ young" or "grande/grown up" and that is why she likes it " mucho aquil/ a lot here". In her story she wrote that in Canada she has a better life than in Mexico. It is better because of the educational opportunities, given that her father does not have to pay for her schooling like he used to in Mexico.

To end this portion of the findings I conclude with a phrase from Candice's written story-I began my new journey again. Her comment communicates the unsettling effects of having to recommence from scratch several times in short intervals of time. Immigrant children embark on a journey that takes them to new beginnings, but the journey can restart again, at the international and local levels.

School and Language-Mi primer día de escuela (My first day of school) / My biggest weekness my communication

This set of findings relate to language and school, two key issues in every immigrant child's life, and major themes that emerged in our conversations. They have been grouped together because immigrant children's experiences with language and school go hand in hand. Isabel's story title, Mi primer día de escuela/ my first day of school, captures a turning point in a child's settlement experience. Several children wrote about their first day of school, expressing their worries about making friends, learning English and being mocked. Jessica explained in her narrative that though she was glad to start school in Canada her biggest weekness [was her] communication. When she arrived to Canada she was nervous because I didn't know one bit of English. On her first day her teacher tried to teach her, but Jessica could not comprehend her (see Illustration 7). Jessica said that it was important for her to learn English because she could not communicate with others, plus she thought that if she said something wrong "de pronto se reian/ maybe they would laugh". Furthermore she thought that "nunca iba a aprender inglés y nunca podía entenderlo/ I was never going to learn English and I could never understand it". She knew that learning the language would enable her to "hacer amiguitas/make friends" and "hacer todo/ do everything". Even though every time she started a new school she got "nerviosa/ nervous", once the girls would approach her she felt better. Jessica wrote that after 9 months in school/ was ready and could speak English! By being ready she meant being 
capable of communicating with others (see lllustration 8) and do "everything that was needed of me". For instance, she performed well in school. She wrote that she was very happy with herself as she got good marks and did good in school. Overall, Jessica thinks "it's fun to learn a new language" and now that she is in French immersion she makes use of her Spanish because the two languages are "kind of similar".

Illustration 7

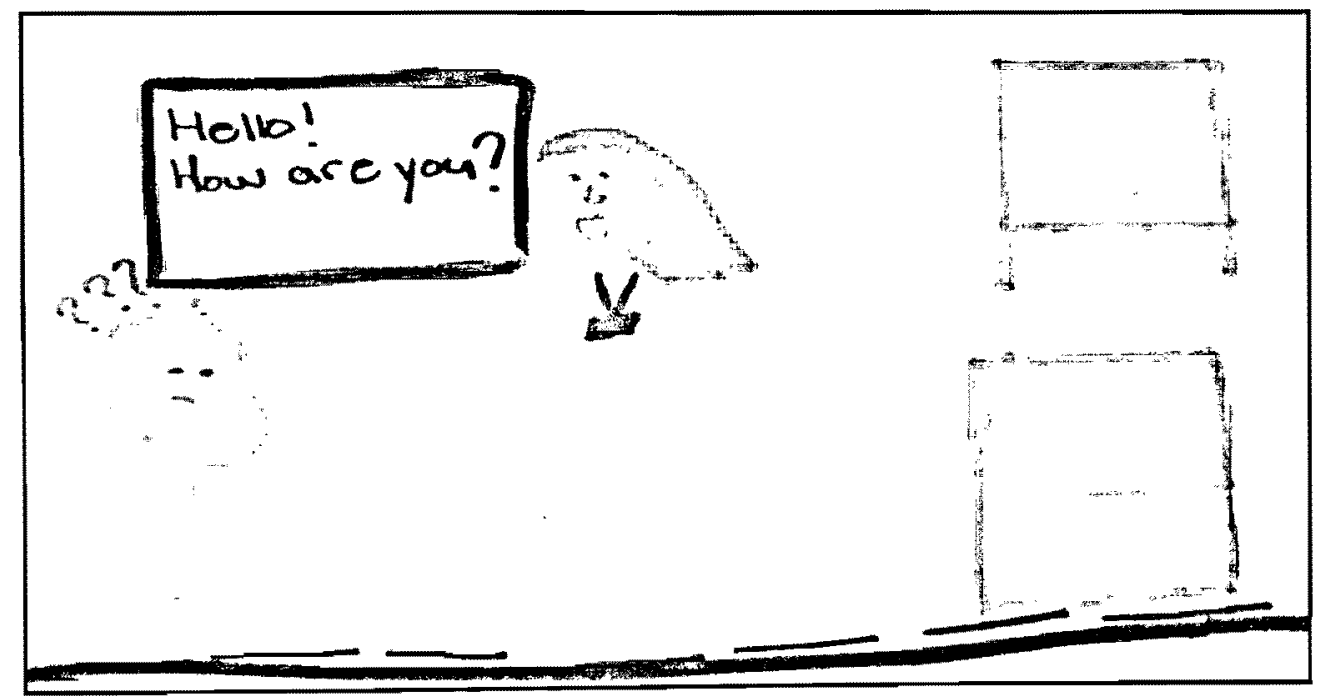

\section{Illustration 8}

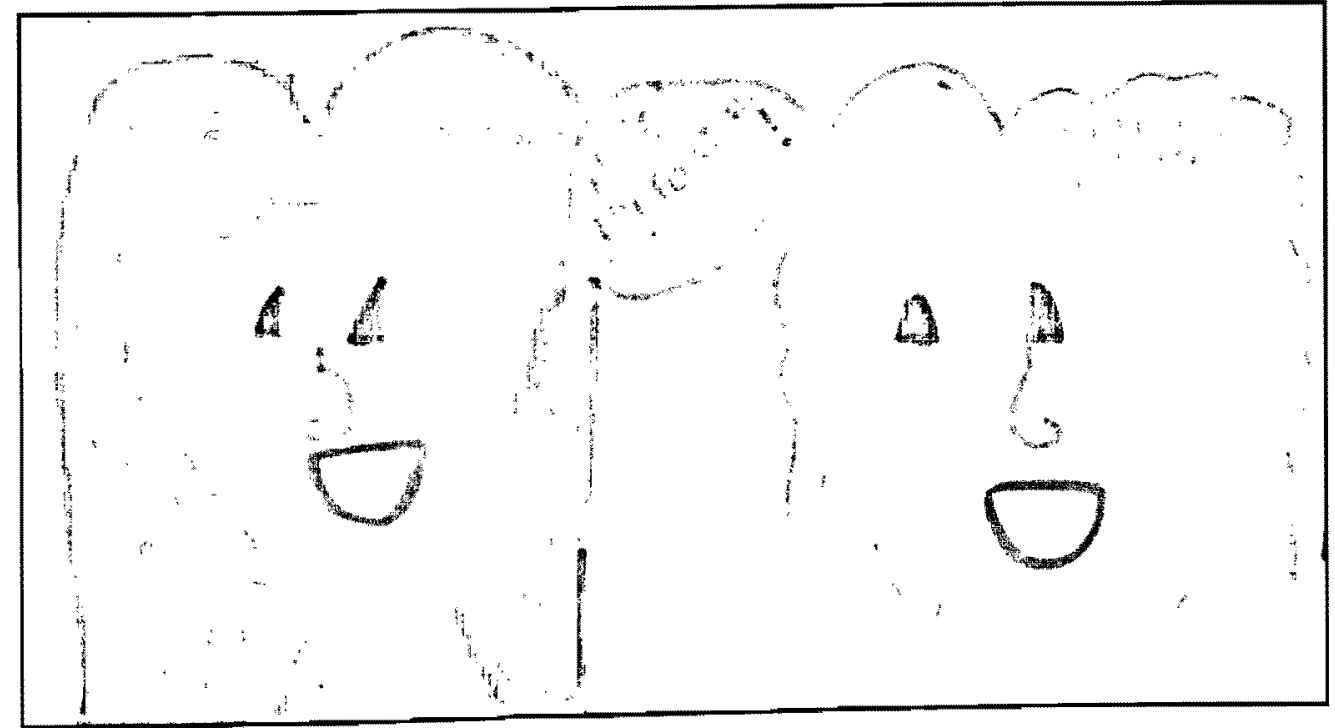

Isabel was also worried about commencing school because she expected children to be "really mean" as they had been in Houston, her family's first point of immigration. On her first day she cried, wanted to stay home, and was nostalgically thinking about Colombia (see Illustration 9). She thought children would make fun of her, so she told her dad to go in with 
capable of communicating with others (see Illustration 8) and do "everything that was needed of me". For instance, she performed well in school. She wrote that she was very happy with herself as she got good marks and did good in school. Overall, Jessica thinks "it's fun to learn a new language" and now that she is in French immersion she makes use of her Spanish because the two languages are "kind of similar".

Illustration 7

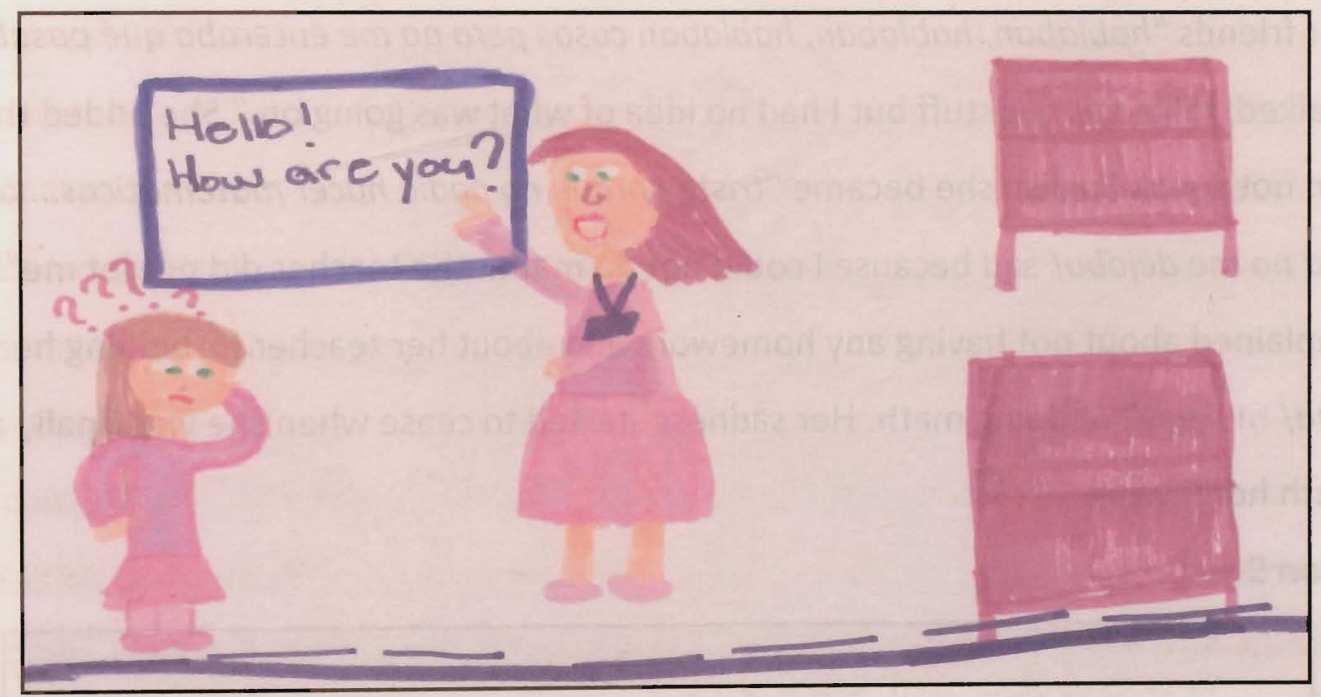

Illustration 8

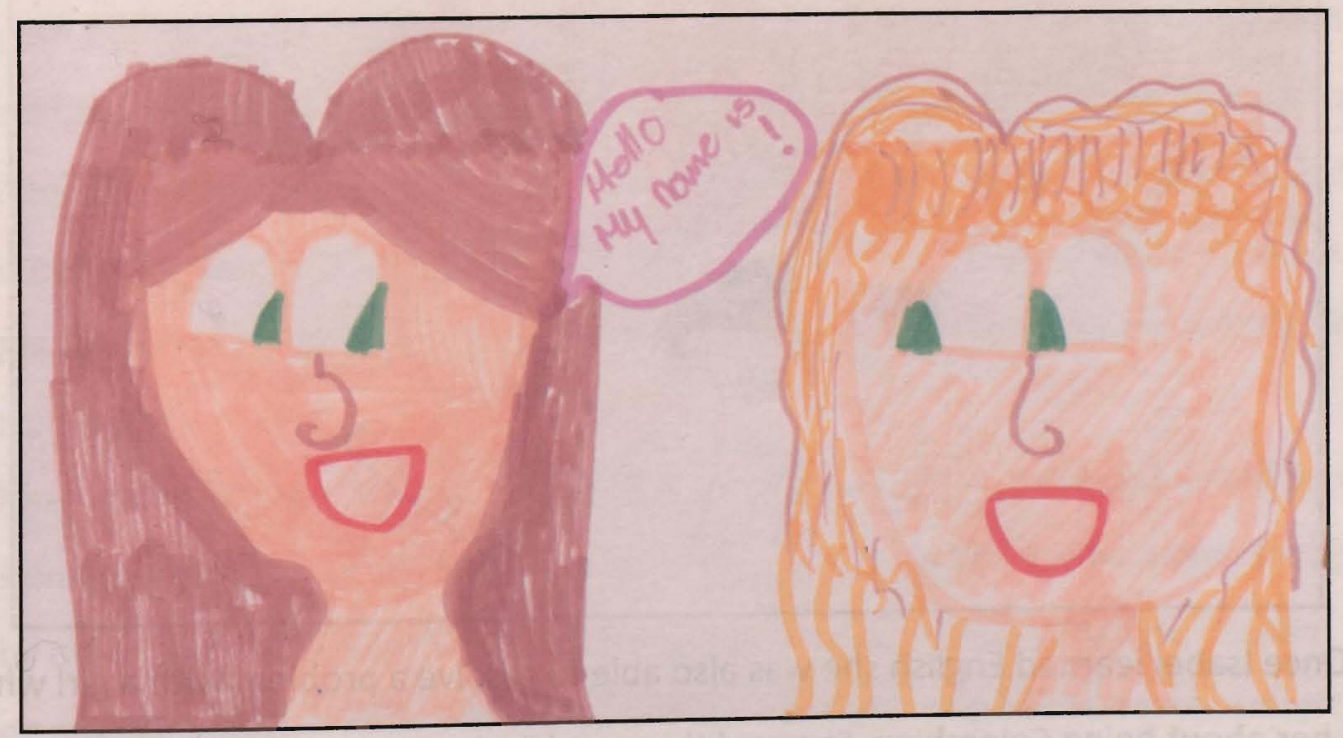

Isabel was also worried about commencing school because she expected children to be "really mean" as they had been in Houston, her family's first point of immigration. On her first day she cried, wanted to stay home, and was nostalgically thinking about Colombia (see Illustration 9). She thought children would make fun of her, so she told her dad to go in with 
her and asked him "que no me dejara sola/ not to leave me alone". Moreover, Isabel, like Jessica, thought that it was "imposible hablar inglés/impossible to speak English". She felt "triste/ sad" and "mal/ bad" because she could not speak or understand English. She said that sometimes she would talk to her classmates but "ellos decian que no me entendian/ they would say that they did not understand me". When they spoke to her, "trataba como mucho de entender pero no podia/ she tried really hard to understand but could not". Isabel was also sad when her friends "hablaban, hablaban, hablaban cosas pero no me enteraba qué pasabal talked, talked, talked about stuff but I had no idea of what was going on." She added that since she could not speak English she became "triste porque no podía hacer matemáticas...la profesora no me dejaba/ sad because I could not do math...the teacher did not let me". She also complained about not having any homework and about her teacher forbidding her to use "mi forma/my way" of doing math. Her sadness started to cease when she was finally allowed to do math homework.

\section{Illustration 9}

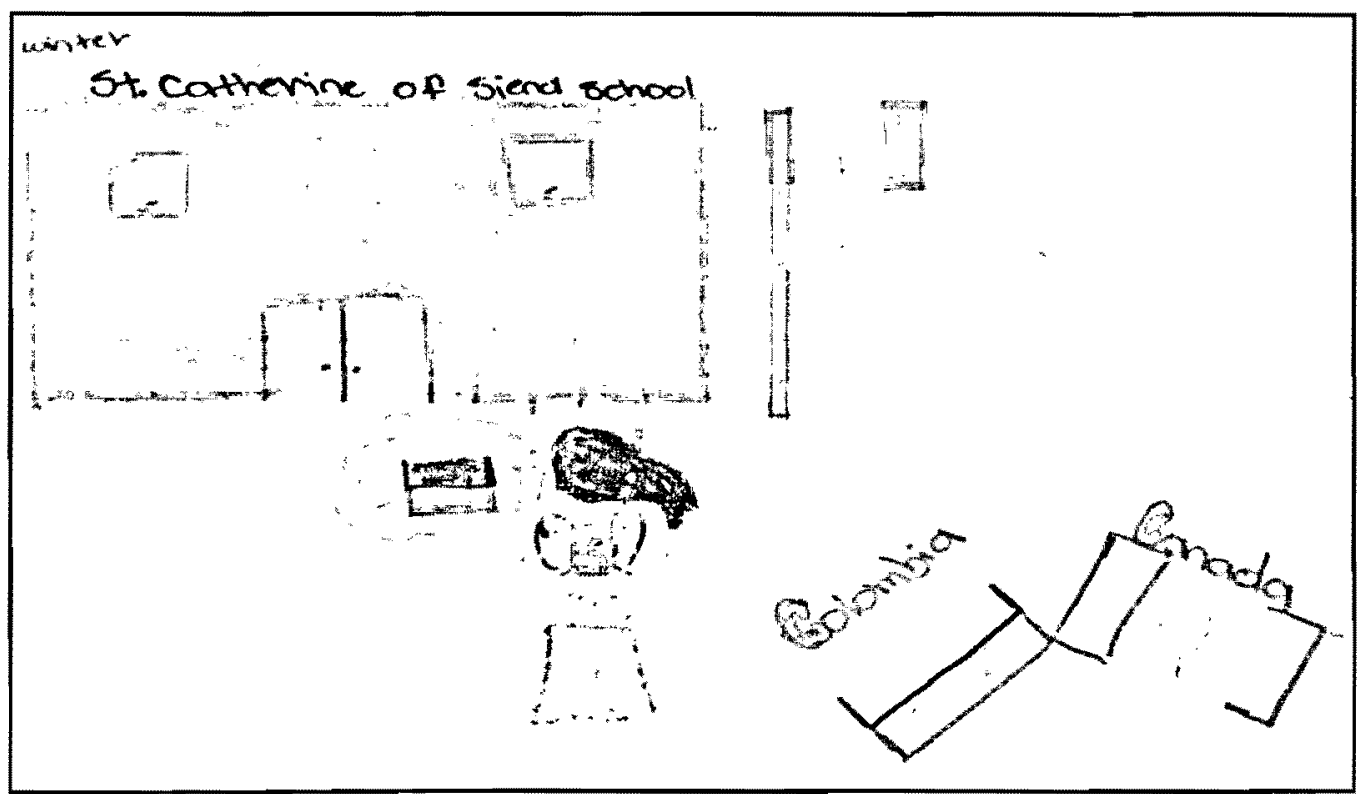

Once Isabel learned English she was also able to resolve a problem with a girl who mocked her about being Colombian. She said that a girl "me decia muchas cosas feas y no sabia lo que ella me estaba diciendo/ used to tell me many ugly things and I did not know what she was saying". However, when she was able to communicate in English, she told the girl that they should become friends because she disliked fighting with people. 
her and asked him "que no me dejara sola/ not to leave me alone". Moreover, Isabel, like Jessica, thought that it was "imposible hablar inglés/ impossible to speak English". She felt "triste/ sad" and "mal/ bad" because she could not speak or understand English. She said that sometimes she would talk to her classmates but "ellos decían que no me entendían/ they would say that they did not understand me". When they spoke to her, "trataba como mucho de entender pero no podía/ she tried really hard to understand but could not". Isabel was also sad when her friends "hablaban, hablaban, hablaban cosas pero no me enteraba qué pasabal talked, talked, talked about stuff but I had no idea of what was going on." She added that since she could not speak English she became "triste porque no podía hacer matemáticas...la profesora no me dejaba/ sad because I could not do math...the teacher did not let me". She also complained about not having any homework and about her teacher forbidding her to use " mi forma/ my way" of doing math. Her sadness started to cease when she was finally allowed to do math homework.

\section{Illustration 9}

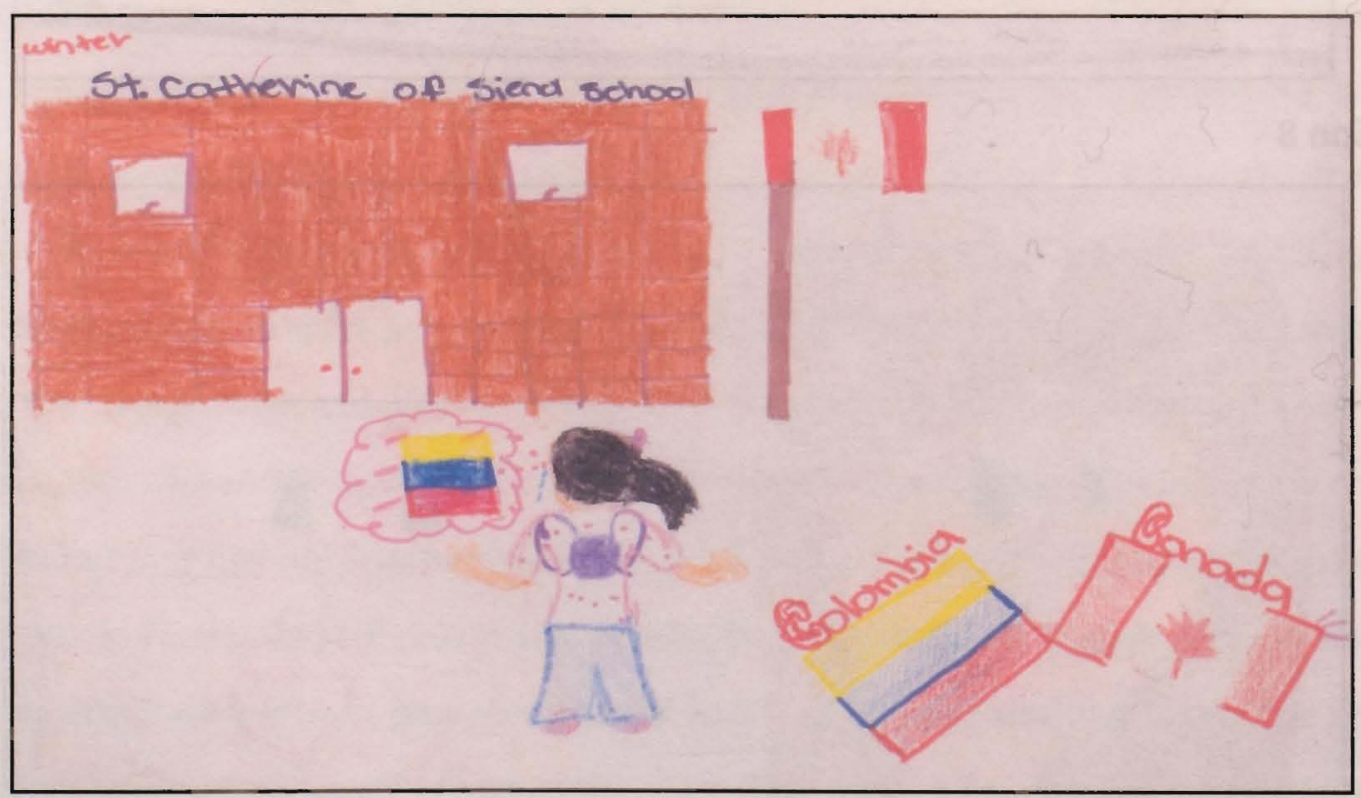

Once Isabel learned English she was also able to resolve a problem with a girl who mocked her about being Colombian. She said that a girl "me decía muchas cosas feas y no sabía lo que ella me estaba diciendo/ used to tell me many ugly things and I did not know what she was saying". However, when she was able to communicate in English, she told the girl that they should become friends because she disliked fighting with people. 
Isabel's rough experience with registering for school also contributed to her negative preconceptions of school. She said that she was "triste porque en la office habia una señora que no me dejaba entrar a la escuela/ sad because in the office there was a lady who did not let me register in school". The secretary kept asking Isabel's parents for documentation and in the end she told Isabel's family "no tenemos ahora cupo/ we don't have space now". The secretary even yelled at her cousin "que no volviera más/ to not come back anymore". This negative exchange stayed with Isabel to this day.

Another finding is that Isabel, Coni, and Daniela, who are from Colombia, complained about their school assignments being too easy in comparison to what they were accustomed to. They explained that in Colombia they were more advanced academically because they had already learned what their peers were just starting to learn in Canada. Furthermore, they disliked having easy tests and being assigned either no homework or very little.

A child's English proficiency also determines the child's ability to make friends. Anthony said he likes his last school better than the other two because he has "muchos amigos/many friends". When I asked him if he had friends when he did not know English he answered: "si, pero estaban en Venezuela/ yes, but they were in Venezuela". That means that when he did not know English he had few or no friends. But now that he speaks English he can make many friends and have more positive experiences in school. Apart from making friends, he also worried about having to talk to the teacher and not being able to do so. Candice, like Anthony, attributes her ability to make friends to her English skills: "luego, después de los años, ya estabo con amigas ya que supe más ingles/ then after those years, I was now with my friends since I knew more English".

Other commonalities I found among some children included being welcomed by their peers in schools. On their first day of school, Coni was asked to join a soccer game, Jessica was greeted by other girls, and Candice felt welcomed despite not knowing English. Despite welcoming environments, children did worry about being excluded. For instance, when I asked them if they had any questions regarding my migration story, Jessica asked me if children made fun of me when I was in school; James asked me if children made fun of me for being in ESL; and Isabel asked me why my classmates were mean to me. 
When James went to school in Canada he was preoccupied about his grades. In Bolivia, he would usually get really good marks on tests like $80 \%-96 \%$. In Canada he was not able to achieve such high grades because of language barriers. In his drawing he made a comparison of his capacity to understand schoolwork in the two countries. In his Bolivian school he knows that he's going to ace this test and in his Canadian school he does not understand a word on this test (see Illustration 10 and Illustration 11). James explained, "I only spoke Spanish and a few words in English. So, I was having trouble and difficulty" because "I wouldn't understand a thing and teachers would look like they were mean to me because I would flunk and fail". In contrast, every time he had a test in Bolivia he would say to himself "this is an easy test because...I know the language. So, then I would get good marks on it". James also discussed an incident that shows how not knowing English interfered with his efforts to succeed in school. In class, he observed that a girl raised her hand to answer the teacher's questions and then said, "I forgot" and the teacher responded "it's O.K.'" James thought "I forgot" was "one of the answers to the book that we were reading" so he imitated the girl, and rose his hand to say "I forgot". Illustration 10

\section{Bolivia stage 2}

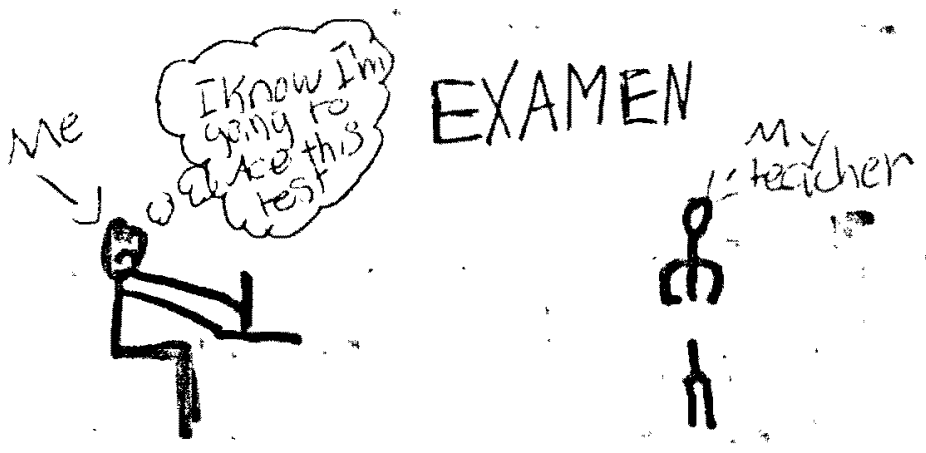


When James went to school in Canada he was preoccupied about his grades. In Bolivia, he would usually get really good marks on tests like $80 \%-96 \%$. In Canada he was not able to achieve such high grades because of language barriers. In his drawing he made a comparison of his capacity to understand schoolwork in the two countries. In his Bolivian school he knows that he's going to ace this test and in his Canadian school he does not understand a word on this test (see Illustration 10 and Illustration 11). James explained, "I only spoke Spanish and a few words in English. So, I was having trouble and difficulty" because "I wouldn't understand a thing and teachers would look like they were mean to me because I would flunk and fail". In contrast, every time he had a test in Bolivia he would say to himself "this is an easy test because...I know the language. So, then I would get good marks on it". James also discussed an incident that shows how not knowing English interfered with his efforts to succeed in school. In class, he observed that a girl raised her hand to answer the teacher's questions and then said, "I forgot" and the teacher responded "it's O.K.'" James thought "I forgot" was "one of the answers to the book that we were reading" so he imitated the girl, and rose his hand to say "I forgot". Illustration 10

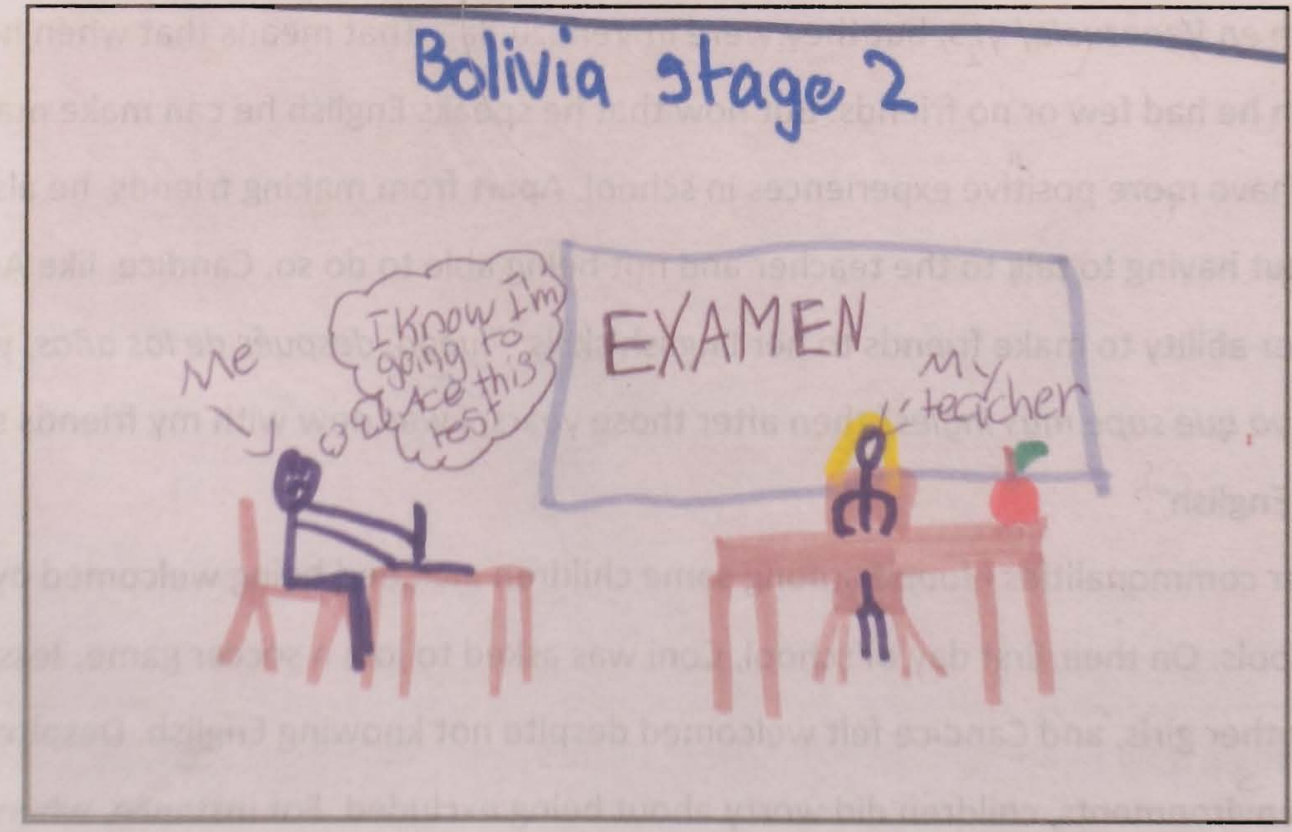




\section{Illustration 11}

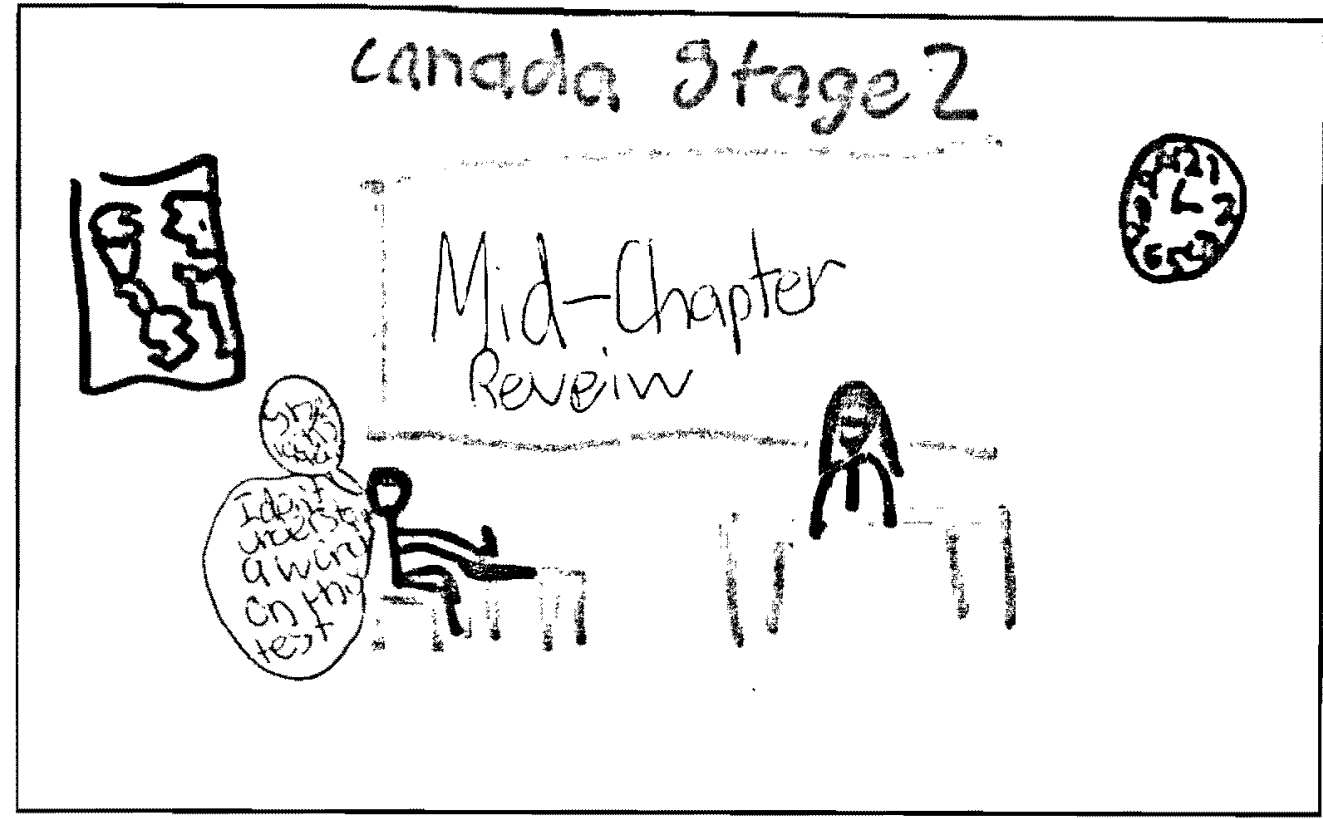

Candice also shared her experiences of learning English. She spoke of her progress learning English as she went from feeling "mal y triste/ bad and sad" to feeling happy because she now knows "cómo hablar inglés mejor/ how to speak English better" (see Illustration 12). She wrote that when she was new to Canada she felt lonely but luckyly there was another girl who speaked Spanish. Meeting children who spoke the same language as her enabled her to make friends and overcome loneliness. Overall Candice thinks, "el inglés es muy difícil/ English is very difficult". Candice also assessed the quality of the ESL classes in the two schools she had attended. In her current school her English skills improved because she was taught complex lessons on verb tenses and nouns, while in her first school she was taught simple things such as rhymes (which she found frustrating and useless). She said that in her current school they want her to know "muchas palabras como los nouns y verbos para que puedas luego decir las cosas/ many words like nouns and verbs so that can I say things". The second school helped her "más que la otra para comunicarme/ more than the other to communicate". 


\section{Illustration 11}

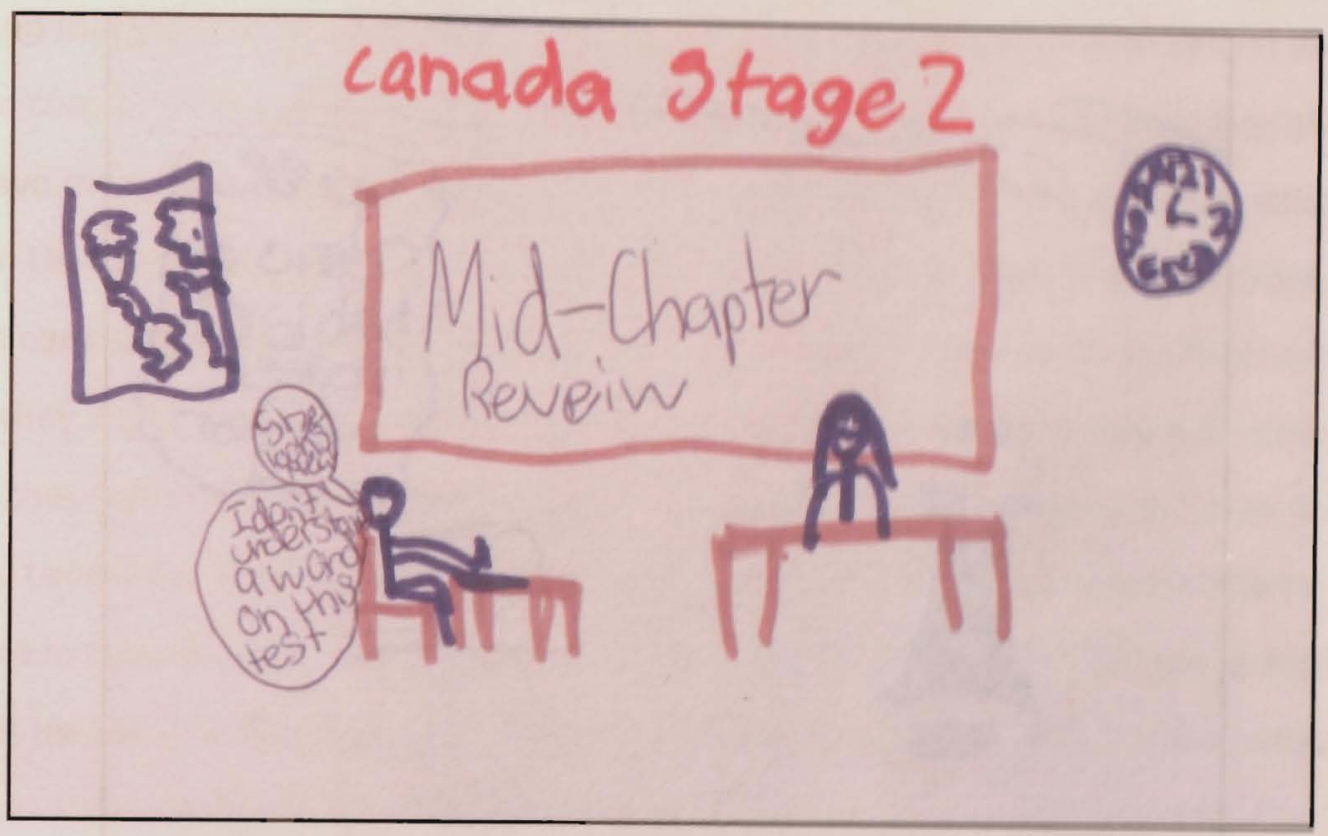

Candice also shared her experiences of learning English. She spoke of her progress learning English as she went from feeling "mal y triste/ bad and sad" to fecling happy because she now knows "cómo hablar inglés mejor/ how to speak English better" (see lllustration 12). She wrote that when she was new to Canada she felt lonely but luckyly there was another girl who speaked Spanish. Meeting children who spoke the same language as her enabled her to make friends and overcome loneliness. Overall Candice thinks, "el inglés es muy dificil/ English is very difficult". Candice also assessed the quality of the ESL classes in the two schools she had attended. In her current school her English skills improved because she was taught complex lessons on verb tenses and nouns, while in her first school she was taught simple things such as rhymes (which she found frustrating and useless). She said that in her current school they want her to know "muchas palabras como los nouns y verbos para que puedas luego decir las cosas/ many words like nouns and verbs so that can I say things". The second school helped her "mas que la otra para comunicarme/ more than the other to communicate". 


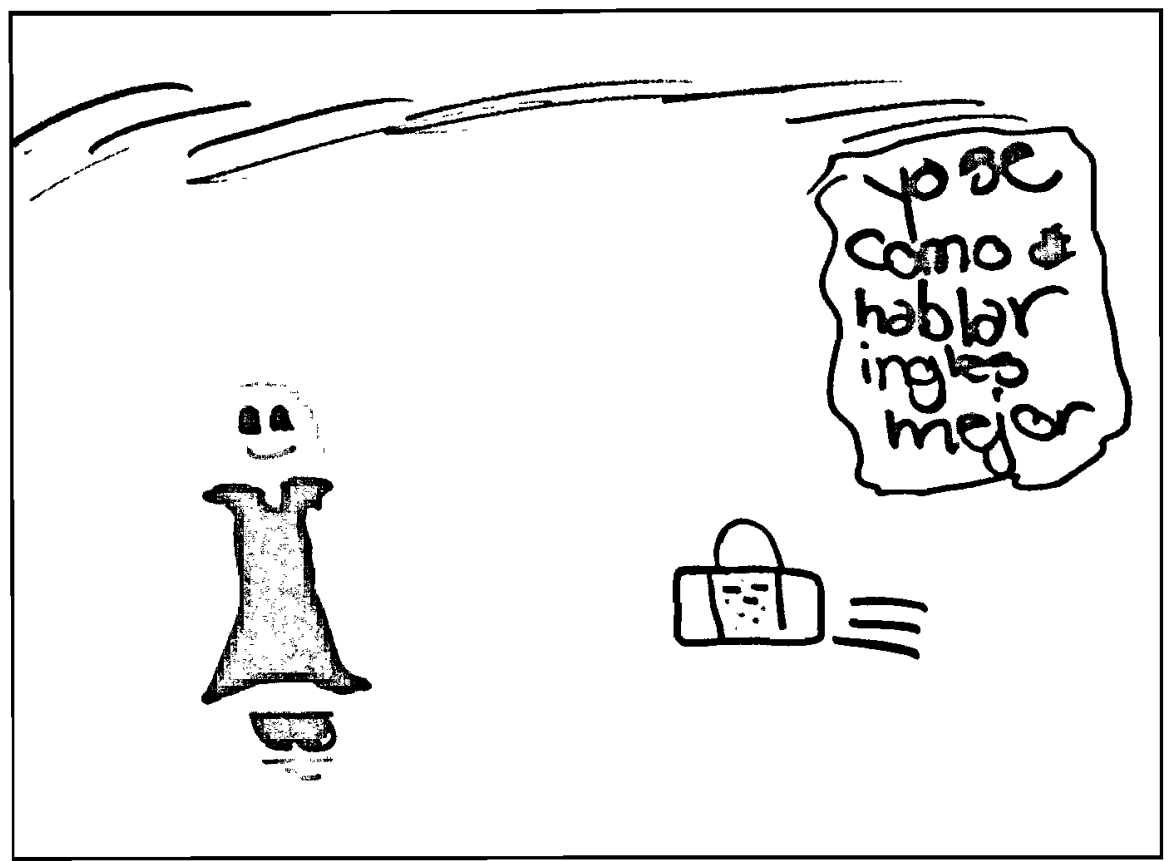

Candice found her first communion a very pleasant experience because "entendía un poquito más [inglés], ya estaba hablando/ I understood a little more [English], I was already speaking". Now she has more "confidencia en mi escuela y todo/ confidence in my school and everything". And, she likes Canada much BETTER because here "me ayudan más/I get more help". By "help" she means that she has access to free education. Candice explained that "aquí puedo tener más oportunidades de estudiar...si estuviera en Mexico mi papá estaría pagando mucho dinero porque iba a una escuela privada/ here I can have more opportunities of studying...if I was in Mexico my dad would be paying a lot of money because I went to a private school".

Though Candice is knowledgeable of her gains in Canada she is also aware of her losses. She explained that now that she speaks English she cannot write well in Spanish. But she practices Spanish by keeping in touch with her cousins through e-mails. Sometimes she does not know how to say things to her parents so she has to ask them to help her. Even though she is nine years old she comprehends the importance of communicating with her family, as she stated "me gustó comunicarme con mis amigas en inglés, pero aún me quiero comunicar bien con mis papás y mis hermanos/ I liked communicating with my friends in English, but I still want to communicate well with my parents and brothers". 
Illustration 12

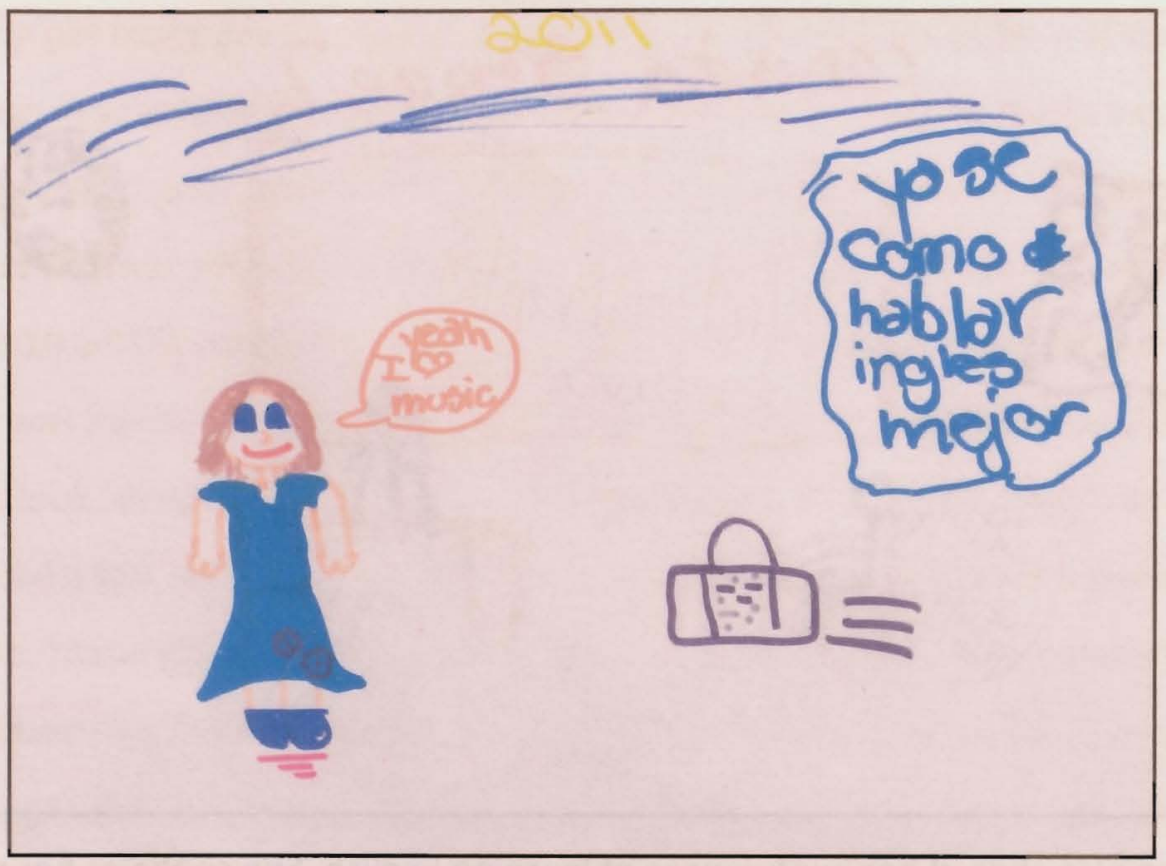

Candice found her first communion a very pleasant experience because "entendia un poquito más [inglés], ya estaba hablando/ I understood a little more [English], I was already speaking". Now she has more "confidencia en mi escuela y todo/ confidence in my school and everything". And, she likes Canada much BETTER because here "me ayudan más/I get more help". By "help" she means that she has access to free education. Candice explained that "aquí puedo tener más oportunidades de estudiar...si estuviera en Mexico mi papá estaría pagando mucho dinero porque iba a una escuela privada/ here I can have more opportunities of studying...if I was in Mexico my dad would be paying a lot of money because I went to a private school".

Though Candice is knowledgeable of her gains in Canada she is also aware of her losses. She explained that now that she speaks English she cannot write well in Spanish. But she practices Spanish by keeping in touch with her cousins through e-mails. Sometimes she does not know how to say things to her parents so she has to ask them to help her. Even though she is nine years old she comprehends the importance of communicating with her family, as she stated "me gustó comunicarme con mis amigas en inglés, pero aún me quiero comunicar bien con mis papás y mis hermanos/ I liked communicating with my friends in English, but I still want to communicate well with my parents and brothers". 
Most interviews were conducted in Spanish, but most of the children's writings were in English and many chose to read the English version of the assent form. Children told me they feel more comfortable writing in English because in school they have to write in English; they no longer have many opportunities to practice their Spanish-writing skills. As a result, children's literacy in their mother tongue deteriorates over time while their English skills improve.

In conclusion, starting school in a new country is a stressful experience for children because they worry about how they will be received by their peers, how they will communicate and how they will perform as students. The major source of worry for these children is language. Language is the factor that either allows or hinders children's opportunity to participate in their school community. They get frustrated when they cannot speak English because it means that they cannot be functional socially (making friends) and academically.

\section{Cultural Brokering: Children Helping Children - I was lucky that there was this other girl that spoke Spanish and English}

In many cases, when we think about cultural brokers, we think about adults and children exchanging help or services with one another. In this study, the children talked extensively about relying on (or them helping) other children as cultural brokers. For example, James shared that he "was lucky that there was this other girl that spoke Spanish and English." He considered himself fortunate to find a bilingual classmate who helped him while he learned English. He said the girl "would explain it all to me". He added that she would "explain everything the teacher said, she would explain to me sentence by sentence...cuz I didn't understand it". The cultural broker used to tell him what he needed to do for his tests, but as he learned more English her assistance minimized. He appreciated her help because he thought that it would help him "do great in school".

Isabel also had a classmate who helped her with translation and interpretation. However, she engaged in reciprocal brokering where she helped her broker as well. In her story Isabel wrote: I helped my friend with math and she helped me with inglish. She helped her broker by teaching her how to do division so that her broker could "hacerlo rápido porque ella no sabia/ do it faster because she did not know how". If Isabel was not able to say something she would ask the broker to interpret for her. For instance, when another classmate offended 
Isabel she asked the broker to interpret what was being said to her and to interpret what she wanted to say back to the classmate. At other times, Isabel received instruction by the broker and she would then use what she learned. For example, her broker wrote on a piece of paper how to say 'I want to go to the washroom'. Recounting that instance, Isabel explained: "me lo aprendi, me lo aprendi, me lo aprendi y ya lo decía yo sola/ I learnt it, I learnt it, I learnt it and then I would say it all on my own". Moreover, the broker and isabel's friends helped to create an inclusive environment for Isabel by speaking in Spanish. Sometimes Isabel's Spanishspeaking friends would speak in English but since they knew that "yo me sentia mal, preferian no hacerlo/ I felt bad, they preferred not to do it".

Daniela discussed her experiences as a broker and the importance of her role. She said she liked to assist non-English speakers because "ya tenía la experiencia de ser una niña nueva y sabia que es muy duro y me gusta ayudarles/already had the experience of being a new girl and I knew that it's very hard and I like to help them". Her comment shows kindness and maturity because she is able to sympathize with the new children and value the significance of brokering. It is also clear that brokering is empowering for these children. Furthermore, she highlights a common need among immigrant children and the way that need can be addressed. When Daniela acts as a broker it is because she either takes the initiative, her teacher asks her to do it or the brokee seeks her help. Daniela's brokering has either been initiated by her teacher, by the brokee's requests or by herself. She explained that she helps her friend with what she does not understand or else her friend would have to go to the computer all the time. Sometimes Daniela tells her that "si necesita ayuda, hacemos las tareas juntas/ if you need help we can do homework together". In this case, cultural brokering allowed the brokee to form a friendship with the broker and to even receive assistance out of school.

Anthony also had a classmate who "traducia todo...y lo que decia la maestra/ translated everything...and what the teacher said". Other children, like Coni, were taught by brokers how to behave and the customs to follow. He said that his "amigo, el que hablaba español, me enseñaba todo que tenía que llevar de lonchera... y cuando decía que no había escuela por días festivales cualquier cosa de esa/ friend who spoke Spanish used to teach him everything he needed to take for lunch and told him when there was no school because of holidays and any 
other thing like that". Coni liked to be told this information because he learned what he was supposed to do in school. Brokers taught him how to "comportarse, las reglas de la clase y las salidas que hacen/ behave, the classroom rules and the fieldtrips they had". His experience shows that brokering does not merely meet interpretation needs, but also provides children with the opportunity to get "inside cultural knowledge". In a way, peers act as guides who give newcomer children tips, advice and warnings on how to navigate their new environment.

Family members can and do act as cultural brokers. Jessica was in the same classes as her cousin, who interpreted for her and introduced her to her future friends. He helped her "hacer amigos, con cosas asi/ to make friends, with things like that". She explained that the girls approached her after her cousin introduced them. Jessica recognized that "necesitaba a [mi primo] conmigo/ I needed [my cousin] with me" because she would tell him something and he would tell it to the teacher. However, "a veces no estaba [mi primo] ahi entonces era duro también/ sometimes [my cousin] wasn't there so it was hard, too". When she moved to another city and started a new school she was worried because "tuve que hacer todo sola porque no tuve a nadie/ she had to do everything on my own because I had nobody". Therefore, brokering among peers proves to be very beneficial to immigrant children as it serves to connect them with their teacher, friends and surroundings. Most importantly, immigrant children acknowledge the value of cooperating with each other.

\section{Goals- Eso quiero ser yo (that's what I want to be)}

In the same way that we talked about their past, children shared with me their aspirations for the future. They talked about what professions they want to pursue and expressed a lot of interest in my master's program. The subtitle for this section- "Eso quiero ser yo" (that's what I want to be) -comes from Sebastian who wants to be a journalist and work for TV or radio because he enjoys performing. I told him that I used to be a reporter and he wanted to know more about it. He also hopes to return to Ecuador when he grows up, though he remains uncertain (see Illustration 6). James wants to go to a certain high school where he can develop his soccer skills in order to be able to later join Brazil's team. Isabel wants to be a psychologist or a pediatrician because she loves to work with children. She helps to take care of her sister 
and she enjoys that very much. Daniela also hopes to work with children because she thinks they are more interesting to work with than adults. Candice likes art and decoration and is inspired by a Canadian interior designer who has two TV shows. She selected Candice as her pseudonym because that is the designer's name.

Often children asked me about my research and my university studies. They wanted me to explain to them what I learned in class, how long my report was going to be, who was going to read it, what were the objectives of my research, where would I work, who would I help once I got a job, why I chose this career path, where have I done my placement, why I liked working with children, and how could I have studied immigration without having to become an immigration officer. Isabel said she had never heard of my program and Daniela said she wanted to pursue the same career path as me. At times it was as if I were the study participant and they were the researchers (which underscores the point that children can be and are active agents in research). They were curious, bright, and extremely engaged.

Lastly, Candice's view of Canada being better than Mexico for educational purposes draws a connection between children's goals and one of the main reasons for their parents' decision to migrate. Children understand as well that their parents' and their own sacrifices will be rewarded in the future.

\section{Feelings- ¿Cómo se sienten? (how do they feel?)}

It might sound redundant or obvious to state that children's emotions are important. However, it is worth highlighting that researchers should be in tune with children's feelings and that parents should be aware of their children's emotional wellbeing. Steve recommended that I find out how immigrant children feel because he thinks it is important to know if they are "tristes/sad" or "felices/ happy". He told me to ask the other children participants: "¿cómo se sienten?/ how do they feel?". And I agreed with him, taking into account his recommendation for the rest of the research sessions.

Candice, for instance, divided her drawing in terms of feelings (see Illustration 13). I noticed that there is a disconnect between the variables utilized by institutions and researchers to evaluate immigrant children and the variables children use to assess themselves. While 
researchers might measure children's adaptation through their English proficiency and grades, children rate their integration in terms of feelings. They use a variety of words to describe their settlement experiences. They do not say my English skills are poor; instead, they might say they are sad or feel lonely and bored. And, when they say they are happy it is usually the result of their acquisition of English and being able to communicate with peers.

\section{Illustration 13}

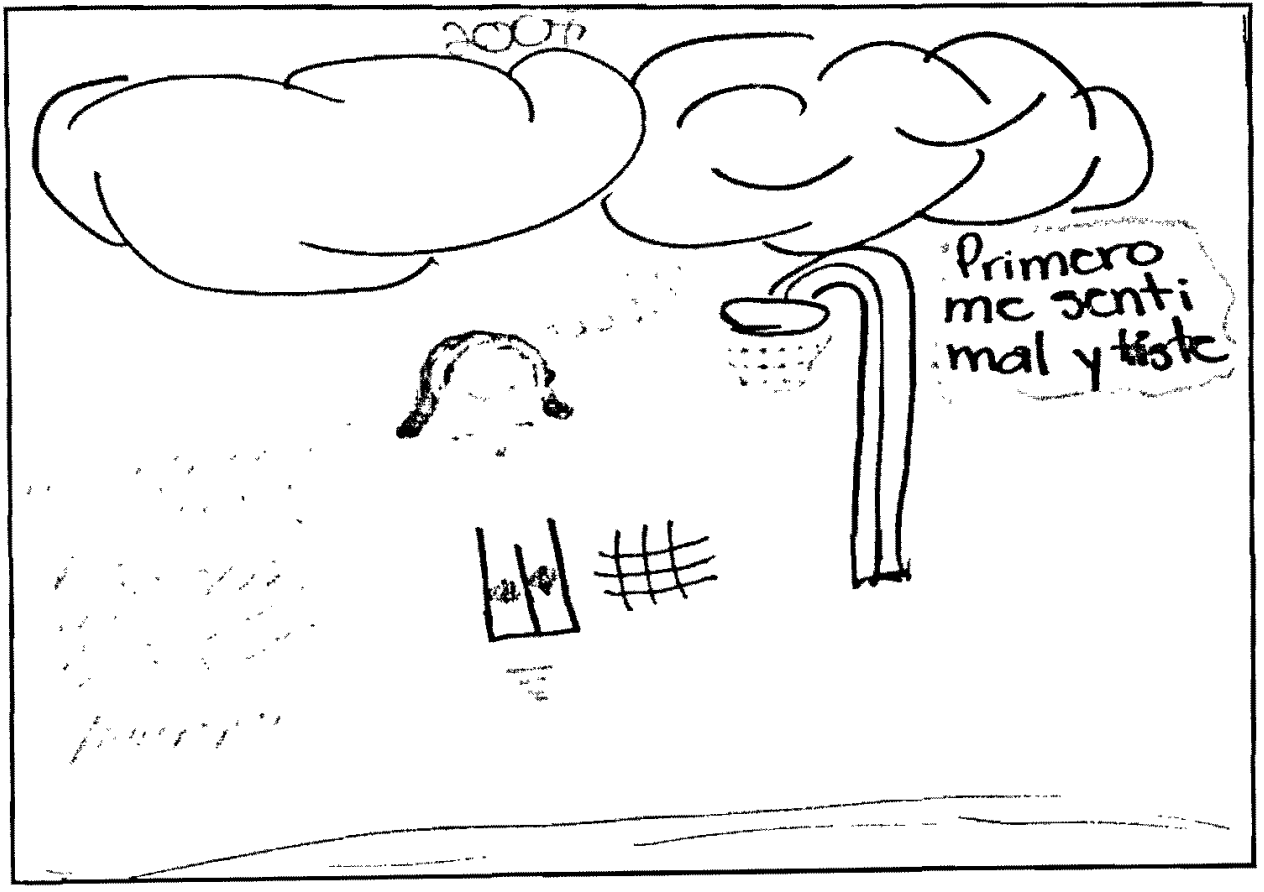

Their stories were filled with simple but meaningful words such as bad, nervous, shy, and happy (see Illustration 14). It is crucial to recognize how children approach their experiences so that researchers can "speak their language" and better understand their way of regarding migration and settlement. Also, paying close attention to their feelings guides researchers and policy makers into the areas and issues that children want assistance with. Parents also must learn that transitions are very difficult for children as well, and that just because they seemingly adapt faster than adults, this does not always translate into positive mental and emotional health. 
researchers might measure children's adaptation through their English proficiency and grades, children rate their integration in terms of feelings. They use a variety of words to describe their settlement experiences. They do not say my English skills are poor; instead, they might say they are sad or feel lonely and bored. And, when they say they are happy it is usually the result of their acquisition of English and being able to communicate with peers.

\section{Illustration 13}

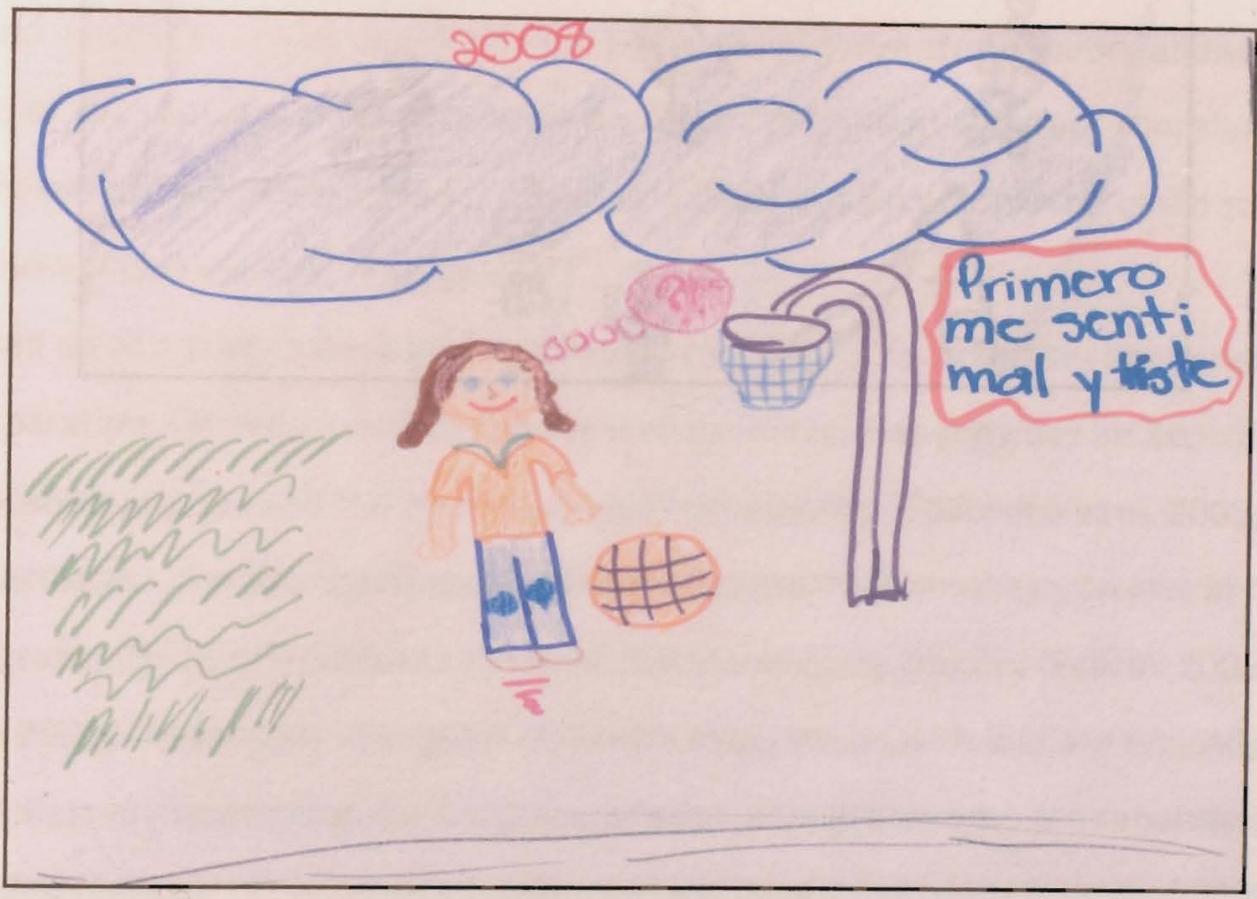

Their stories were filled with simple but meaningful words such as bad, nervous, shy, and happy (see Illustration 14). It is crucial to recognize how children approach their experiences so that researchers can "speak their language" and better understand their way of regarding migration and settlement. Also, paying close attention to their feelings guides researchers and policy makers into the areas and issues that children want assistance with. Parents also must learn that transitions are very difficult for children as well, and that just because they seemingly adapt faster than adults, this does not always translate into positive mental and emotional health. 
wustrator

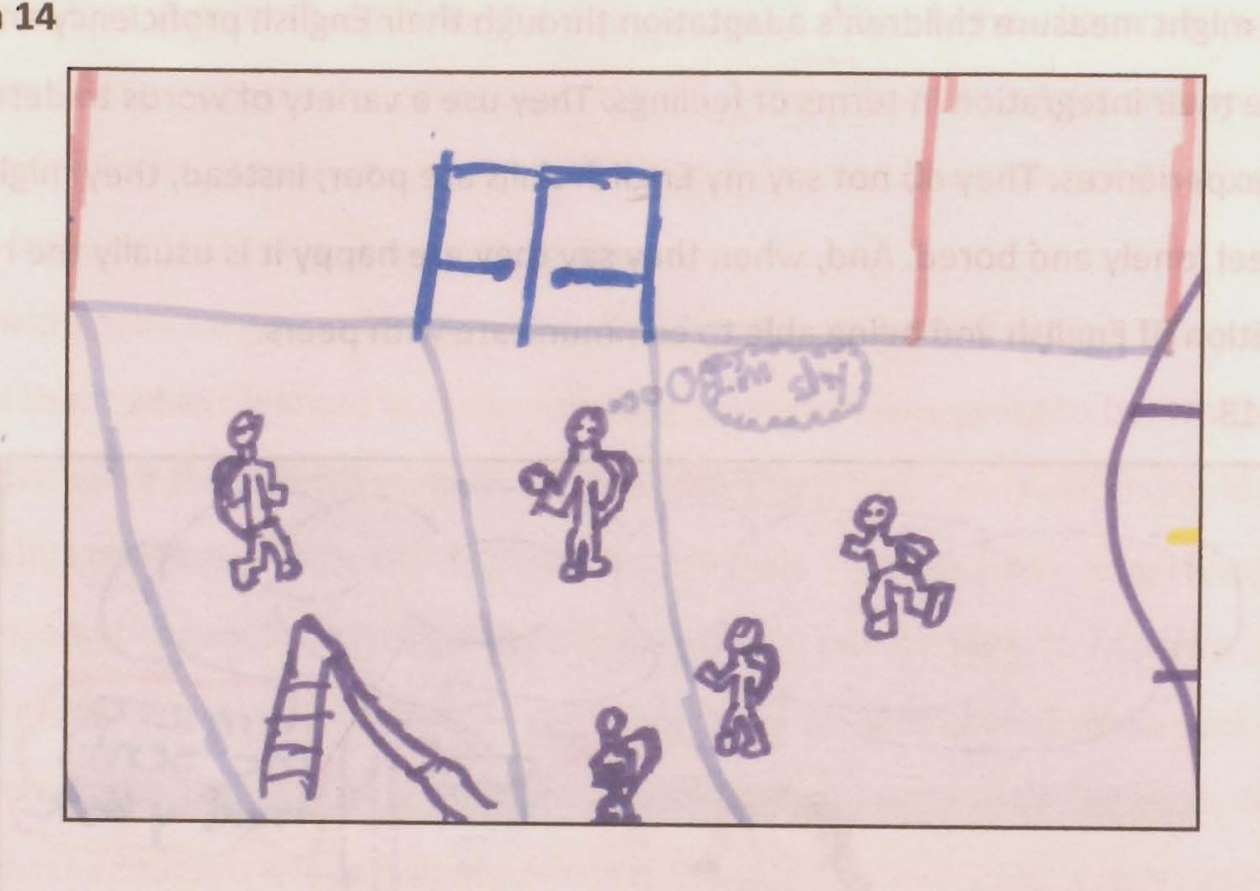




\section{Discussion}

The literature concurs with many findings from the current study, but I have found that there are some issues and themes that remain absent from most scholarly research. Certain themes are understudied because immigrant children do not have the chance to act as key informants, meaning that they are unable to shed light on new issues. The new sociology of childhood approach gives children an opportunity to inform research, policy and caregivers about how they feel and what their needs are. In addition, the acculturative stress theory allows for the exploration of the stressors that cause anxiety amongst immigrant children. Therefore, the fusion of these theoretical frameworks encourages children's inclusion in research so that they can tell us how they experience settlement.

Based on this study's findings a common stressor for Latin American immigrant children is family separation. Literature on loss experienced by immigrants provides an accurate account of the separation process and the repercussions on immigrants (Todorova et al. 2005; Falicov 2003). Nevertheless, the shortcomings of these studies are their emphasis on loss in relation to adult immigrants (ibid.) or to children left behind in the sending country (Falicov 2005; Orozco and Orozco 2001). This means immigrant children's experiences with loss are typically overlooked. Researchers discuss the hardships of adult immigrants who are separated from their extended families, but in terms of children this type of discussions is limited (Orozco and Orozco 2001; Todorova et al. 2005). According to the literature, the separation that is considered the most painful for children is that from their parents who emigrate before them (Falicov 2005; Orozco and Orozco 2001). Interestingly, children in the current study expressed that the separation from their grandmothers is devastating. Immigrant children, then, seem as affected by loss as their adult counterparts due to their separation from family members other than their parents.

Existing research is also well aware of the bond that develops between grandparents and children left behind, which leads to a painful separation when children emigrate to reunite with their parents (Orozco and Orozco 2001; Bernhard et al. 2008). Nonetheless, this type of separation is not explored when children emigrate simultaneously with their parents. This promotes the belief that a child is able to form an intimate bond with grandparents only when 
the parents are absent. As a result, most studies ignore the rupture of the grandchild/grandmother dyad in the case of immigrant children who migrate along their parents. The root of this belief may be found in the relatively narrow North American definition of family, which typically excludes how other cultures define family. Even though policy makers and researchers acknowledge the need for a broader concept of family, much of this research is not reflective of this. For example, studies take for granted the struggles of immigrant children who no longer live with their grandmothers (Todorova et al. 2005; Falicov 2003).

Some researchers are highly knowledgeable about Latin American family structures and this group's emphasis on familialism; but despite having this knowledge, they have not examined the close relationships that exist between grandchildren and grandmothers prior to immigration (Fuller-Thomson and Minkler 2007a; Goodman and Silverstein 2002). Consequently, most research disregards how children are affected by living away from their "second mothers". In sum, I found that children do experience loss because they miss their grandmothers' love, care, companionship, and support. The consequences of separating from the extended family are also a reality for immigrant children. Their feelings of loss do not branch from the loss their parents experience; rather, they are a product of the separation from the grandmother/grandparent who is no longer there with and for them.

Another stressor for immigrant children is residential mobility. Scholars argue that residential mobility is detrimental to children in terms of school performance and social capital (Bose et al. 2007; Hanna 2003). But for the most part, most research focuses on children's academic success (Tucker et al. 1998; Hagan et al. 1996), and often ignores other factors that affect mobile children. For example, anxiety, uncertainty and instability related to residential mobility negatively affect children. However, the aforementioned are often not addressed due to the assumption that children's wellbeing is reflected in their academic success. Moreover, the use of scales and surveys impede children from sharing their particular opinions and emotions on having to move from one place to another. Children are often not asked about how they feel when they move, what their expectations are, what they struggle with, what they miss, how they overcome obstacles and how they cope with having to start anew several times in a row. In the current study, mobile children did not worry about their academic performance; 
instead, they were anxious, nervous, shy and hesitant about making new friends, leaving old friends behind, overcoming loneliness, making sense of their moves, finding stability and being welcomed by their new school community.

Studies reveal that children dislike separating from their peers and struggle fitting into new groups of friends (Bose et al. 2007; Tucker et al. 1998). However, the disruption of parents' networks, which encompass teachers, neighbours and family friends, is seen as more threatening to children's welfare. This view accords with the notion of adults as the agents in children's lives. Ironically, what I found preoccupies children the most is the disruption and creation of their own social capital.

The literature also does a thorough job reporting the causes of residential mobility: living conditions, changes in income, school quality, transportation and local services motivate people to move to a different area (Fong and Hou 2004; Yu and Myers 2007). But as previously mentioned, what concerns children is how their lives change and how they adapt to those changes, not why they move. Immigration research does address the emotional and psychological effects of moving across countries (Bonovitz 2004; Hanna 2003), but it often does not take into account the additive effects of that international movement combined with local residential mobility. This is because the process of migrating from country to country is treated as a separate phenomenon from residential mobility in postmigration. Paradoxically, it has been proven that immigrants are more mobile than natives (Bose et al. 2007; Tucker et al. 1998). This pattern in immigrant families raises important research questions such as whether residential mobility accentuates or creates new challenges for immigrant children and whether immigrant children approach residential mobility more effectively than natives due to their previous experiences of international mobility. The process of starting all over again several times in a short period deserves greater attention so that children can receive proper support during transitions. Lastly, the popular framing of immigration as the movement from country $A$ to country $B$ acts as a limitation to research because this pattern does not apply to all immigrants. Some migrant children make multiple migrations, which means that their experiences in one country influence their expectations of the next country. However, this dynamic is frequently ignored in research. 
When children move to another country, they transition to a new school and usually a new language, too. Though these are highly important and decisive changes in their lives, scholars' focus on school experiences (Schugurensky 2007; Hanna 2003) drives attention away from other pressing issues in immigrant children's lives (i.e., grandmothers' absence). Literature on Latin American immigrant students highlights issues of early school leaving and poor academic performance (OISE 2010; O'Reiley \& Yau 2009). The literature as well notes that immigrant students are not encouraged or expected to succeed academically because they are viewed as incompetent (Orozco and Orozco 2001; Díaz 2002). As a result they are placed in levels incongruent with their actual capacities. Children in this study did not identify problems with their academic performance; instead they complained about not being challenged enough, which made them feel underestimated, useless and marginalized. They also emphasized the limitations of having low English proficiency such as not being able to make friends, understand teachers and read texts. Though studies have highlighted children's quick and easy acquisition of the second language (Orellana 2001; Orellana 2009), scholars are starting to recognize that language acquisition is not as simple as it seems. Some, like García Coll and Magnuson, explain that learning a new language is a stressful and long process for immigrant children. The more children worry about their inability to cornmunicate, the more they invest in learning English. The children who participated in this study said they wanted to acquire English so that they could overcome loneliness, form friendships, understand what was said to them and achieve high grades.

The literature states that two sources of worry for English language learners are exclusion and bullying (Bettencourt 2001; Souto-Manning 2007). Even though children in this project were not actually excluded or bullied on the basis of their English proficiency in Canadian schools, one of their biggest fears was exactly that. They feared peers would laugh at them and say bad things about them. Perhaps Canada's multiculturalism policy helps to create a more welcoming environment for these children, who in some cases did experience bullying in the U.S.

Researchers advise schools to celebrate first languages and promote their development while acknowledging the cultural contributions of immigrant children (Colbert 2010; Kilbride 
2000). This approach teaches children not to think of their home language as a weakness but as an asset that helps advance their second language acquisition. Moreover, it helps prevent home language loss, which is a common preoccupation among parents. In this study children themselves were concerned about language loss and implemented their own initiatives to preserve their first language such as calling and writing to their grandmothers in their first language.

The quality of ESL education is also another issue that is identified by researchers (People for Education 2009; Orozco and Orozco 2001). Children involved in this study were also aware of the flaws with ESL programs. For instance, some mentioned their lessons were oversimplified, failing to teach them what they were most in need of.

Another recurring theme in immigrant children literature is identity conflict and cultural clashes (Menjivar 2002; Louie 2006). In the present study no child expressed issues or concerns with cultural identity. Perhaps the fact that most studies concentrate on immigrant youth explains this discrepancy, given that youth (more so than children) are concerned with defining their identity. Research also concentrates on parents' school involvement and their influence on their children's school lives (Bettencourt 2000; Bernhard 2009). The common practice of focusing on youth and parents results in the exclusion of immigrant children's voices. Lastly, studies recognize that school policies (i.e., registration procedures) might also hamper immigrant children's integration since they can be kept away from school (Orozco and Orozco 2001) - a situation that was evident in the present study.

There is a great deal of literature that informs on the dynamics of cultural brokering (Orellana 2009; Love and Buriel 2007). It is a fact that children aid their parents' settlement by translating and interpreting for them in a variety of settings. Children's assistance is framed as highly valuable for parents and institutions. Most studies have gathered their data through the use of quantitative methods where immigrant youth, children and parents are asked to rate the frequency of cultural brokering episodes and the brokers' satisfaction (Benner 2011; Weisskirch 2005). Therefore, the psychological repercussions and the benefits of cultural brokering on children are well known. However, the literature on cultural brokering often overlooks brokering within classrooms. There is research on language mediation within dual-language 
classrooms (Olmedo 2003; Angelova et al. 2006), but its findings derive from ethnographic observations. Consequently, language mediation outside dual-language classrooms is understudied and children do not get an opportunity to express their views on mediation. The children who participated in this study highlighted the significance and the utility of receiving language mediation. They also mentioned that providing mediation for peers was a rewarding experience because they could help other immigrant children who were struggling with the same things they struggled with in the past. Their mediators translated school assignments and tests, taught them phrases and helped them communicate with teachers and other classmates. In addition, mediators in their classrooms introduced them to new customs and instructed them on school protocol.

In sum, immigrant children have not been asked what type of brokering is most meaningful to them, why is it significant, whom they broker for, how their brokering helps others, how they feel and what they would like to see change. Furthermore, it is important to be aware that children sometimes are the ones who receive mediation, so they should be asked who brokers for them, how that contributes to their lives, why they appreciate it, how they feel when they get assistance and what suggestions they have to improve mediation within the classroom. Researchers should expand the scope of their studies beyond brokering for parents and mediation in dual-language classrooms. Mediators and tutees should be interviewed in the present in order to gain a better understanding of their current prime concerns.

The gaps in the literature identified above do not signify that existing research is irrelevant. It just means that when children are involved in research new themes are exposed. It is natural to obtain different findings when immigrant children become the principal informants on their settlement experiences. Finally, when there is freedom of expression in a study's design, immigrant children can identify for themselves the areas they want to focus on. 


\section{Limitations}

The limitations in the current study include time and sample characteristics (i.e., size, nonprobability). Time acted as a limitation in the sense that there could perhaps have been more sessions to meet with each child. It cannot be assumed that a one-time conversation with the child is sufficient to enable me to completely interpret his/her circumstances, nor can it be assumed that a child's experiences are limited to what s/he expressed during the research session. Also, when I analyzed the data I realized that there were follow-up questions that I would like to have asked in a second session.

Given the sampling technique-non-probability, snow-ball and purposive sampling, and the sample size of 10 "findings cannot be generalized beyond the population sampled" (Bryman et al. 2009 p. 201), to include other children from Latin America, other ethnicities and children from other cultures. This non-probability sample leads to results that are not representative of the experiences of all Latin American immigrant children living in Canada. Finally, there is no way of determining if these children are typical or atypical compared to other Latin American children. 


\section{Recommendations}

The recommendations from this study do not solely result from the interview findings but from the entire research process and they are targeted to different stakeholders. The stakeholders include researchers, policy makers, settlement workers, school staff and parents.

\section{Researchers}

Researchers should strive to conduct research with children regardless of restrictive regulations by the ethics board (they are looking to protect the interest of children, after all). Researchers' experience on relating, interacting and interpreting children and the study's objectives are crucial to obtaining ethics approval. In all stages of the research process the researcher must keep in mind the best interests of the child. For example, a researcher should be well stocked with a variety of materials that children would find appealing or dress in a way that will make the adult-child barrier less pronounced.

Children should be given a great deal of freedom throughout the research process, including being able to dictate the order of the questions in the interview or select their own writing materials. I also recommend employing unstructured interviews that permit children to express what they consider to be important. They should also be encouraged to share their recommendations for the study. Researchers should be flexible when interviewing children because sometimes children want to make changes and they feel comfortable when researchers accommodate their requests. Another approach that makes children feel comfortable is one in which researchers make it evident that they enjoy sharing with their child participants. A way to accomplish that is to share one's personal experiences with children and engage in conversations on subjects unrelated to the interview topics. I found that it is also easier to establish rapport when researchers share the same linguistic and cultural background and migration experiences as the child participants.

Additionally, some researchers avoid conducting research with children because they predict parents would act as gatekeepers. However, this study helps to demonstrate that in some cultures parents are actually very enthusiastic about their children's participation in research. 


\section{Policy Makers}

Policy makers should evaluate the impact the absence of grandmothers has on children. They should listen to immigrant children, learn about their needs and give them the opportunity to grow up with an essential member of their family. The immigration of Latin American grandmothers can be facilitated so that grandmothers visit their grandchildren or live with them in Canada. This requires policy makers to expand their definition of family. Perhaps grandmothers can be guaranteed a visa that allows them to visit or reside in Canada for the first five years of the child's arrival. As a result children can receive their grandmothers' support, care, and love while they adapt to their new home.

The government can also eliminate the need for much of immigrant families' residential mobility by improving their opportunities for appropriate housing. If families have access to jobs, high-quality schools, transportation, and a range of other services they are more likely to remain in one place (Hanna 2003).

Lastly, policy makers should take into account that children do understand and are also greatly affected by policy decisions. Susana, for example, hugged the judge who granted her family refugee status, but he asked her: "Who are you?" and then she thanked him but he responded, "'For what?" A simple act such as recognizing a child's gratitude might seem insignificant to the decision maker, but in reality it means a lot to the child.

\section{Settlement Workers}

Children in this study also identified extracurricular activities such as sports and theatre as helpful in alleviating the stress caused by settlement. Hence, the settlement sector should design and implement a variety of programs that encourage immigrant children to both mingle with other children and utilize their talents. The programs are not only entertaining but also educational and healthy because they drive immigrant children's attention away from their struggles and allow them to feel useful. Lastly, children can be active and form friendships despite being new to their community.

Settlement services should also offer more counseling and make it available in multiple languages. Steven, for instance, liked his counseling sessions in Spanish but did not like the 
sessions in English. Settlement workers should be attentive to the psychological needs of immigrant children because if they lack proper support they will face more difficulties settling in Canada, which can have long-term effects. Suarez-Morales and Lopez (2009) advocate for preventive measures such as identifying the sources of worry and teaching Latin American youth how to cope with anxiety. They suggest that family therapy can be an effective method to reduce anxiety during the settlement period (ibid.). Apart from therapists, teachers and school counsellors can also help immigrant children deal with stressors (Hanna 2003).

\section{School}

School-related recommendations address teachers, school staff and curriculum developers. Isabela does not like her school's secretary because when she tried to register in school the secretary yelled at her family and said there were no spots for Isabela. This incident demonstrates that all school personnel should be aware of their attitude towards newcomer children because the way they treat them shapes children's perception of their school community. As a result, school staff should strive to simplify the registration process and create a welcoming environment for immigrant children. In addition, Hanna (2003) explains that attention should be given to the quality of schools and their programs for newcomers in order to reduce families' residential mobility.

Though the Settlement Workers in Schools (SWIS) program exists in some schools, there are schools that will greatly benefit from employing settlement workers. They can help with registration and interpreting in order to promote understanding between school staff and immigrant families. The SWIS program should also organize orientations for newcomers in elementary schools to familiarize them with the school environment and staff prior to commencing classes. Currently, orientation programs in Ontario are only provided to high school and middle school students (SWIS 2010).

Teachers should also transform their belief that ESL students are incapable of handling mainstream schoolwork. Immigrant children need to be challenged because it boosts their selfesteem by making them feel useful, smart and talented. It is a way for them to counteract their low English proficiency. Moreover, teachers should be aware of the cultural brokering dynamics 
already in place within classrooms. Teachers should maximize the benefits of language mediation by celebrating solidarity, ensuring equality between broker and brokee, and promoting reciprocal brokering (Coyoca and Lee 2009). Schools should also make an effort to preserve and develop native language literacy among immigrant children. Children in this study explained that most of the time they wrote and read in English so their Spanish literacy skills were rusty. Moreover, children should be encouraged to see the home language as an asset instead of focusing on their English language deficiencies.

\section{Parents}

In most instances, recommendations made in immigration research target the government and service providers, but the people closest to the participants are rarely addressed. Parents should be attentive to their children's needs, worries, feelings, and accomplishments. Apart from knowing about their problems, they need to give their children a lot of support and time to help them solve those problems. An effective approach discussed by children in this study is having parents explain to them what is going on and what will happen in the future. When parents explained that they will see their family again, that they are waiting for their "papers", that they will attend a certain school for an amount of time, etc., children felt relieved and happier. Parents should not assume that children are oblivious to changes nor should they expect children to conform to the situation the family faces. Children need to know the causes, the length of time, and the expected outcomes of what they are going through. As a result, their stress and uncertainty decrease while their hope increases. Lastly, immigrant parents should have a close relationship with their children because it makes children feel more secure when encountering settlement hardships. Simple activities such as playing games, doing crafts and sports are effective ways for parents to help children cope with the new environment. 


\section{Conclusion}

From the start to the end of this project the message has been clear and simple: immigrant children should be involved in research. There is extensive and valuable literature on the subject area of Latin American immigrant children, but adults such as teachers, parents and youth act as key informants. When immigrant children participate in research, the use of quantitative methods limits their responses to those topics of interest to the researcher. Moreover, studies tend to focus on either youth or kindergarten immigrants. The particular experiences of the ten children who helped me in this project make it evident that when immigrant children are encouraged to share their stories they reveal what is truly important to them. Knowing what hampers and facilitates their settlement is crucial to learning about their needs and assets in order to create and implement programs and initiatives that support them. In fact, their input is extremely valuable.

The age of immigrant children does not mean that they are incapable of identifying their needs, expressing their feelings and voicing their opinions. Their worlds are complex and their narratives are compelling. Receiving a tour of their lives as migrants is not only an engaging experience but also an informative lesson for parents, school personnel, policy makers, researchers and settlement workers. Their stories leave powerful messages that direct us to the questions that they want us to ask such as, "¿cómo se sienten?/ how do they feel?". Basically they are telling us to stop ignoring their voices. 


\section{Appendices}

\section{Appendix 1}

\section{Yo cuento}

Mi nombre es Mónica Valencia y estoy haciendo mi posgrado en Inmigración y Establecimiento en la Universidad de Ryerson. Mi proyecto de grado investigará cómo los niños inmigrantes de Latinoamérica interpretan sus experiencias migratorias.

Muy pocas investigaciones se enfocan en las experiencias de los niños inmigrantes. "Yo cuento" es una investigación que le dará a los niños latinoamericanos la oportunidad de compartir lo que ellos piensan sobre su proceso migratorio.

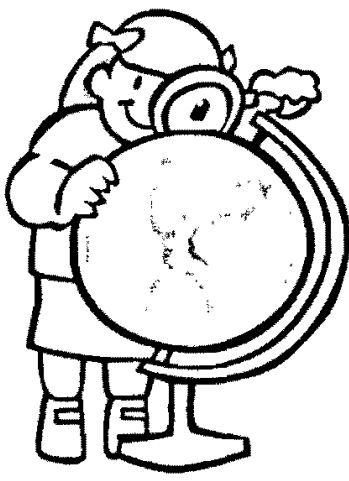

Si usted y su niño/a están interesados en participar en este estudio, por favor contácteme al envíeme un correo a . Los niños que quieran participar deben tener entre 9 y 11 años de edad y haber llegado a Canadá en los últimos cinco años. Los niños dibujarán y escribirán una pequeña historia sobre su traslado a Canadá. Estas actividades se realizarán en una biblioteca cerca de su casa.

Su participación es voluntaria y confidencial. El nombre de su hijo/a no aparecerá en el reporte final. 


\section{Appendix 2}

Asentimiento informado

Investigadora: Mónica Valencia Yo Cuento: niños inmigrantes de Latinoamérica cuentan sus historias

,

Mónica sí puede hablar conmigo hoy

Mónica No puede hablar conmigo hoy

$\square$ Lo que yo diga sí se puede grabar en un cassette

$\square$ Lo que yo diga No se puede grabar en un cassette

f Mónica si puede usarmi dibujo si

7 Mónica si puede usar mi dibujo en su tarea y ella Nava a poner mi nombre para que nadie sepa que yo lo dibujé

Mónica No puede usar mi dibujo en su tarea

Nombre: Set........tign

Investigadora: .. Mún.ica...Valencia...........
Fecha: Mol, Ap!ll $25 / 2011$

Fecha: 1 grill-2.5.2. 2011 


\section{Appendix 3}

\section{List of Topics for Unstructured Interview}

This list outlines possible topics to be raised by the children during the research sessions. The following topics are common across the literature on immigrant children, including children from Latin America.

Identity Formation: hybrid identities, acculturation, parents' cultural expectations, traditions, transnationalism, home.

Language: acquisition and retention, language preference, link between culture and language, language barriers, ESL.

School: interaction with peers, relations with teachers, performance, school environment, classes, comparison of schools in native country and Canada.

Cultural Brokering: translation, responsibilities, family roles, family dynamics, bilingual skills, achievements as cultural brokers.

Other: weather, food, grandparents and other family members outside Canada, games, goals, hobbies, likes and dislikes, trip to Canada, neighbourhoods, parent's work and siblings; visiting the "home country". 


\section{Bibliography}

Albanese, P. (2009). Children in Canada Today. Don Mills, Canada: Oxford University Press. Angel, M. (2009). "Spanish-speaking Youth and Early School Leaving in Toronto: Towards Improving the Family Culture". In Schugurensky, D., Mantilla, D., Serrano, J. (eds.) Four in Ten. Toronto: Latin American Research Education and Development Network, Transformative Learning Centre and Ontario Institute for Education Studies 11-13. Angelova, M. Gunawardena, D., and Volk, D. (2006). Peer teaching and learning: Coconstructing language in a dual language first grade. Language \& Education: An International Journal, 20(3): 173-190.

Anisef, P., and Kilbride, K. (2003). Managing Two Worlds: The Experiences and Concerns of Immigrant Youth in Ontario. Toronto: Canadian Scholar's Press.

Ankori, G. (2003). "'Dis-Orientalisms:' Displaced bodies/embodied displacements in contemporary Palestinian art". In Ahmed, S., Castañeda, C., Fortier, A., Sheller, M. (eds.) Uprootings/Regroundings: Questions of Home and Migration. Oxford: Berg 59-90.

Bacallao, M., and Smokowski, P. (2007). The costs of getting ahead: Mexican Family System Changes after Immigration. Family Relations 56(1): 52-66.

Bagby, D. (2007). Transnational processes, communications, and interpersonal relationships of international elementary school students in an English for speakers of other languages program. ProQuest Information and Learning Company. Universty of Florida 1-133.

Bagilishya, D., Heusch, N., Rousseau, C., and Lacroix, L. (1998). Jouer en classe autour d'une histoire. PRISME, 28: 88-103.

Bascuñán, P. (2009a). "School dropout rate of Spanish-speaking students". In Schugurensky, D., Mantilla, D., Serrano, J. (eds.) Four in Ten. Toronto: Latin American Research Education and Development Network, Transformative Learning Centre and Ontario Institute for Education Studies 18-21.

Bascuñán, L. (2009b). "Addressing the high school dropout rate of Spanish-speaking Students". In Schugurensky, D., Mantilla, D., Serrano, J. (eds.) Four in Ten. Toronto: Latin American Research Education and Development Network, Transformative Learning Centre and Ontario Institute for Education Studies 14-17.

Benner, A. (2011). Latino adolescents' loneliness, academic performance, and the buffering nature of friendships. Journal of Youth and Adolescence, 40(5): 556-567.

Bernhard, J., Torres, F., Nirdosh, S., Freire, M. (1997). Latin Americans in a Canadian primary school: Perspectives of parents, teachers and children on cultural identity and academic achievement. Early Childhood Education Publications and Research, Paper 11.

Bernhard, J., Landolt, P., and Goldring, L. (2008). Transnationalizing Families: Canadian Immigration Policy and the Spatial Fragmentation of Caregiving Among Latin American Newcomers. International Migration, 47(2): 152-180.

Bernhard, J. (2009). "Latin American students in the TDSB: Research findings and recommendations". In Schugurensky, D., Mantilla, D., Serrano, J. (eds.) Four in Ten. Toronto: Latin American Research Education and Development Network, Transformative Learning Centre and Ontario Institute for Education Studies 22-25.

Betancourt, G. (2009). "School dropout among the children of Latin American immigrants". In 
Schugurensky, D., Mantilla, D., Serrano, J. (eds.) Four in Ten. Toronto: Latin American Research Education and Development Network, Transformative Learning Centre and Ontario Institute for Education Studies 26-28.

Bettencourt, E. (2000). Recent research on newcomer youth. Citizenship and Immigration Canada.

Bleiker, C., Ginieniewicz, J., Madigan, A., Bernhard, J., Winsler, A. (2008). "Read my story!"

Using the early authors program to promote early literacy among diverse, urban preschool children in poverty. Journal of Education for Students at Risk, 13(1): 76-105. Bonovitz, J. (2004). The child immigrant. American Journal of Psychoanalysis, 64: 129-141. Bose, S., Haynie, D., and South, S. (2007). Student mobility and school dropout. Social Science Research, 36(1): 68-94.

Boyd, D. (2006). Resilience in newcomer families. Canadian Issues, Spring: 85-86.

Bryman, A., Teevan, J., Bell, E. (2009). Social Research Methods. Don Mills, Canada: Oxford University Press.

Caplan, S. (2007). Latinos, acculturation, and acculturative stress: a dimensional concept analysis. Policy, Politics, \& Nursing Practice, 8(2): 93-106.

Castañeda, C. (2002). Figurations: Child, Bodies, Worlds. Durham: Duke University Press. Castro, A. (2009). "Preventing school dropout among Hispanic students". In Schugurensky, D., Mantilla, D., Serrano, J. (eds.) Four in Ten. Toronto: Latin American Research Education and Development Network, Transformative Learning Centre and Ontario Institute for Education Studies 38-39.

Chee, A., Lam, W., Thorne, B. and Orellana, M. (2001). Transnational childhoods: the participation of children in processes of family migration. Social Problems, 48(4): 572-588. Citizenship and Immigration Canada. (2010a). "Facts and figures 2009- immigration overview: Canada-permanent residents less than 15 years of age by gender, age and category". Retrieved from http://www.cic.gc.ca/english/resources/statistics/facts2009/permanent/05.asp (accessed July 24, 2011).

Citizenship and Immigration Canada. (2010b). "Facts and figures 2009-immigration overview:

Canada-permanent residents by age and source area". Retrieved from http://www.cic.gc.ca/english/resources/statistics/

facts2009/permanent/09.asp (accessed July 24, 2011).

Citizenship and Immigration Canada. (2010c). "Facts and figures 2009- immigration Overview:

Canada- permanent esidents by province or territory and source area". Retrieved from http://www.cic.gc.ca/english/ resources/

Astatistics/facts2009/permanent/14.asp (accessed July 24, 2011).

City of Toronto. (2007). "Backgrounder: Release of the 2006 census on language, immigration, citizenship, mobility/migration". Retrieved from

http://www.toronto.ca/demographics/pdf/2006_lang_imm_citizenship_mobility_backgro under.pdf (accessed July 24, 2011).

Colbert, J. (2010). Welcoming Newcomer Children: The Settlement of Young Immigrants and Refugees. Kitchener, Canada: Fairmeadow.

Corsaro, W. (2005). The Sociology of Childhood, $2^{\text {nd }}$ edn. London: Sage.

Coyoca, A., and Lee, J. (2009). A typology of language-brokering events in dual-language 
immersion classrooms. Bilingual Research Journal, 32(3): 260-279.

Cummins, J. (2001). Negotiating Identities: Education for Empowerment in a Diverse Society. $2^{\text {nd }}$ Edition. Los Angeles: California Association for Bilingual Education.

Cummins, J., Bernhard, J., Campoy, I., Ada, A., Winsler, A., Bleiker, C. (2006). Identity texts and literacy development among preschool English language learners: Enhancing learning opportunities for children at risk for learning disabilities. Teachers College Record, 108 (11): 2380-2405.

D'Andrea, M. (2009). "The disadvantages of Latino youth in Toronto". In Schugurensky, D., Mantilla, D., Serrano, J. (eds.) Four in Ten. Toronto: Latin American Research Education and Development Network, Transformative Learning Centre and Ontario Institute for Education Studies 45-47.

Diaz, E. (2002). Mexican immigrant children in urban Phoenix: Transitions to life, language, and school. ProQuest Dissertations and Theses. Arizona State University 1-350.

Doyle, E., Hynes, K., and Greene, K. (2011). Self-care among school-aged children of immigrants. Children and Youth Services Review, 33(5): 783-789.

Dual-Language Book Club. (2009). "Dual-language book collection". Retrieved from http://www.duallanguagebookcollection.com/ (accessed July 24, 2011).

Elliot, L. (2011, February 14). "Visa cuts hit parents of immigrants hardest". Canadian Broadcasting Corporation. Retrieved from http://www.cbc.ca/news/canada/story/2011/02/14/attaran-immigration.html (accessed July 24, 2011).

Entorf, H., and Lauk, M. (2006). Peer effects, social multipliers and migrants at school: an international comparison. IZA Discussion Paper 2182.

Esquivel, G., Oades-Sese, G., Jarvis, A. (2010). Culturally Sensitive Narrative Interventions for Immigrant Children and Adolescents. Maryland: University Press of America.

Falicov, C. (2003). "Immigrant family processes". Normal Family Processes. In Walsh F. (ed.). New York: The Guilford Press 280-300.

Falicov, C. (2005). "Ambiguous Loss: risk and resilience in Latino immigrant families". In SuárezOrozco, M., Suárez-Orozco, C., and Qin-Hilliard, D. (eds.) The New Immigration: An Interdisciplinary Reader. New York: Routledge 197-206.

Fantino, A., and Colak, A. (2001). Refugee children in Canada: Searching for identity. Child Welfare, 53(5): 587-596.

Fassler, R. (1998). Room for talk: Peer support for getting into English in an ESL kindergarten. Early Childhood Research Quarterly, 13(3): 379-409.

Fernandéz, L., and Reyes, L. (1999). Control del comportamiento en familias extendidas. Universidad Nacional Experimental Francisco de Miranda 1-8.

Freire, M., and Bernhard, J. (1999). What is my child Learning in elementary school? Culturally contested issues between teachers and Latin American families. Canadian Ethnic Studies, 31(3): 72-94.

Fong, E., and Hou, F. (2009). Residential patterns across generations of new immigrant groups. Sociological Perspectives, 52(3): 409-428.

Fuller-Thomson, E., and Minkler, M. (2007a). Mexican American grandparents raising grandchildren: Findings from the census 2000 American community survey. Families in Society, 88(4): 567-574. 
Fuller-Thomson, E., and Minkler, M. (2007b). Central American grandparents raising grandchildren. Hispanic Journal of Behavioral Sciences, 29(1): 5-18.

Garcia Coll, C., and Magnuson, K. (2005). "The psychological experience of immigration: a developmental perspective". In Suárez-Orozco M., Suárez-Orozco C., and Qin-Hilliard D. (eds.) The New Immigration: An Interdisciplinary Reader (2005). New York: Routledge 105134.

Gaztambide-Fernández, R., and Guerrero, C. (2009). "Initial findings and future goals of proyecto Latino: Inquiring into the experiences of Latino/a students in Toronto's public schools". In Schugurensky, D., Mantilla, D., Serrano, J. (eds.) Four in Ten. Toronto: Latin American Research Education and Development Network, Transformative Learning Centre and Ontario Institute for Education Studies 54-58.

Gentemann, K., and Whitehead, T. (1983). The cultural broker concept in bicultural education. Journal of Negro Education, 52(2): 118-129.

Goodman, C., and Silverstein, M. (2002). Grandmothers raising grandchildren: Family structure and Well-being in culturally diverse families. The Gerontologist, 42(5): 676-689.

Hagan, J., MacMillan, R., Wheaton, B. (1996). New kid in town: Social capital and the life course effects of family migration on children. American Sociological Review 61(3): 368-385.

Hanna, W. (2003). Mobility and the children of Langley Park's immigrant families. The Journal of Negro Education 72(1):63-78.

Harzig, C., and Hoerder, D. (2006). In Wong, L., Satzewich, V., (eds.) Transnational Identities and Practices in Canada. Vancouver: UBC Press.

Hill, M., Wager, F., Bailey, N., Day, R., Hamilton, D., and King, C. (1996). Engaging with primaryaged children about their emotions and well being: Methodological considerations. Children \& Society, 10: 129-144.

Igoa, C. (1995). The Inner World of the Immigrant Child. New Jersey: Lawrence Erlbaum Associates.

James, A., Jenks, C., and Prout, A. (1998). Theorizing Childhood. Oxford: Polity Press.

Kilbride, K. (1997). "The child in a diverse world". In Kilbride K., (ed.) Include Me Too!: Human Diversity in Early Childhood. Toronto: Harcourt Brace Canada 3-19.

Kilbride, K. (2000). A Review of the literature on the human, social, and cultural capital of immigrant children and their families with implications for teacher education. Toronto: Joint Centre of Excellence for Research on Immigration and Settlement. No. 13: 3-16.

King, M. (2007). The sociology of childhood as scientific communication: Observations from a social systems perspective. Childhood, 14(2): 193-213.

Kohnert, K., Yim, D., Nett, K. Kan, P., and Duran, L. (2005). Language, intervention with linguistically diverse preschool children: a focus on developing home language(s). Speech and Hearing Services in Schools 36(3): 251-264.

Lacroix, L., Rousseau, C., Singh, A., Gauthier, F., Benoit, M. (2005). Creative expression workshops in school: Prevention programs for immigrant and refugee children. The Canadian Child and Adolescent Psychiatry Review, 14(3): 77-80.

León, A., and Serrano, M. (2010). Si las abuelas se disponen a cuidar, madres y padres pueden emigrar. Revista venezolana de estudios de la mujer, 15(35): 91-116.

Louie, V. (2006). Growing up ethnic in transnational worlds: Identities among secondgeneration Chinese and Dominicans. Global studies in Culture and Power, 13: 363-394. 
Love, J., and Buriel, R. (2007). Language brokering, autonomy, parent-child bonding, biculturalism, and depression. Hispanic Journal of Behavioral Sciences, 29(4): 472-491.

MacNaughton, G. (2001). Silences and subtexts in immigrant and non-immigrant's children's understandings of diversity. Childhood Education, 78(1): 30-36.

Masís, P., and Vargas, M. (2007). Papel social de las abuelas en el seno familiar: percepciones de un grupo de mujeres mayores residentes en comunidades urbanas de Costa Rica. Boletín científico - Universidad de Costa Rica Escuela de Nutrición 1-17.

Matthews, S. (2007). A window on the 'new' sociology of childhood. Sociology Compass, 1(1): 322-334.

McLaren, A. (2006). Immigration and parental sponsorship in Canada: Implications for elderly women. Canadian Issues, Spring: 34-37.

Menjivar, C. (2002). Living in two worlds? Guatemalan-origin children in the United States and emerging transnationalism. Journal of Ethnic and Migration Studies, 28(3): 531-552.

Milan, A., and Hamm, B. (2003). Across the generations: Grandparents and grandchildren. Canadian Social Trends, 71(2): 2-7.

Morales, A., and Hanson, W. (2005). Language brokering: an integrative review of the literature. Hispanic Journal of Behavioral Sciences, 27(4): 471-503.

Morgan, M., Gibbs, S., Britten, N., Maxwell, K. (2002). Hearing children's voices: Methodological issues in conducting focus groups with children aged 7-11 Years. Qualitative Research, 2(1): 5-20.

Morrow, V. \& Richards, M. (1996). The ethics of social research with children: an overview. Children \& Society. 10: 90-105

Murray, W., Scheyvens, R., and Scheyvens, H. (2003). "Working with marginalized, vulnerable or privileged groups". In Scheyvens, R. \& Storey, D. (eds.) Development Fieldwork: a Practical Guide, Padstow: Sage Publications 167-193.

Neuman, L. (2010). Social Research Methods: Qualitative and Quantitative Approaches. Boston: Allyn and Bacon, Inc.

Nowak, K., and Shkandrij, M. (2004). The symbolic world of the bilingual child: Digressions on language acquisition, culture and the process of thinking. Journal of Instructional Psychology, 31(4): 284-292.

Olmedo, I. (2003). Language mediation among emergent bilingual children. Linguistics and Education, 14(2): 143-162.

Ontario Council of Agencies Serving Immigrants. (2011a). "No real solutions for family reunification delays in leaders debate". Last updated April 13, 2011. Retrieved from http://www.ocasi.org/index.php?qid=1081 (accessed July 24, 2011).

Ontario Council of Agencies Serving Immigrants. (2011b). "OCASI position on family reunification". Last updated February 22, 2011. Retrieved from http://www.ocasi.org/index.php?qid=1069 (accessed July 24, 2011).

Ontario Institute for Studies in Education. (2010). Proyecto Latino year 1- exploratory research. Toronto: Centre for Urban Schooling Department of Curriculum, Teaching \& Learning University of Toronto.

O'Reilly, J., and Yau, M. (2009). 2008 Parent census, kindergarten-grade 6: System overview and detailed findings. Toronto: Toronto District School Board.

Orellana, M. (2001). The work kids do: Mexican and Central American immigrant children's 
contributions to the household, school and community in California. Harvard Educational Review, 71(3): 366-389.

Orellana, M. (2009). Translating childhoods: Immigrant youth, language, and culture, Piscataway: Rutgers University Press.

Osuma, J. (2006). Relaciones familiares en la vejez: vínculos de los abuelos y de las abuelas con sus nietos y nietas en la infancia. Revista multidisciplinar de gerontología, 16(1): 16-25.

Park, S., and Sarkar M. (2007). Parents' attitudes toward heritage language maintenance for their children and their efforts to help their children maintain the heritage language: $a$ case study of Korean-Canadian immigrants. Language, Culture and Curriculum, 20(3): 223235.

People for Education. (2009). Annual report on Ontario's public schools 2009. Toronto.

Perren, S., Grünigen, R., Alsaker, F., and Nagele, C. (2010). Immigrant children's peer acceptance and victimization in kindergarten: the role of local language competence. British Journal of Developmental Psychology, 28: 679-697.

Phelan, P., Davidson, L., and Cao, H. (1991). Students' multiple worlds: Negotiating the boundaries of family, peer, and school cultures. Anthropology and Education Quarterly, 22: 224-250.

Planillo, A. (2004). Abuelos, abuelas, nietos y nietas. El punto de vista infantil. INDIVISA, Boletín de estudios e investigación, 5: 35-42.

Proudfoot, S. (2010, October 6). "Immigrants' Children Play Family Interpreter". Edmonton Journal A4.

Pulido, L., Orellana, M. and Dorner, L. (2003). Accessing assets: Immigrant youth's work as family translators or "para-phrasers". Social Problems, 50(4): 505-524.

Qin-Hilliard, D. (2001). Children of Immigration. Harvard Educational Review, 71(3): 599-602.

Region of Halton. (2011). "Social profile of Halton: Who we are and who we will be". Retrieved from www.halton.ca/common/pages/UserFile.aspx?fileld=5576 (accessed July 24, 2011).

Region of Peel. (2007a). Bulletin: 2006 census mobility \& migration. Retrieved from http://www.peelregion.ca/planning/bulletins/2006/2006-migrate.pdf (accessed July 24, 2011).

Region of Peel. (2007b). "Ethnic origin statistics, 2006 census- ethnic origins in Peel and the area municipalities". Retrieved from

http://www.peelregion.ca/planning/pdc/data/census/ethnic-origin-2006.htm (accessed July 24, 2011).

Rotter, J., and Hawley, L. (1998). Therapeutic approaches with immigrant families. The Family Journal, 6(3): 219-222.

Rousseau, C., and Heusch, N. (2000). The trip: a creative expression project for refugee and immigrant children. Art Therapy: Journal of the American Art Therapy Association, 17(1): 31-40.

Rousseau,C., Drapeau, A., Lacroix, L., Bagilishya, D., Heusch, N. (2005). Evaluation of a classroom program of creative expression workshops for refugee and immigrant children. Journal of Child Psychology and Psychiatry, 46(2): 180-185.

Rubinstein-Ávila, E. (2003). Negotiating power and redefining literacy expertise: Buddy reading in a dual-immersion programme. Journal of Research in Reading, 26(1): 83-97.

Schugurensky, D. (2007). "Does education equalize opportunities? The implications of the TDSB 
cohort analysis for democracy and meritocracy". Diversity in Education Parents' Forum. Toronto: Ethnocultural Community Network of the Toronto District School Board.

Smart, J., and Smart, D. (1995). Acculturative stress. The Counseling Psychologist, 23(1): 25-42. Souto-Manning, M. (2007). Immigrant families and children (re)develop identities in a new context. Early Childhood Education Journal, 34(6): 399-405.

Spanish Speaking Education Network. (2010). "About us". Retrieved from http://ssen.ca/?page_id=169 (accessed July 24, 2011).

Statistics Canada. (2008). Census Snapshot-Immigration in Canada: a portrait of the foreignborn population, 2006 Census. Catalogue no. 11-008-X.

Suárez-Morales, L., and Lopez, B. (2009). The impact of acculturative stress and daily hassles on pre-adolescent psychological adjustment: Examining anxiety symptoms. The Journal of Primary Prevention, 30(3-4): 335-349.

Suárez-Orozco, C., and Suárez-Orozco, M. (2001). Children of Immigration. Cambridge, MA: Harvard University Press.

SWIS. (2010). "About SWIS". Retrieved from http://swisontario.ca/2/About-Us (accessed July 29, 2011).

Taylor, L., Cummins, J., Bernhard, J., Ada, A., Winsler, A., Bleiker, C., and Campoy, I. (2008). Affirming plural belonging: building on students' family-based cultural and linguistic capital through multiliteracies pedagogy. Journal of Early Childhood Literacy, 8(3): 269294.

Teledgi, A. (2006). Family reunification: the key to successful integration. Canadian Issues, Spring: 94-96.

The Review. (2007, October 19). "Skills for grandparents". 14.

Thompson, E. (2003, December 10). "Many grandparents raising grandchildren". Leader Post A3.

Tobío, C. (2003). Cambio social y solidaridad entre generaciones de mujeres. Feminismo/s, 2: 153-166.

Todd, D. (2011, February 26). "Federal plan to reduce number of parents, grandparents allowed into Canada angers immigrant communities". Vancouver Sun A10.

Todorova, I., Louie, J., Suárez-Orozco, C. (2005). "Making up for lost time: the experience of separation and reunification among immigrant families". In Suárez-Orozco M., SuárezOrozco C., and Qin-Hilliard D. (eds.) The New Immigration: An Interdisciplinary Reader. New York: Routledge 179-196.

Tucker, J., Marx, J., and Long, L. (1998). "Moving on": Residential mobility and children's school lives. Sociology of Education, 71(April): 111-129.

United Nations. (2007). "Convention on the rights of the child". Retrieved from http://www2.ohchr.org/english/law/crc.htm (accessed July 24, 2011).

Villar, F., Triadó, C., and Martínez, G. (2000). El rol y la importancia de los abuelos para sus nietos adolescentes. Annuario de psicología, 31(2): 107-118.

Wagner, J. (1999). Visual sociology and seeing kid's worlds. Visual Studies, 14(1): 3-6.

Weisskirch, R. (2005). The relationship of language brokering to ethnic identity for Latino early adolescents. Hispanic Journal of Behavioral Sciences, 27(3):286-299.

Wolf, D. (1997). Family secrets: Transnational struggles among children of Filipino immigrants. Sociological Perspectives, 40(3): 457-482. 
Yu, Z., and Myers, D. (2007). Convergence or divergence in Los Angeles: Three distinctive ethnic patterns of immigrant residential assimilation. Social Science Research, 36:254-285.

Zeitvogel, K. (2011, February 18). "Being bilingual a good brain work-out, experts say". The Gazette. Retrieved from http://www.montrealgazette.com/ health/Being+bilingual+good+brain+work+experts/4311018/story.html laccessed July 24, 2011). 